\title{
Über Fesselungshyperglykämie und -glykosurie beim
} Kaninchen.

\author{
Von \\ ljuro Fujii. \\ (藤 井猪十郎)
}

(Aus dem physiologisehen Institut [Prof. Y. Sata Tohoku Universität zu Sendai.)

Kap. I. Einleitung.

\section{Inhaltsübersicht.}

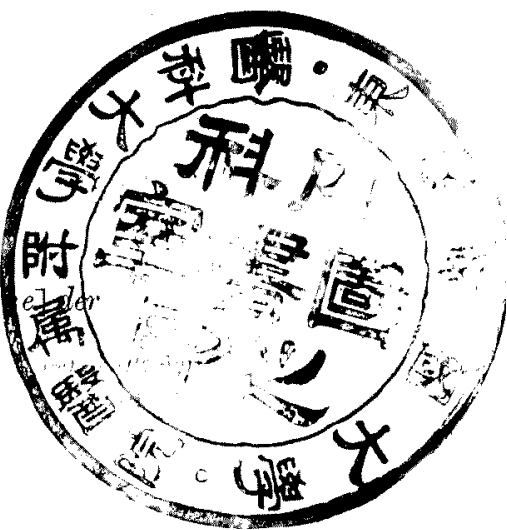

Kap. II. Methodik und normaler Blutzucker- und Harnzuckergehalt des Kaninchens

Kap. III. Hyperglykämie und Glykosurie bei langdauernder Fesselung.

Kap. IV. Hyperglykämie und Glykosurie bei kurzdauernder Fesselung.

Kap. V. Kann Fesselungshyperglykämie und -glykosurie durch Wiederholung der Fesselung zum Verschwinden gebracht werden?

Kap. VI. Kann Fesselungshyperglykämie und -glykosurie durch Schutz gegen Erniedrigung der Körpertemperatur verhütet werden?

Kap. VII. Kann Fesselungshyperglykämie und -glykosurie nach beiderseitiger Splanchnikotomie entstehen?

Kap. VIII. Zusammenlassung.

\section{Kap. I. Einleitung.}

Im Jahre 1878 fanden R. Boehm und F. A. Hoffmann ${ }^{1)}$, dass bei der Katze jedesmal Glykosurie hervorgerufen werden kann, wenn man sie auf dem Operationstische fesselt. Diese Erscheinung wurde von ibnen als ,Fesselungsdiabetes" bezeichnet.

Ihre Versuchsresultate waren folgende: Wenn die Katze ohne Narkose auf dem Operationstische gefesselt liegt und tracheotomiert wird, fängt Ausscheidung des Zuckers im Harne etwa eine halbe Stunde nach der Fesselung an und dauert durchschnittlich etwa sechs Stunden lang. Nach ihren Erfahrungen an ïber hundert Katzen ist der Fesselungsdiabetes desselben Tieres eine ganz konstante Erscheinung.

1) R. Boehm und F. A. Hoffmann, Schmiedeberg's Arch. 8 (1878), 271. 
Tracheotomie ist keine notwendige Bedingung zum Zustandekommen des Fesselungsdiabetes. Die Harnmenge vermehrt sich manchmal beim Fesselungsdiabetes und geht sogar mit der Intensität der Glykosurie Hand in Hand. Die Polyurie fehlt aber beim Fesselungsdiabetes nicht selten. Der Blutzuckergehalt steigt höher als der normale Wert, aber doch nur in geringem Grade (Nach ihren Bestimmungen ist der normale Blutzuckergehalt der Katze durchschnittlich $0,15 \%(0,12-0,31 \%)$, und sie fanden den Blutzuckergehalt von $0,2 \%, 0,26 \%$ und $0,34 \%$ bei drei gefesselten Katzen). Die Verminderung des Glykogengehaltes der Leber ist anch gering.

Schon vor Boehm und Hof fmann war darauf aufmerksam gemacht worden, dass bei verschiedenen Tieren durch rełativ geringfügige Eingriffe zuweilen G]ykosurie auftritt, aber diese Frage wurde nicht weiter studiert) (sieb auch Boehm u. Hoffmann). B. Naun y ${ }^{2)}$ und C. B o ek u. F. A. Hof fma n $n^{3)}$ konnten keine Blutzuckervermehrung beim langdauernd gefesselten Kaninchen konstatieren. (E. L. Scott ${ }^{4}$ ) zitierte aus Naunyn, dass $\mathrm{N}$ a un y n die Fesselungshyperglykämie des Tieres gesehen hätte. Dies soll aber ein Versehen $\mathrm{S}$ cot t's gewesen sein.)

Beim 'l'ierversuche für den experimentellen Diabetes ist Fesselung des Tieres auf dem Operationstiche oft unvermeidlich. Den Fesselungsdiabetes an anderen Versuchstieren, welche zur Erforsching des experimentellen Diabetes gebraucht werden, zu probieren und die Art und Weise seiner Entstehung klar zu stellen, ist ja für das Studium gewisser Formen des experimentellen Diabetes unentbehrlich. Trotzdem ist der Fesselungsdiabetes noch auf lange Zeit hinaus unberücksichtigt geblieben.

C. Eckhard ${ }^{11}$, der $z$ war vor Boehm und $\mathrm{H}$ of f mann den Fesselungsdiabetes des Kauinchens beobachtete, berücksichtigte ihn bei dem Versuche über die Polyurie durch die Verletzung des Bodens des vierten Hirnventrike's; aber $\epsilon \mathrm{r}$ hat ihn nicht weiter studiert. Ihm gegenüber hat M. H. F is cher ${ }^{5)}$ behauptet, dass beim Kaninchen der Fesselungsdiabetes überhaupt nicht vorkonmt. Er sah niemals Glykosurie bei sechs Kaninchen, welche 24-36 Stunden lang auf dem Operationstisch getesselt worden waren.

W. B. Cannon, der mit D. de la $\mathrm{Paz}^{6)}$ die Adrenalinsekretion aus den Nebennieren der Katzo bei Affekten wie Wut oder Schreck, und mit R. G. Hoskins ${ }^{7}$ dieselbe Erscheinung bei der Asphyxie

1) C. Eckhard, Zeitschr. Biol. $44(1903), 407$.

2) B. Naunyn, Schmiedeberg's Arch. $3(1875 ; 157$.

3) C. Bock und F. A. H offmann, zit. n. J. Seegen, Die Zuckerbildung im Tierkïrper, Berlin 1890, s. 105.

4) E. L. Scott, Amer. Journ. Physiol. 34 (1914), 271.

5) M. H. Fischer, Pflüger's Arch. 109 (1905), 12-13.

6) W. B. Cannon und D. de la Paz, Amer. Journ. Physiol. 29 (1911), 64.

7) W. B. Cannon und K. G. Hoskins, Amer. Journ. Physiol. 29 (1911-12), 274. 
und Reizung des sensiblen Nerven sah, hat weiter mit A. 'T. Shohl und W. S. Wright' beobachtet, dass bei der Katze Glykosurie nur auftritt, wenn sie Affekte wie Wut oder Schreck hat, während keine Glykosurie auftritt, so lange sie nicht aufgeregt ist, selbst wenn sie auf dem Operationstisch gebunden wird. Die alte weibliche Katze verhält sich meistens ruhig auf dem Operationstische. Nach ihrer Meinung hat wohl der Befund von Boehm und Hoffmann, dass bei der Katze Glykosurie durch Fesselung hervorgerufen wird, seinen Grund in einem Affekte der Katze, nicht aber in der Fesselung selbst. Deshalb sollte man nach ihrer Meinung diese Erscheinung nicht „Fesselungsdiabetes, " sondern ,emotional glycosuria“ nennen.

Was den Fesselungsdiabetes beim Kaninchen anbetriff, so hatte niemand seit Eckhard acht darauf gegeben. Ja I. Bang schrieb in dem Kapitel „Psychische Erregungen“ auf Seite 51 seines Buches „Der Blutzucker" (1913) sogar, dass beim Kaninchen Hyperglykänie und Glykosurie durch Fesselung auf dem Operationstische trotz häufiger Schreckäusserung nie auftritt, im Gegensatze zur Katze. Aber bald nachher hat, noch in demselben Jahre, und zwar aus Bang's Laboratorium selbst, A. Th. B. Ja cobs en ${ }^{2)}$ mitgeteilt, dass er beim Kaninchen. recht bedeutende Hyperglykämie durch Aufbinden auf dem Operationstische auftreten sah, und dass das Tier dabei grossen Schrecken äusserte. Und seines Erachtens ist es die natürlichste Annahme, den Schreck als Ursache dieser Hyperglykämie zu betrachten. Weiter fügte er hinzu, dass es wohl berechtigt ist, auf Grund der Tatsache, welche Bang selbst ihm mitteilte, dass nämlich er, Bang, der zahlreiche Untersuchungen an Kaninchen vorgenommen hatte, nur ein paarmal Hyperglykämie solcher Art feststellen lsonnte. Von Jacobsen unabhängig und kurz nach ihm, haben E. Hirsch und H. Reinbach ${ }^{3 !}$ mitgeteilt, dass beim Kaninchen durch Fesselung und eine kleine zur Blutentnahme vollzogene Operation Hyperglykämie und Glykosurie auftraten, dass der Grad der Hyperglykämie und Glykosurie bei der Narkotisierung des Kaninchens durch Morphium, Äther und ähnliches sehr abhängig von der Fesselung des Tieres war, das heisst, dass bei der Narkotisierung ohne Fesselung die Vermehrung des Blutzuckergehaltes nur gering

1) W. B. Cannon, A. T. Shohl und W.S. Wright, Amer. Journ. Physiol. 29 (1911-12), 280.

2) A. Th. B. Jacobsen, Biochem. Zeitschr. 5 I (1913), 443.

3) E. Hirsch und H. Reinbach, Hoppeseyler's Zeitschr. 87 (1913), 121. 
war, wie bei der Blutentnahme ans der Ohrvene beim nicht gefesselten Kaninchen, und dass es deshalb sehr fraglich sei, ob Narkotika als solche allein Hyperglykämie des Tieres verursachen können. Weiter haben sie stark betont, dass man beim Versuche zur Feststellung der Frage, ob die Einspritzung irgend einer Substanz oder eines Narkotikums Hyperglykämie herbeiführen kann, vorher erst unbedingt die Blutzuckersteigerung durch die Fesselung, Blutentnahme und anderes berücksichtigen müsse. Bei jhren fünf Versuchen der Fesselung allein ohne Operation am Halse (Blutentnahme aus der Ohrvene), hat der Blutzuckergehalt des Kaninchens 0,20-0,35\% erreicht. Bei ihren zwei Versuchen der Fesselung und Blossleguug der Halsarterie war der maximale Blutzuckergehalt 0,35 und $0,42 \%$. Nach ihren Versuchsresultaten müsste, wenn bei gewissen Versuchen am Kaninchen über den experimentellen Diabetes die Fesselung des Tieres und kleine Operationen wie Blosslegung der Gefässe zur Unterstützung der Versuche herbeigezogen werden, der Blutzuckergehalt einen äusserst hohen Wert zeigen, um aus so einfachen Versuchen wie Hirsch und Reinbach den Schluss ziehen zu kömnen, dass die bezweckte Bedingung Hyperglykämie herbeiführt.

Die Abhandlung von $\mathrm{Hirsch}$ und Reinbach hat viel Aufnerksamkeit auf sich

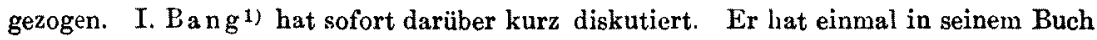
betont, dass beim Kaninchen eine derartige Hyperglykämie, wie sie der Fesselungsdiabetes der Katze darstellt, nicht vorkommt. Doch kurz nachher wurde seine Aufmerksamkeit darauf gelenkt, wie die Publikation Jacobsen's zeigt. Er hat weiter der Meinung von $\mathrm{Hirsch}$ und Reinbach beigestimmt, dass diese Art Hyperglykämie vielleicht für mehrere, früher beschriebene Hyperglykämieformen verantwortlich sei. Schon kurz vor Jacobsen's Publikation hat er selbst mit Stenström besonders für die asphyktische Hyperglykämie beim Kaninchen auf diese Möglichkeit hingewiesen. Kaninchen, welche direkt zu Versuchen verwendet werden, zeigen recht regelnässig psychische Hyperglykämie. (Vergleiche Ja cobsen S. 450.) Aber wenn sie erst an das Laboratoriunsleben gewöhnt worden sind, tritt Hyperglykämie nicht mehr auf. Auf Grund wiederholter Beobachtungen, dass gewöhnte Kaninchen keine Hyperglykämie bekommen, obgleich sie schreien und sich unruhig verhalten, wenn sie aufgebunden werden, betrachtete er die Verhältnisse als komplizierte, und hat deshalb zur Benennung solcher Art Hyperglykämie den Ausdruck ,,psychische Hyperglykümie" statt , Schreckhyperglykämie" vorgeschlagen. (Die Benennung ,schreckhyperglykümie" wurde ja ron Jacobsen, Mitarbeiter von I. Bang, selbst (S. 450) und nicht von Hirsch und Reinbach vorgeschlagen. In der Mitteilung der beiden Jetzten über die Fesselungsbyperglykümie und -glykosurie beim Kaninchen ist nirgends "Schreckhyperglykämie" oder auch nur das Wort "Schreck" zu finden. 'Trotzdem scheinen sowohl Bang (S. 44), der Lehrer von Jacobsen, und J. Müller") (S. 290), der Lehrer von Hirsch und

1) I. Bang, Hoppe-Seyler's Zeitschr. 88 (1913), 44.

2) J . Müller, Hoppe-Seyler's Zeitcchr. 91 (1914), 287. 
Reinbach, merkwürdigerweise zu glauben, dass die Bezeichnung ,Schreckhyperglykämie" zuesrt von $\mathrm{Hirsch}$ und Reinbach vorgeschlagen worden sei.

Anderseits wurde die Publikation von $\mathrm{Hirsch}$ und Reinbach von Fr. Rolly und Fr. Oppermann ${ }^{1)}$ stark angegriffen. Es war eine Polemik über die Prioritätsfrage. Die letzteren haben $\mathrm{E} \mathrm{ckh}$ ard, Oppler und $\mathrm{R}_{\mathrm{o}} \mathrm{a}$ und andere und die Beschreibungen hierron aus früheren eigenen Mitteilungen wieder besprochen. Dass E ckhard schon vor Boehm und $\mathrm{H}$ off $\mathrm{man} \mathrm{n}$ die Fesselungsglykosurie des Kaninchens und darüber später wieder im Jahre 1903 geschrieben hat, ist schon oben erwähnt. Aber bei ihm liegt kein systematische Studium darüber vor. Es dürfte sich wohl bei $\mathrm{Hirsch}$ und Reinbach un einen Übersehen alter vereinzelter Literatur handeln, als sie schrieben: „Etwas dem an Katzen ron $\mathrm{B} \ddot{\mathrm{h}} \mathrm{hm}$ und $\mathrm{H}$ of $\mathrm{fmann}$ gefundenen Fesselungsdiabetes Analoges ist ja für das Kaninchen bisher nicht, bekannt." (S. 122) Ja, Boeh m und Hoff man n zitierten Eckhard's Befund in ihrer zweiten Abhandlung. Aber in ihrer Mitteilung haben Rolly und Oppermann ${ }^{2}$ ) nur ganz kurz geschrieben: "Überhaupt möchten wir auf Grund eigener Erfahrungen dav or warnen, Kaninchen als Versuchsobjekte bei derartigen Experimenten zu verwenden, da die Blutzuckerwerte bei diesen Tieren öfter nicht recht kontrollierbare Schwankungen zeigen, ja schon Fesselung oder andere sensible Reizung hier zu einer Erhöhung des Blutzuckers führen könren." (S. 201.) In ihren weiteren Mitteilungen haben sie nur dieselbe Meinung wiederholt. Von einer systematischen Darstellung darüber keine Rede! Dieser Angriff wurde sofort von J. M üller, dem Lehrer von Hirsch und Reinbach, kräfig zurückgewiesen. Die Publikationen aus Bang's Laboratorium, welche Rolly und Oppermann zu Gunsten ihrer Behauptung zitiert hatten, wurden von Müll e r zum Gegenbeweis dafür benutzt. Wenn der Blutzuckergehalt des Kaninchens leicht veränderlich sei, so müsse man sorgfültig den Grund und die Art und Weise seiner leichten Veränderlichkeit suchen. Das ist ja auch eine Erforschung des experimentellen Diabetes! Die Fesselung wurde von Jacobsen und Hirsch und Reinbach als Bedingnng der Hyperglykämie beim Kaninchen erkannt. Durch solche systernatische Untersuchungen werden unsere Kenntnisse über den Mechanismus der Hyperglykämie immer reicher und tiefer. Rolly und Oppermann haben den Blutzuckergehalt des Hundes mit Recht konstant gefunden. Bang ${ }^{3)}$ hat einmal die Unbrauchbarkeit des Hundes für Blutzuckeruntersuchung ausgesprochen, denn der Blutzuckergehalt des Hundes physiologisch ziemlich grossen Schwankungen unterworfen ist $(0,08-0,22 \%)$. Etwa wie es Rolly und Oppermann beim Kaninchen ging. Nach der Publikation ron Hirsch und Reinbach hat Bang seine Meinung über die Blutzuckersch wankungen beim Hunde etwas geändert. In Wirklichkeit ist der normale Blutzuckergehalt sowohl des Hundes als auch des Kaninchens recht konstant.

Betreffs der Bezeichnung der Hyperglykämie durch Fesselung und demähnliches bat Müller "Afektglykümie" statt "psychische Hyperglykämie" als hezeiclınender vorgeschlagen. Wie schon oben zitiert wurde, haben Cannon") und seine Schïler im Jahre 1911 den Fesselungsdiabetes der Katze von Boehm und Hoffmann weiter studiert und als Bedingung für die Entstehung der Glykosurie Affekte wie Wut und Schreck, nicht blosse Fesselung, gefunden und sie daraufhin "emotional glycosuria" genannt. Diese Benennung ist von Bang und Müller gar nicht berührt worden.

1) Fr. Rolly und Fr. Oppermann, Hop pe-Seyler's Zeitschr. 88 (1913) 155.

2) Fr. Rolly und Fr. Oppermann, Biochem. Zeitschr. 48 (1913), 200.

3) I. Bang, , Der Blutzucker “ Wiesbaden 1913, S. 31.

4) W. B. Cannon, A. T. Shohl und W.S. Wright, Amer. Journ. Physiol. 29 $(1911-12), 230$. 
Bang hat aber die Arbeit von Cannon gekannt („Blutzucker" S. 52.), und Múl uer wahrscheinlich auch (S. 291.). Als Bezeichnung für diese Form der Hyperglykämie und-glykosurie wäre vielleicht „emotional glycosuria" (Cannon), "Affektglykämie" (Müller) zutreffender als ,psychische Hyperglykämie" (Bang), denn jener Ausdruck kennzeichnet die Bedingung des Zustandekonmens dieser Hyperglykämie viel genauer, und der Begriffsinhalt von "psychischen Erregungen" ist ungenau und heutzutage in der Psychologie nicht mehr gebrauchlich. (Dies wurde mir brieflich von Herrn Prof. Chiba, psychologisches Institut der Universität zu Kyoto, mitgeteilt, wofür ich Herrn Prof. Chib a hier nochmals meinen herzlichen Dank ausspreche).

Aber mit Bezug auf die Entstehungswejse der Hyperglykämie und Glykosurie durch Fesselung sind von einigen Forschern noch andere Faktoren als Affekte als Hauptmomente angenommen worden ( $M$ ül le r, S. 291 und G. N. Stew art und J. M. Rog of $\mathbf{f}^{\mathbf{t}}$ )). Nach Suketaka Morita") tritt die Hyperglykämie beim grosshimlosen Kaninchen auch durch Fesselung, Aderlass, Äther, Diuretin und Reizung des sensiblen Nerven auf. Daher kann man jetzt die Frage nach dem Mechanisnus der Entstehung des Fesselungsdiabetes durch die Affekte noch immer nicht als gründlich geklärt betrachten.

In diesen meinen hier vorligenden Versuchen habe ich nur die Veränderungen des Blutzuckergehalts des Kaninchens bei der Fesselung studiert. Deshalb babe ich als Überschrift dieser Abhandlung „Fesselungshyperglykämie und -glykosurie" gewähit.

Kurz nach Hirsch und Reinbach haben $A$. Loewy und S. Rosenberg.37 Versuche über den normalen Blutzuckergehalt des Hundes publiziert, die bei der Publikation von Hirsch und Rein bach schon in Gang waren. Zur Blutzuckerbestimmung haben sie 20 bis 30 ccm Blut der A. carotis oder A. femoralis entnommen. Der Blutzuckergehalt des Hundes schwankt, aber nur in geringem Masse als beim Kaninchen. Der Zuckergehalt des Hundeblutes, welches sie unter Vermeidung von Schmerzempfindung entnommen haben, betrug 0,114 bis $0,15 \%$; die Variation war also nicht so gross. Im nächsten Jahre haben Hirsch und Reinbach" eine Mitteilung über dieselben Versuche am Hunde veröffentlicht. Darin konnten sie die Hyperglykämie durch Fesselung auch konstatieren, nur in einem geringeren Grade als beim Kaninchen, wie Loewy und Rosenberg. Beim Hunde tritt auch Hyperglykämie durch Morphinn, Äther und Chloroform auf. Diese Hyperglykämie tritt nach Hirsch und Reinbach infolge von Körpertemperaturerniedrigung, Abspannen der Muskeln und psychische Aufregung im Anfangstadium der Narkose ein. Um den normalen Blutznckergehalt der Katze festzustellen, hat E. L. Scott $\left.{ }^{5}\right)$ die Katze auf einmal geliöpft (dazu nư drei Sekunden nötig), und aus den Halsgefäs-

1) G. N. Stewart und J. M. Rogoff, Amer. Journ. Physiol. 44 (1917), 572.

2) Suketaka Morita, Schmiedeberg's Arch. 78 (1915), 188.

3) A. Loew y und S. Rosenberg, Biochem. Zeitschr. 56 (1913), 114.

4) E. Hirsch und H. Reinbach, Hoppe-Seyler's Zeitschr. 91 (1914), 292.

5) E. L. Scott, Amer. Journ. Physiol. 34 (1914), 271. 
sen die Blutprobe entnommen (dazu fünfzehn bis zwanzig Minuten nötig). Der durchschnittliche Blutzuckergehalt aus zweiundzwanzig Katzen ist 0,069\% (0,056 bis 0,096\%). Infolge der Narkose mittelst Äther oder Chloroform hat er auch Hyperglykämie beobachtet, aber die Meinung über die Entstehungsweise der Narkosenhyperglykänie von Hirsch und Reinbach nicht weiter erörtert. P. A. Shaffer ${ }^{1)}$ hat die Blutprobe aus der $\mathrm{V}$. jugularis oder A. femoralis des Hundes mittelst Durchstechens der Haut darüber mit einer scharfen Spritznadel bekommen. Nach seiner Bestimmung ist der normale Blutzuckergehalt des Hundes 0,02 bis $0,065 \%$ and erhöht sich rurch Äthernarkose, Blosslegung der Halsgefässe und dergleichen mehr. Er neigt dazu, diese Hyperglykämie als Folge der Affekte und nicht als Wirkung der Narkotika selust zu deuten. Die Meinung von E. L. Ross and H. McGuigan ${ }^{2)}$ ist gerade das Gegenteil von der Shaffer's, denn nach ihnen wird der Grad der Hyperglykämie desto grösser, je länger die Dauer der Narkose ist. G. N. S tewart und J. M. Rogoff ${ }^{3}$ konnten Vermehrung des Blutzuckergehaltes bei der nicht gefesselten Katze, die vor einem bellenden Hunde erschrak, nicht jedesmal finden; dagegen konnten sie immer die Hyperglykämie bei der gefesselten und von einem bellenden Hunde erschreckenden Katze, ja sogar bei der Katze, welche bloss gefesselt da lag, ohne irgend einen weitern Eingriff zu bekommen. Sie wollen zwar die Existenz der Affekthyperglykämie nicht verneinen, aber sie nur als selten annehmen. Deshalb soll i. E. die Fesselungshyperglykämie und -glykosurie einen ganz anderen Entstehungsmechanismus als die Affekthyperglykämie und -glykosurie haben.

Die Forschung des Fesselungshyperglykämie und -glykosurie hat natürlich als solche grosse Bedeutung. Ausserdem ist bei experimentellen Untersuchungen gewisser Diabetesformen Fesselung des Tieres nicht selten unvermeidlich. Deshalb wird man solchen Fällen die Versuchsresultate garnicht richtig beurteilen können, ohne genauere Kenntnis von der Fesselungshyperglykämie und -glylosurie zu besitzen. Trotz so umfangreicher Untersuchungen verschiedener Forscher in diesem Jahrzehnt, die ich oben zusammengestellt habe, muss man sie doch noch sehr mangelhaft nennen. Viele Unklarheiten und Streitfragen bleiben noch bestehen. Jedenfalls sind noch viel systematische und vielseitige Untersuchungen darüber recht wünschenswert.

1) P. A.Sh a ffer, Journ. biol. Chem. 19 (1914), 297.

2) E. L. Ross und H. MeGuigan, Journ. biol, Chem. 22 (1915), 407;

3) G. N. Stewart und J. M. Rogoff, Amer. Joura. Physiol. 44 (1917), 543. 


\section{Kap. 11. Methodik.}

Versuchstiere: Zum Versuche wurde nur das männliche Kaninchen benutzt, wegen der Leichtigkeit der Harnaufnahme durch Katheterisierung. Nach Cannon und seinen Mitarbeitern ist der junge Kater sehr leicht aufgeregt, die aile Katze dagegen ruhig. Die Glykosurie tritt bei den leicht aufgeregten früher, bei den ruhigen viel später oder gar nicht (so lange, wie sie ruhig sind) auf. Was für einen Einfluss das Geschlecht und Alter auf den Fesselungsdiabetes beim Kaninchen hat, ist bis jetzt noch nicht bekannt. Ich habe nur Kaninchen benutzt, welche weder zu jung noch zu alt waren und sie hauptsächlich nach ihrem Körpergewicht ausgesucht.

Die Kaninchen wurden mindestens über eine Woche lang in den Kaninchenstall aufgenommen, wo im Kasten mit Wandungen aus Metalldrahtnetz zwei Kaninchen oder im grossen Kasten mehrere zusammenleben, und nur mit Tofukara ${ }^{1)}$ gefüttert. Mindestens während der Dauer von vier bis sieben Tagen vor dem Versuche wurden sie in den Kasten im Versuchszimmer oder Korrid or vor demselben aufgenommen (weil wir häufig bemerkt haben, dass das Körpergewicht des Kaninchens zwei bis drei Tage nach seiner Aufnahme ins Versuchszimmer aus dem Tierstall abnahm), und auch mit Tofukara gefüttert. Etwa $250 \mathrm{~g}$ Tofukara wurden jeden Tag einmal in der Zeit zwischen drei und fünf Uhr nachmittags gegeben.

Ich habe ein und dasselbe Kaninchen nur einmal zum Versuche gebraucht. Nur bei den speziellen Versuchsreihen, wie in Kap. V, habe ich ein und dasselbe Kaninchen zweimal oder mehrmals zur Fesselung gebracht. In unserem Institut wurde an einem Ohr des Kanincheus eine nummerierte, kleine, rundliche Metallplatte befestigt.

Blutentnahme, Harnaufnahme und Körpertemperaturmessung: Die Blutprobe wurde dem R. posterior V. auricularis ( Krause, Anatomie des Kaninchens, II. Aufl, Leipzig 1884, S. 274) entnommen. Dazu wurden wenigstens 3-4 Tage vor dem Versuche der Halssympathicus und N. auricularis magnus gleicher Seite wie die Vene, aus welcher die Blutprobe entnommen werden sollte, unter Fesselung auf den Operationstische ohne Narkose durchschnitten. Die Ohrgefïsse blieben über einen Monat hindurch erweitert, was für die Blutentnahme sehr günstig war. Keine Schmerzempfindung bei der Blutentnahme. Diese Operation ist sehr einfach, aber doch auch von ziemlich grosser Bedeutung beim Versuche des experimentellen Diabetes, weil dadurch die sensible Reizung bei der Blutentnahme absolut vermeiden werden kann, welche ein Moment der Hyperglykämie des zentralen Mechanismus' bildet. Hirsch und Reinbach, die nach Bang's Mikromethode die Blutzuckerbestimmung ausführten, haben einen geringeren Grad der Hyperglykämie durch die Blutentnahme aus der Ohrvene beim nicht gefesselten Kaninchen konstatiert.

Bei der Bestimmung des normalen Blutzuckergebaltes wurde die Blutprobe aus der Ohrvene des nicht gefesselten, sondern nur im grossen Metallbecken (mit dem Durchmesser von etwa einem halben Meter) ruhig sitzenden Kaninchens entnommen. Die Harnaufnahme und Körpertemperaturmessung habe ich ausgeführt, indem ich das Kaninchen einfuch in meinem Arm ruhig hielt.

Die erste d. h. normale Blutprobe beim Fesselungsversuche wurde auch in dieser Weise entnommen. Das Tier wurde dann gefesselt, der Harn aufgenommen und die Analtemperatur gemessen. Wenn diese drei Manipulationen auf einmal ausgeführt wurden, wurde erst die Blutprobe entnommen, gewogen und in ein Luftbad getan, dann der

1) Ko. Naito, Diese Ztschr. 1 (192)), 134. 
Harn aufgenommen und zuletzt die Körpertemperatur gemessen.

Blutzuckerbestimmung: Im Beginn des Versuches habe ich den Zuckergebalt des Blutserums bestimmt; das Blutserum wurde nach der Methode von Rona und Michaelis enteiweisst und dessen Zuckergehalt nach Bertrand bestimmt. Bei dieser Methode musste ich mich ausser mehrmaligen Harnzuckerbestimmungen mit einmaliger Blutentnahme begnügen, weil bei der Blutentnahme das Kaninchen auf den Operationsstisch aufgebunden, seine Halsgefässe blossgelegt und eine ziemljch grosse Menge Blut entnommen werden muss. Doch habe jch mit dieser Methode ziemlich zahlreiche Versuche angestellt, und deren Resultate stimmen mit denen in dieser Mitteilung gut überein. (Siehe Tohoku-Igaku-Zasshi (jap.) 5 (1920), S. 24.)

Nachher aber, habe ich aus oben geschilderten Gründen endlich diese Methode verlassen, und bin zu I. Bang's Mikromethode ${ }^{132)}$ der Blutzuckerbestimmung übergegangen. Die Jod- und Stärkelösung wurden nach der Beschreibung von $\mathrm{K}$. B rahm und A. Schittenhelm ${ }^{3}$ ) hergestellt. Statt der Torsionswage wurde eine gewöhnliche chemische Wage mit der Empfindlichkeit ron $1 \mathrm{mg}$ kenutzt. Damit kann man bei einiger Übung schnell wiegen. Die Zeit, die nötig ist, un die Blutprobe aus dem R. posterior V. auricularis auf das Fliesspapierchen zweimal aufzunehmen, es zu wiegen und in das Luftbad von $80^{\circ}-100^{\circ} \mathrm{C}$ hineinzutun, beträgt ungefähr zwei bis drei Minuten. (Vergleiche Bang1) (S. 22)!) Es ist sebr wichtig, die Blutprobe aus der Ohrrandrene schnell zu entnehnen, um dadurch den Wasserverlust der Blutprobe möglichst zu rermeiden.

Beim Kochen des Reduktionskolbens ist es sehr wichtig, die Flammengrösse konstant zu halten. Der Gasdruck im Institute zeigt sehr grosse Schwankungen. Um dessen Einfluss auszuschalten, habe ich den Gasdruckregulator der Firma $\mathrm{N}$ ishimura in Kyoto, der klein und sehr handlich ist, benutzt.

Bestimmung des Harnzuckers. Nach Bertrand. Bei der Beurteilung der Glykosurie (besser "Glycuresis" nach S. R. Benedict und seinen Mitarbeitern4)) ist es viel wichtiger, absolute Harnzuckermenge pro Zeiteinbeit als Prozentgehalt zu vergleichen. Ich habe beide Zahlen angegeben.

Bestimmung des Säure - resp. Alkaligrades des Harnes. Weil die Harnmenge in zwei bis drei Stunden häufig zu klein ist, habe ich die Methode ron A m. Vozárik5) in folgender Weise benutzt. 1-2 cem Harn wird mit destilliertem Wasser bis auf 10 ecm verdünnt und dann mit $n / 50$ Natronlauge resp. n/50 Salzsäure, unter Anwendung von Phenolphtalein als Indikator, titriert. Der Säure- resp. Alkaligrad ist durch eine Menge der Normallösung, die nötig ist, um $10 \mathrm{~cm}$ Harn zu neutralisieren, bezeichnet.

Beurteilung des Gehaltes der Nebennieren an chromaffiner Substanz. Nach J. Negrin und E. Th. Brücke's Methode ${ }^{6 / 7)}$

Temperatur, Feuchtigkeit; atmosphärischer Druck und Abkühlungsgrad im Versuchszimmer. Die Zimmertemperatur wurde jedesmal nach der Körpertemperatur-

1) I. Bang, Biochem. Zeitschr. 49 (1913), 19.

2) I. Bang, Biochem. Zeitschr. 57 (1913), 300.

3) K. Brahm und A.Schittenhelm, T. Brugsch und A. Schittenhelm's Technik d. spez. klin. Untersuchungsmethoden, II. Teil, Berlin u. Wien 1914, 600.

4) S. R. Benedict, E. Osterberg und I. Neuwirth, Journ. biol. Chem. 34 (1918), 217.

5) Am. Vozárik, Pqüger's Arch. 111 (1906), 473.

6) J.Negrin und E. Th. Brücke, Zeitschr. b:ol. Techn. u. Method. 3 (1914), 311.

7) I. F uji i, diese Zeitschr, 1 (1920), 44. 
messung des Tieres abgelesen. Ausserdem haben wir, um die Temperatur, Feuchtigkeit und den atmosphürischen Druck im Versuchszimmer ununterbrochen zu kennen, im Versuchszimmer drei betreffende Selbstregistrierungsapparate.

Das Versuchszinmer wurde vom November bis zum März des folgenden Jahres durch Zentralheizung ( und einen Gasofen geheizt.

In allgemeinen war die relative Feuchtigkeit im Sommer etwa 70-81, und im Winter etwa 55-70. Im Frühling und Herbst steht sie zwischen der des Sommers und Winters. Die Barometerhöhe zeigte fast keinen Unterschied je nach den Jahreszeiten und war etwa 750-760 $\mathrm{mm} \mathrm{Hg}$, abgesehen von ihrer temporären Erniedrigung bei Wind. Nur im Sommer ist sie ein wenig niedrig und im Winter ein wenig hocb.

Um zu beurteilen, ob ein Zimmer oder sonst ein Ranm hygienisch ist, pflegt man gewöhnlich ausser der Temperatur und Feuchtigkeit die chemische Zusammensetzung der Zimmerluft zu bestimmen. Das aber genügt doch nicht. Denn L. Hil11)2) hat mit seinen Mitarbeitern festgestellt, dass man in einem Raum, in dem die Luft in chemischen Sinne unrein ist, weder ein unangenehmes noch ein Ermüdungsgefühl hat und nie erkrankt, so lange die Temperatur und Feuchtigkeit im Raum niedrig sind. Deshalb ist die Wärmestauung die alleinige Ursache dieser Art von Unangenehmlichkeitsgefühl und alle Symptome, an welchen man in einem von Menschen überfüllten Zimmer leidet, stammen von der Wärmestauung her. Den Grad des Wärmererlustes des Körpers in gewissen Grenzen zu halten, ist für Hygiene des Zimmers eine sehr notwendige Bedingung. Der Würmeverlust aus dem Tierkörper geschieht durch Strahlung, Leitung und Wasserverdampfung. Wir kennen zwar den Abkühlungsgrad durch Strahlung mittelst des Thermometers und auch noch den durch Wasserverdampfung mittelst des Psychometers nach A ugust. Durch diese zwei Apparate aber können wir doch den Abkühlungsgrad infolge Leitung bei der Luftbewegung nicht messen.

Schon vor ungeführ hundert Jahren wurde einmal eine Methode ausgedacht, das Gefühl, verursacht durch den Temperatursinn der Haut, objektiv zu beurteilen. ${ }^{3)}$ Es geschah auf die Weise, dass man das gewöhnliche Thermometer bis auf $100^{\circ} \mathrm{F}$ erwärmte und die Grade, um welche es in einer halben Minute oder in zehn Sekunden von $100^{\circ} \mathrm{F}$ herabsank, mass.

Nenerdings hat L. Hill(1)2)1) das Katathermometer (oder Comfortmeter) konstruiert. Das Katathermometer besteht aus zwei Thermometern mit Kolben und zwar hat das eine einen Trockenkolben und das andere eiuen Nasskolben. Die Ausführung der Messung ist fulgende: Erst werden die beiden Kolben in warmes Wasser getaucht, dann sufort aus dem Wasser herausgenommen, wenn der rot gefürbte Alkohol bis auf $110^{\circ} \mathrm{F}$ gestiegen ist, und darauf die Zeit abgelesen, welche zum Herabsinken der Alkoholsäule von $100^{\circ} \mathrm{F}$ bis $90^{\circ} \mathrm{F}$ nötig ist.

Der Trockenkolben kühlt sich durch Strahlung und Leitung ab; der Nasskolben ausserdem noch durch Wasserstrahlung. Die Grösse und Form der Kolben sind so konstruiert, dass der Würmeverlust des Körpers hygienisch ist und sich jemand wohl

1) L. Hill, Lancet, $1913,1285$.

2) L. Hill, M. Flack, J. McIntosh, R. A. Rowland und H. B. Walker, Smithsonian Miscellaneous Collections, 60 (1913), No. 23.

3) W. Heberden, Philos. Transact. Roy. Soc. London, 1826, Part II. 69.

4) L. Hill, O. W. Griffith und M. Flack, Philos. Transact. Roy. Soe. London, B. $207(1916), 183$. 
fühlt, wenn diese Zeit für den Trockenkolben 2,5 bis 3 Minuten und für den Nasskolben 45 Sekunden bis I Minute beträgt. Der Apparat wurde auch von anderen ${ }^{1)}$ als sehr brauchbar bestätigt.

Bei jedem Versuche habe ich zweimal, und zwar im Beginn und am Ende des Versuchs, den Abkühlungsgrad des Versuchszimmers, nahe dem Operationstische, auf dem das Kaninchen gefesselt lag, mittelst des Katathermometers gemessen.

\section{Der Blutzuckergehalt des normalen nicht gefesselten Kaninchens.}

Versuch I.

28. XI. 1918. Kaninchen fo $1750 \mathrm{~g}$.

\begin{tabular}{|c|c|c|c|c|c|c|c|c|}
\hline \multirow{3}{*}{ Zeit } & \multirow{3}{*}{$\begin{array}{c}\text { Körper- } \\
\text { tempera- } \\
\text { tur } \\
\left({ }^{\circ} \mathrm{C}\right)\end{array}$} & \multirow{3}{*}{$\begin{array}{c}\text { Blut- } \\
\text { zucker } \\
(\%)\end{array}$} & \multicolumn{4}{|c|}{ Harn } & \multirow{3}{*}{$\begin{array}{c}\text { Zimmer- } \\
\text { tempera- } \\
\text { tur } \\
\left({ }^{\circ} \mathrm{C}\right)\end{array}$} & \multirow{3}{*}{$\begin{array}{l}\text { Kata- } \\
\text { thermometer }\end{array}$} \\
\hline & & & \multirow{2}{*}{$\begin{array}{l}\text { Menge } \\
(\mathrm{ccm})\end{array}$} & \multirow{2}{*}{$\underset{\text { Reak- }}{\text { tion }}$} & \multicolumn{2}{|c|}{ Zucker } & & \\
\hline & & & & & $(\%)$ & $\begin{array}{l}\text { g pro } \\
\text { Std. }\end{array}$ & & \\
\hline 8.56 A.M. & 38,2 & 0,09 & & alkal. & 0,015 & & 20,0 & $\begin{array}{lr}\text { Nasskolben } & 1.39 \\
\text { Trockenkolben } 3.02\end{array}$ \\
\hline 9.57 & 37,9 & 0,11 & & & & & 20,5 & \\
\hline 10.57 & 37,8 & 0,10 & & & & & 21,0 & \\
\hline 12.00 & 38,0 & 0,10 & & & & & 21,5 & \\
\hline 1.00 P.M. & 38,1 & 0,10 & 10,0 & alkal. & 0,015 & 0,0037 & 22,5 & \\
\hline 1.57 & 38,1 & 0,10 & & & & & 23,0 & \\
\hline 2.58 & 38,0 & 0,10 & & & & & 23,5 & \\
\hline 3.58 & 38,0 & 0,09 & 12,5 & alkal. & 0,030 & 0,0012 & 24,0 & $\begin{array}{l}\text { Nasskolben } 1.53 \\
\text { Trockenkolben3.18 }\end{array}$ \\
\hline
\end{tabular}

Versuch II.

31. I. 1919. Kaninchen $\hat{o} 1700 \mathrm{~g}$.

\begin{tabular}{|c|c|c|c|c|c|c|c|c|}
\hline \multirow{3}{*}{ Zeit } & \multirow{3}{*}{$\begin{array}{c}\text { Körper- } \\
\text { tempera- } \\
\text { tur } \\
\left({ }^{\circ} \mathrm{C}\right)\end{array}$} & \multirow{3}{*}{$\begin{array}{l}\text { Blut- } \\
\text { zucker } \\
(96)\end{array}$} & \multicolumn{4}{|c|}{ Harn } & \multirow{3}{*}{$\begin{array}{c}\text { Zimmer- } \\
\text { tempera- } \\
\text { tur } \\
\left({ }^{\circ} \mathrm{C}\right)\end{array}$} & \multirow{3}{*}{$\begin{array}{c}\text { Kata- } \\
\text { thermometer }\end{array}$} \\
\hline & & & \multirow{2}{*}{$\begin{array}{c}\text { Menge } \\
(\mathrm{ccm})\end{array}$} & \multirow{2}{*}{$\begin{array}{c}\text { Reak- } \\
\text { tion }\end{array}$} & \multicolumn{2}{|c|}{ Zucker } & & \\
\hline & & & & & $(\%)$ & $\begin{array}{l}\text { g pro } \\
\text { Std. }\end{array}$ & & \\
\hline $9.10 \mathrm{~A} \mathrm{M}$ & 38,7 & 0,09 & & $\begin{array}{l}\text { sauer } \\
\quad(3,5)\end{array}$ & 0,016 & & 6,5 & $\begin{array}{lr}\text { Nasskolben } & 1.16 \\
\text { Trockenkolben } 1.36\end{array}$ \\
\hline 10.40 & 39,3 & 0,11 & & & & & 9,0 & \\
\hline 12.10 P.M. & 39,1 & 0,12 & 29,7 & $\begin{array}{l}\underset{(6,5)}{\text { sauer }} \\
(6,5)\end{array}$ & 0,016 & 0,0024 & 11,0 & \\
\hline 1.43 & 38,9 & 0,11 & & & & & 13,5 & \\
\hline 3.07 & 38,7 & 0,13 & & & & & 14,5 & \\
\hline 5.10 & 39,1 & 0,09 & 12,0 & $\begin{array}{l}\text { sauer } \\
\qquad(41,0)\end{array}$ & 0,016 & 0,0005 & 15,0 & $\begin{array}{l}\text { Nasskolben } 1.10 \\
\text { Trockenkolben } 1.58\end{array}$ \\
\hline
\end{tabular}

1) C. E. A. Winslow, Science, 43 (1916), 716. 


\section{Versuch III.}

27. IV. 1919. Kaninchen 令 $1715 \mathrm{~g}$.

\begin{tabular}{|c|c|c|c|c|c|c|c|c|}
\hline \multirow{3}{*}{ Zeit } & \multirow{3}{*}{$\begin{array}{c}\text { Körper- } \\
\text { tempera- } \\
\text { tur } \\
\left({ }^{\circ} \mathrm{C}\right) \\
\end{array}$} & \multirow{3}{*}{$\begin{array}{c}\text { Blut- } \\
\text { zucker } \\
(\%)\end{array}$} & \multicolumn{4}{|c|}{ Harn } & \multirow{3}{*}{$\begin{array}{c}\text { Zimmer- } \\
\text { tempera- } \\
\left({ }^{\circ} \mathrm{C}\right)\end{array}$} & \multirow{3}{*}{$\begin{array}{c}\text { Kata- } \\
\text { thermometer }\end{array}$} \\
\hline & & & \multirow{2}{*}{$\left|\begin{array}{c}\text { Menge } \\
(\mathrm{ccm})\end{array}\right|$} & \multirow{2}{*}{$\begin{array}{c}\text { Reak- } \\
\text { tion }\end{array}$} & \multicolumn{2}{|c|}{ Zucker } & & \\
\hline & & & & & $(\%)$ & $\begin{array}{l}\text { g pro } \\
\text { Std. }\end{array}$ & & \\
\hline 9.08 A.M & 38,6 & 0,09 & & $\begin{array}{l}\text { sauer } \\
(6,5)\end{array}$ & 0,016 & & 16,0 & $\begin{array}{l}\text { Nasskolben } 1.02 \\
\text { Trockenkolben } 2.57\end{array}$ \\
\hline 10.07 & 39,0 & 0,09 & & & & & 16,5 & \\
\hline 11.38 & 39,1 & 0,10 & 10,0 & $\begin{array}{l}\text { sauer } \\
(11,0)\end{array}$ & 0,016 & 0,0006 & 17,5 & \\
\hline 1.07 P.M. & 38,8 & 0,09 & & & & & 18,5 & \\
\hline 2.38 & 39,2 & 0,09 & 7,9 & $\begin{array}{l}\text { sauer } \\
(15,0)\end{array}$ & 0,048 & 0,0013 & 19,0 & \\
\hline 4.09 & 39,4 & 0,09 & & & & & 19,0 & \\
\hline 5.35 & 39,2 & 0,09 & $\begin{array}{l}\text { Kein } \\
\text { beim } K \\
\text { terisat }\end{array}$ & $\begin{array}{l}\text { Harn } \\
\text { athe- } \\
\text { ion }\end{array}$ & & & 19,0 & $\begin{array}{l}\text { Nasskolben } 1.09 \\
\text { Trockenkolben } 3.39\end{array}$ \\
\hline
\end{tabular}

Der Blutzuckergehalt im Beginn des Versuches bei den oben beschriebenen drei Versuchsbeispielen betrug 0,09\%.

Der normale Blutzuckergehalt, d.h. der Blutzuckergehalt im Beginn aller Versuche in dieser Mitteilung (Aus dem Blutzuckergehalt der Versuchsreihe im Kap. V. wurde nur der im Beginn des ersten Versuches mitgerechnet.) und der Mitteilung über die Ätherhyperglykämie und -glykosurie beim Kaninchen, welche ich bald in diesem Journal publizieren werde, ist durchschnittlich $0,106 \%$, und zwar folgender :

Der normale Blutzuckergehalt des normalen Kaninchens.

\begin{tabular}{c|c|c|c}
\hline $\begin{array}{c}\text { Blutzucker in } \\
\%\end{array}$ & $\begin{array}{c}\text { (Fesselungsversuche }) \\
\text { Fälle }\end{array}$ & $\begin{array}{c}\text { (Ätherversuche } \\
\text { Fülle }\end{array}$ & Zusammen \\
\hline 0,07 & 1 & 0 & 1 \\
0,08 & 2 & 2 & 4 \\
0,09 & 26 & 4 & 30 \\
0,10 & 28 & 16 & 44 \\
0,11 & 28 & 10 & 33 \\
0,12 & 18 & 4 & 22 \\
0,13 & 6 & 1 & 7 \\
0,14 & 4 & 0 & 5 \\
0,15 & 2 & $(38)$ & 2 \\
& $(110)$ & & $(148)$ \\
\hline
\end{tabular}

Der durchschnittliche Wert ist bei den Fesselungsversuchen 0,106 $\%$, bei den Atherversuchen $0,104 \%$ und alle zuammen bei 148 
Kaninchen (drei Kaninchen wurden zweimal dazu benutzt) 0,106\%. Die Mehrzahl der Kaninchen hat einen Blutzuckergehalt von 0,09-0,12 $\%$. Doch haben wir noch keinen Grund, den Blutzuckergehalt unter $0,08 \%$ als hypoglykämisch und den über $0,13 \%$ als hyperglykämisch sofort bedingungslos anzusehen.

Der Blutzuckergehalt des beiderseitig splanchniliotomierten Kaninchens zeigt ganz denselben Wert, nämlich folgender :

Der Blutzuckergehalt des beiderseitig splanchnikotomierten $\mathrm{Kaninchens.}$

\begin{tabular}{c|c|c|c}
\hline $\begin{array}{c}\text { Blutzucker in } \\
0 \%\end{array}$ & $\begin{array}{c}\text { (Fesselungsversuche) } \\
\text { Fälle }\end{array}$ & $\begin{array}{c}\text { (ätherversuche) } \\
\text { Fälle }\end{array}$ & Zusammen \\
\cline { 1 - 2 } 0,08 & 1 & 0 & 1 \\
0,09 & 0 & 8 & 8 \\
0,10 & 3 & 3 & 6 \\
0,11 & 3 & 5 & 8 \\
0,12 & 3 & 6 & 9 \\
0,13 & 0 & 3 & 3 \\
& $(10)$ & $(\mathbf{2 5})$ & $(35)$
\end{tabular}

Der durchschnittliche Blutzuckergehalt ist bei den Fesselungsversuchen $0,107 \%$, bei den Ätherversuchen $0,107 \%$ und alle zusammen bei 35 Kaninchen also 0,107 \%. Die Mehrzahl ist anch 0,09-0,12\%. Diese Werte stimmen ganz gut mit denen bei normalen d.i. nicht spianchnikotomierten Kaninchen überein.

Der normale Blutzuckergehalt des Kaninchens nach den Bestimmungen von verschiedenen Experimentatoren, welche Bang's Mikromethode benutzt haben, ist folgender:

I. Bang durchschnittlich $0,10 \%(0,08-0,13 \%$ 40 ? Kaninchen).

(Der Blutzucker, Wieshaden 1913, S. 31.)

A. Th. B. Jacobsen , $0,12 \%(0,08-0,18 \%$. 41 Falle $)$.

(Biochem. Zeitschr. 51 (1913), 443.)

G. Bö̈ $\quad$ e $\quad 0,11 \%(0,07-0,14 \% \quad 49$ Kaninchen).

(Biochem. Zeitschr. 58 (1914), 716.)

I. Bang $\quad$ 0,12\% $(0,09-0,18 \%$. 26 Kaninchen).

(Biochem. Zeitschr. 58 (1914), 236.)

T. Stenström $\quad " \quad 0,11 \%(0,07-0,13 \%$. 9 Kaninchen $)$.

(Binchem. Zeitschr. 58 (1914), 472.)

M. Imamura $\quad, \quad 0,102 \%(0,095-0,108 \%$. 16 Kaninchen).

(Ijishimbun, 1916, Nr. 957, 1. (jap.)

M. Kage yama $\quad, \quad 0,107 \%(0,097-0,112 \%$. 9 Kaninchen).

(Acta Scholae Medicinalis Universitatis Imperialis in

Kioto, 1 (1916), 215. (deutsch.)) 
T. Suzuki durchschnittlich $0,100 \%(0,080-0,135 \%$. 10 Kaninchen $)$.

(Tokyo-Igakkwai-Zasshi, 30 (1916), 1165. (jap.))

R. Hara u. I. Matsui , $\quad 0,09 \%(0,07-0,11 \%$. 39 Kaninchen).

(Chūō-Igakkwai-Zasshi, 25 (1918), 87. (jap.))

N. Sekita

R. Doi

Derselbe

N. Sekita
$" \quad 0,10 \%(0,08-0,12 \%$. 18 Kaninchen).

(Tokyo-Igakkwai-Zasshi, 32 (1918), 813. (jap.))

, $0,13 \%(0,10-0,17 \% . \quad 16 \mathrm{Kaninchen})$.

(Tohoku-Igaku-Zasshi, 4 (1919), 200. (jap.))

$0,12 \%(0,08-0,15 \%$. 9 Kaninchen).

(Tohoku-Igaku-Zasshi, 4 (1919), 488. (jap.))

$0,10 \%(0,089-0,111 \%$. 18 Fälle $)$.

(Tokyo-Igakkwai-Zasshi, 34 (1920), 144. (jap.))

Bei der Berechnung der durchschnittlichen Zahl habe ich vicht mitgerechnet: bei Bö̈ die Bestimmungen des Kaninchens, welches an einem und demselben Tage wiederholt zum Versuche gebraucht ist, bei Suzuki den Blutzuckergehalt im Beginn des Versuches des hungernden Kaninchens und bei Sekita den des Kaninchens, welches schon einmal vorher Chinin bekommen hatte. Kage yama und Suzuki haben die Kontrollblutzuckerbestimmung wenigstens $\mathrm{zweimal}$ im Beginn jedes Versuchs angestellt; deshalb habe ich deren Mittelwert als den normalen Blutzuckergehalt jedes Kaninchens bei ihnen berechnet.

Wie die obigen Versuchsbeispiele zeigen, vermehrt sich der Blutzuckergehalt des Kaninchens während des Verlaufes von sieben bis acht Stunden nur wenig, falls dem nicht gefesselten Tier die Blutprobe nach je einer bis zwei Stunden aus der Ohrvene entnommen und die Körpertemperatur gemessen und der Harn bisweilen durch Katheterisierung aufgenommen wird. Der Bhtzuckergehalt zeigt sogar bei dem dritten Versuchsbeispiele fast keine Schwankungen. Ähnliches hat schon M. Kage y a ma beobachtet, wahrscheinlich Jacobsen anch.

Der Harnzuckergehalt und die Körpertemperatur bleiben auch dabei unverändert.

\section{Kap. III. Die Hyperglykämie und -glykosurie bei langdauernder Fesselung.}

Dem Kaninchen wurde die erste Blutprobe aus der Ohrvene ohne Fesselung entnommen, und dann wurde das 'Tier auf dem Operationstisch in Rückenlage gefesselt. Während der Fesselung von fünf bis acht Stunden wurden die Entnahme der Blutprobe und Messung der Körpertemperatur fast stündlich vorgenommen. Der Harn wurde bisweilen durch Katheterisierung entnommen.

Zu verschiedenen Jahreszeiten während zweier Jahre, seit dem Herbst 1918, habe ich etwa 83 Kaninchen dazu benutzt. 
(Alle Versuche jeder Versuchsreihe habe ich tabellarisch zusammengestellt und als Beispiel Versuchsprotokolle von einigen Versuchen jeder Versuchsreihe ausführlich wiedergegeben).

$$
\text { Versuch IX. }
$$

19. XII. 1918. Kaninchen $\hat{\delta} 1965 \mathrm{~g}$.

\begin{tabular}{|c|c|c|c|c|c|c|c|c|}
\hline \multirow{3}{*}{ Zeit } & \multirow{3}{*}{$\begin{array}{c}\text { Körper- } \\
\text { tempera- } \\
\text { tur } \\
\left({ }^{\circ} \mathrm{C}\right)\end{array}$} & \multirow{3}{*}{$\begin{array}{l}\text { Blut- } \\
\text { zucker } \\
(0)\end{array}$} & \multicolumn{4}{|c|}{ Harn } & \multirow{3}{*}{$\begin{array}{c}\text { Zimmer- } \\
\text { tempera- } \\
\text { tur } \\
\left({ }^{\circ} \mathrm{C}\right)\end{array}$} & \multirow{3}{*}{$\begin{array}{c}\text { Kata- } \\
\text { thermometer }\end{array}$} \\
\hline & & & \multirow{2}{*}{$\begin{array}{l}\text { Menge } \\
(\mathrm{ccm})\end{array}$} & \multirow{2}{*}{$\begin{array}{l}\text { Reak- } \\
\text { tion }\end{array}$} & \multicolumn{2}{|c|}{ Zucker } & & \\
\hline & & & & & $(\%)$ & $\begin{array}{l}\text { g pro } \\
\text { Std. }\end{array}$ & & \\
\hline 9.00 A.M & & 0,09 & & & & & & \\
\hline 9.15 & gefesselt & & & & & & & \\
\hline 9.16 & 37,8 & & & alkal. & 0,030 & & 12,0 & \\
\hline 9.18 & & 0,09 & & & & & & Nasekolhen \\
\hline 9.35 & & & & & & & & Trockenkolben 2.10 \\
\hline 10.18 & 35,6 & 0,16 & & & & & 14,0 & \\
\hline 11.35 & 35,6 & 0,20 & 5,0 & saver & 0,196 & 0,0043 & 17,0 & \\
\hline 12.56 P.M & 35,7 & 0,22 & 4,9 &,$(18,0)$ & 1,465 & 0,0552 & 18,0 & \\
\hline 3.10 & 35,9 & 0,20 & & & & & 20,0 & \\
\hline 4.35 & & & & & & & & 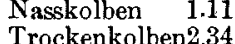 \\
\hline 5.06 & 36,5 & 0,16 & 8,0 & $\begin{array}{l}\text { sauer } \\
(46,0)\end{array}$ & 1,230 & 0,0237 & 20,5 & \\
\hline 5.20 & Tod dur & $\operatorname{ch~} \mathrm{Nac}$ & kenschI & & & & & \\
\hline
\end{tabular}

Marksubstanz der Nebennieren mittelmässig gefärbt, kein Unterschied zwischen beiden Nebennieren.

Versuch XLVI.

4. IV. I920. Kaninchen of $2170 \mathrm{~g}$.

\begin{tabular}{|c|c|c|c|c|c|c|c|c|}
\hline \multirow{3}{*}{ Zeit } & \multirow{3}{*}{$\begin{array}{c}\text { Körper- } \\
\text { tempera- } \\
\text { tur } \\
\left({ }^{\circ} \mathrm{C}\right)\end{array}$} & \multirow{3}{*}{$\begin{array}{c}\text { Blut- } \\
\text { zucker } \\
(\%)\end{array}$} & \multicolumn{4}{|c|}{ Harn } & \multirow{3}{*}{$\begin{array}{c}\text { Zimmer } \\
\text { tempera- } \\
\text { tur } \\
\left({ }^{\circ} \mathrm{C}\right)\end{array}$} & \multirow{3}{*}{$\begin{array}{c}\text { Kata- } \\
\text { thermometer }\end{array}$} \\
\hline & & & \multirow{2}{*}{$\begin{array}{l}\text { Menge } \\
\text { (ccm) }\end{array}$} & \multirow{2}{*}{$\begin{array}{l}\text { Reak- } \\
\text { tion }\end{array}$} & \multicolumn{2}{|c|}{ Zucker } & & \\
\hline & & & & & $(\%)$ & $\begin{array}{l}\text { g pro } \\
\text { Std. }\end{array}$ & & \\
\hline 10.10 A.M. & & 0,09 & & & & & & \\
\hline 10.15 & gefesselt & & & & & & & \\
\hline 10.16 & 38,6 & & & alkal. & 0,013 & & 13,0 & \\
\hline 10.30 & & & & & & & & Trockenkolben 2.41 \\
\hline 11.15 & 36,4 & 0,20 & & & & & 14,0 & \\
\hline 12.15 P.M. & 36,3 & 0,30 & 11,3 & alkal. & 3,913 & 0,2211 & 15,3 & \\
\hline 1.15 & 36,5 & 0,32 & & & & & 16,5 & \\
\hline 2.15 & 36,7 & 0,26 & 11,7 & sauer & 9,263 & 0,5419 & 17,8 & \\
\hline 3.15 & 36,8 & 0,27 & & & & & 18,8 & \\
\hline 4.15 & 37,0 & 0,26 & & & & & 20,0 & $\mathrm{Nacsk}$ \\
\hline 4.40 & & & & & & & & Trockenkolben 3.51 \\
\hline 5.15 & 37,0 & 0,26 & 10,5 & sauer & 9,110 & 0,3189 & 21,0 & \\
\hline
\end{tabular}


Versuch LXX.

30. VII. 1920. Kaninchen of $2030 \mathrm{~g}$.

\begin{tabular}{|c|c|c|c|c|c|c|c|c|}
\hline \multirow{3}{*}{ Zeit } & \multirow{3}{*}{$\begin{array}{c}\text { Körper- } \\
\text { tempera- } \\
\text { tur } \\
\left({ }^{\circ} \mathrm{C}\right)\end{array}$} & \multirow{3}{*}{$\begin{array}{c}\text { Blut- } \\
\text { zucker } \\
(\%)\end{array}$} & \multicolumn{4}{|c|}{ Harn } & \multirow{3}{*}{$\begin{array}{c}\text { Zimmer- } \\
\text { tempera- } \\
\text { tur } \\
\left({ }^{\circ} \mathrm{C}\right)\end{array}$} & \multirow{3}{*}{$\begin{array}{l}\text { Kata- } \\
\text { thermometer }\end{array}$} \\
\hline & & & \multirow{2}{*}{$\begin{array}{l}\text { Menge } \\
(\mathrm{ccm})\end{array}$} & \multirow{2}{*}{$\begin{array}{l}\text { Reak- } \\
\text { tion }\end{array}$} & \multicolumn{2}{|c|}{ Zucker } & & \\
\hline & & & & & $(\%)$ & $\begin{array}{l}\text { g pro } \\
\text { Std. }\end{array}$ & & \\
\hline 9.07 A.M. & & 0,09 & & & & & & \\
\hline 9.12 & gefesselt & & & & & & & \\
\hline 9.13 & 38,4 & & & alkal. & 0,013 & & 26,3 & \\
\hline 9.22 & & & & & & & & $\begin{array}{l}\text { Nasskolben } 1.44 \\
\text { Trockenkolben6.35 }\end{array}$ \\
\hline 10.18 & 37,0 & 0,12 & & & & & 27,1 & \\
\hline 11.15 & 36,6 & 0,12 & 12,2 & neutral & 0,013 & 0,0008 & 27,9 & \\
\hline 1215 P.M. & 36,4 & 0,12 & & & & & 28,3 & \\
\hline 1.15 & 36,4 & 0,11 & 22,4 & sauer & 0,013 & 0,0015 & 28,9 & \\
\hline 2.16 & 36,7 & 0,11 & & & & & 29,1 & \\
\hline 3.15 & 36,7 & 0,11 & & & & & $\Sigma 9,1$ & \\
\hline 3.24 & & & & & & & & $\begin{array}{l}\text { Nasskolben } 1.57 \\
\text { Trockenkolben } 8.50\end{array}$ \\
\hline 4.18 & 36,9 & 0,10 & 13,1 & sauer & 0,013 & 0,0006 & 28,9 & \\
\hline
\end{tabular}

Der Blutzuckergehalt steigt bi allen Versuchen schon in der ersten Stunde nach der Fesselung deutlich, nimmt allmählich weiter zu, erreicht meistens in drei bis fünf Stunden sein Maximum $(0,12-0,44$ $\%$ ) und nimmt alsdann langsam wieder ab. Doch kommt er auf den Anfangswert in acht Stunden noch nicht zurück, was die längste Versuchsdaner meiner Versuche war. Den Harn habe ich nicht stündlich wie die Blutprobe, sondern nur von Zeit zu Zeit aufgenommen. "Der Vergleich der zeitlichen Veränderungen des Harnzuckergehaltes rnit denen des Blutzuckergehaltes ist deshalb etwas schwer. Doch ist es nicht zu gewagt, zu behaupten, dass die Veränderungen der beiden ungefähr parallel laufen. Meistens wird die Glykosurie bald deutlich, wenn der Blutzuckergehalt etwa 0,2\% erreicht. Aber doch nicht ohne Ausnahmen.

Die Körpertemperatur des Kaninchens sinkt nach der Fesselung alluählich und bietet etwa ein Spiegelbild zum Blutzuckergehalt. Doch kann man nicht mit Sicherheit sagen, dass die Hyperglykämie und Glykosurie desto grösser sind, je grösser die Körpertemperaturerniedrigung ist.

Die Tabelle I zeigt, dass ohne eine einzige Ausnahme der Blutzuckergehalt des auf dem Operationstisch in Rückenlage gefesselten Kaninchens mehr oder weniger zunimmt. Und es scheint mir, dass 
im Winter und Frühling die Fesselungshyperglykämie und -glykosurie etwa intensiver als in anderen Jahreszeiten ist.

Der durchschnittliche Wert der Differenz zwischen dem Anfangswert des Blutzuckers und seinem Maximalwert während der Fesselung zeigt für jede einzelne Jahreszeit folgendes Bild : im Winter (Dezember bis Februar) 0,16\% (0,07-0,34\%.23 Beispiele), im Frühling (März bis Mai) $0,14 \%(0,04-0,25 \% .21$ Beispiele), im Sommer (Juni bis August) 0,11 \% (0,03-0,22\%. 19 Beispiele), und im Herbst (September bis November) $0,09 \% \quad(0,03-0,18 \% .20$ Beispiele). Der Harnzucker verhält sich auch dabei wie der Blutzucker. Im Wintes und Frühling tritt die Glykosurie etwa bei vier Fünftel der Versuche auf, dagegen im Sommer und Herbst etwa bei der Hälfte.

Im Winter ist das Versuchszimmer während der Tageszeit durch die Zentralheizung und den Gasofen so warm, wie im Frühling oder Herbst. In der Nacht aber ist es dort sehr kalt. An Tagen ohne Zentralheizung wie z.B. am Sonntag, ist die Zimmertemperatur etwa $5-10^{\circ} \mathrm{C}$, wenn der Ofen nicht angezündet wird.

Nach den Messungen des Abkühlıngsgrades mittelst des L. Hill'schen Katathermometers ist das Versuchszimmer im Frühling und Herbst sehr hygienisch, d.h. die Zeit für den Nasskolben ist etwa 1,5 Minuten, und für den Trockenkolben etwa 2,5-3,5 Minuten. Im Sommer sind sie über 2 Minuten resp. 4-7 Minuten, d.h. zu lang. An dem Wintertagen mit Heizung sind sie etwa wie im Frühling und Herbst. Wenn aber nicht geheizt wurde, ist die Zeit für den Trockenkolben besonders kurz.

Also scheint es mir, dass irgend eine Beziehung zwischen der Intensität der Fesselungshyperglykämie und -glykosurie und den Jahreszeiten vorhanden ist. Es ist eine schon allbekannte Tatsache, dass durch die Abkühlung des Tieres Hyperglykämie und Glykosurie auftritt. Es ist auch mitgeteilt, dass die äussere Temperatur Einfluss auf den Harnzuckergehalt des pankreaslosen Hundes und den Blutzuckergehalt des normalen Hundes hat. Da der Fesselungsdiabetes eine Art Diabetes zentralen Mechanismus' ist, ist es schon denkbar, dass er in der kalten Jahreszeit stärker auftritt.

Der Gehalt der Leber an Glykogen, welches die Muttersubstanz des vermehrten Blutzuckers beim Diabetes zentralen Mechanismus' darstellt, schwankt mit den Jahreszeiten. Beim Frosch ist er im Sommer kleiner und im Herbst grösser.1) 2)3) Beim Kaninchen ist er im Winter dreimal grösser als in Sommer.4) Nach Maignon ${ }^{5}$ ) schwant der Glykogngehalt des M. biceps femoris des Hundes nach den Jahreszeiten nnd zwar ist er am Ende des Winters und am Anfang des Frühlings maximal, und am Ende des Sommers minimal. Ishimori ${ }^{6}$ ) fand auch die Glykogenbildung in der Kaninchenleber im Sommer bedeutend vermindert, im Vergleich zu der in Winter und

1) O. Moszeik, Pflüger's Arch. 42 (1888), 556.

2) J. A thanasi u, Pflüger's Arch. 74 (1899), 561.

3) E. Pflüger, Pfl üger's Arch. 120 (1907), 253.

4) O. KisseI, Verhandl. der Physik.-Med. Gesellsch. Würzburg, Neue Folge. 30 $(1896), 77$.

5) Ma ignon, zit. nach R. Lépine, Lo diabete sucré, Paris 1909, S. 114.

6) K. Ishimori (石林), Chāō-Igakkwai-Zasshi, 112 (1913), 1. (jap.) 
Tabelle

\begin{tabular}{|c|c|c|c|c|c|c|c|c|}
\hline \multirow[b]{3}{*}{$\mathrm{Nr}$. } & \multirow[b]{3}{*}{$\begin{array}{c}\text { Körper- } \\
\text { gewicht } \\
\text { (g) }\end{array}$} & \multirow[b]{3}{*}{ Datum } & \multirow{3}{*}{$\begin{array}{l}\text { Fesse- } \\
\text { lungs- } \\
\text { dauer } \\
\text { (Std.) }\end{array}$} & \multicolumn{3}{|c|}{ Blutzucker } & \multirow{2}{*}{\multicolumn{2}{|c|}{$\frac{\text { Harn }}{(\%)}$}} \\
\hline & & & & & Maximum & & & \\
\hline & & & & $\begin{array}{c}\text { Fesse- } \\
\text { lung } \\
(\%)\end{array}$ & $\begin{array}{c}\text { während } \\
\text { der } \\
\text { Fesselung } \\
(\%)\end{array}$ & $\begin{array}{c}\text { bis zum } \\
\text { Maximum } \\
\text { (Std.) }\end{array}$ & $\begin{array}{l}\text { Kurz nach } \\
\text { der } \\
\text { Fesselung }\end{array}$ & $\begin{array}{c}\text { Maximum } \\
\text { wälirend } \\
\text { der } \\
\text { Fesselung }\end{array}$ \\
\hline 1 & 1230 & 6. IX. & 5,0 & 0,10 & 0,15 & 4,25 & 0,012 & 0,035 \\
\hline 2 & 1750 & $\begin{array}{l}1918 . \\
\text { 7. IX. }\end{array}$ & 7,5 & 0,13 & 0,17 & 4,3 & 0,030 & 0,060 \\
\hline 3 & 1610 & 13. IX. & 8,0 & 0,14 & 0,19 & 3,0 & 0,012 & 0,074 \\
\hline 4 & 2035 & $20 . \mathrm{IX}$ & 8,0 & 0,11 & 0,15 & 3,25 & 0,015 & 0,049 \\
\hline 5 & 1560 & $25 . \mathrm{JX}$. & 7,0 & 0,15 & 0,30 & 7,0 & 0,012 & 1,665 \\
\hline 6 & 1630 & 4. $\mathrm{X}$. & 7,0 & 0,10 & 0,22 & 5,5 & 0,045 & 1,483 \\
\hline 7 & 2110 & 18. XI. & 6,0 & 0,10 & 0,32 & 3,0 & 0,015 & 3,573 \\
\hline 8 & 1900 & 20. XI. & 8,0 & 0,09 & 0,29 & 5,3 & 0,015 & 12,440 \\
\hline 9 & 1965 & 19. XII. & 8,0 & 0,09 & 0,22 & 3,7 & 0,030 & 1,465 \\
\hline 10 & 2025 & 6. I. & 7,5 & 0,07 & 0,21 & 3,0 & 0,016 & 2,344 \\
\hline 11 & 1320 & $18 . \mathrm{I}$ & 6,5 & 0,10 & 0,19 & 1,5 & 0,015 & 0,042 \\
\hline 12 & 1470 & 26. I. & 8,0 & 0,09 & 0,23 & 3,5 & 0,017 & 3,139 \\
\hline 13 & 2095 & 1. II. & 3,0 & 0,10 & 0,23 & 1,7 & 0,035 & 3,920 \\
\hline 14 & 1725 & 5. V. & 7,0 & 0,09 & 0,24 & 3,5 & 0,016 & 4,415 \\
\hline 15 & 1680 & 18. V. & 7,5 & 0,08 & 0,27 & 3,5 & 0,018 & 6,422 \\
\hline 16 & 1515 & 20. V. & 7,5 & 0,09 & 0,21 & 3,0 & 0,034 & 1,008 \\
\hline 17 & 1550 & 25. V. & 7,0 & 0,10 & 0,25 & 5,7 & 0,017 & 5,232 \\
\hline 18 & 1510 & 27. V. & 8,5 & 0,11 & 0,15 & 3,25 & 0,017 & 0,052 \\
\hline 19 & 1480 & 3. VI. & 7,5 & 0,09 & 0,23 & 3,0 & 0,017 & 4,464 \\
\hline 20 & 1795 & 18. VI. & 7,5 & 0,11 & 0,25 & 4,5 & 0,017 & 0,373 \\
\hline 21 & 1900 & 30. IX. & 6,0 & 0,09 & 0,15 & 3,0 & 0,013 & 0,013 \\
\hline 22 & 1905 & 3. X. & 7,0 & 0,11 & 0,15 & 1,0 & 0,052 & 0,039 \\
\hline 23 & 1780 & 4. $\mathrm{x}$. & 8,0 & 0,12 & 0,26 & 3,0 & 0,013 & 6,422 \\
\hline 24 & 1875 & $7 . X$ & 7,0 & 0,11 & 0,28 & 3,0 & 0,026 & 9,290 \\
\hline 25 & 1680 & 27. XI. & 7,0 & 0,14 & 0,17 & 1,0 & 0,013 & 0,026 \\
\hline 26 & 1685 & 28. XI. & 7,0 & 0,11 & 0,25 & 1,0 & 0,013 & 1,380 \\
\hline 27 & 1785 & 4. XII. & 8,0 & 0,12 & 0,21 & 3,0 & 0,013 & 0,039 \\
\hline
\end{tabular}




\begin{tabular}{|c|c|c|c|c|c|c|c|}
\hline \multicolumn{3}{|l|}{ zucker } & \multicolumn{2}{|c|}{ Körpertemperatur } & \multirow[b]{3}{*}{$\begin{array}{c}\text { Zimmer- } \\
\text { temperatur } \\
\left({ }^{\circ} \mathrm{C}\right) \\
\end{array}$} & \multicolumn{2}{|c|}{ Katathermometer } \\
\hline & \multicolumn{2}{|c|}{ g pro Stunde } & \multirow{2}{*}{$\begin{array}{c}\text { Kurz } \\
\text { nach } \\
\text { der } \\
\text { Fesselung } \\
\left({ }^{\circ} \mathrm{C}\right) \\
\end{array}$} & \multirow{2}{*}{\begin{tabular}{|c|} 
Minimum \\
während \\
der \\
Fesselung \\
$\left({ }^{\circ} \mathrm{C}\right)$ \\
\end{tabular}} & & \multirow[b]{2}{*}{$\begin{array}{l}\text { Nass- } \\
\text { kolben }\end{array}$} & \multirow[b]{2}{*}{$\begin{array}{c}\text { Trocken- } \\
\text { kolben }\end{array}$} \\
\hline $\begin{array}{c}\text { Zeit bis } \\
\text { zum } \\
\text { Maximatim } \\
\text { (Std.) }\end{array}$ & $\begin{array}{l}\text { Maximum } \\
\text { während } \\
\text { der } \\
\text { Fesselung }\end{array}$ & $\begin{array}{c}\text { Zeit bis } \\
\text { zum } \\
\text { Maximum } \\
\text { (Std.) }\end{array}$ & & & & & \\
\hline 5,0 & 0,0003 & 5,0 & 38,3 & 36,6 & $26,0-28,5$ & $\begin{array}{l}1.58 \\
2.15\end{array}$ & $\begin{array}{l}4.47 \\
7.08\end{array}$ \\
\hline 4,5 & 0,0014 & 7,5 & 38,6 & 37,0 & $26,5-28,0$ & $\begin{array}{l}2.11 \\
1.52\end{array}$ & $\begin{array}{l}3.15 \\
3.40\end{array}$ \\
\hline 6,0 & 0,0010 & 8,0 & 37,8 & 36,2 & $23,5-24,5$ & $\begin{array}{l}1.4 \mathrm{l} \\
1.40\end{array}$ & $\begin{array}{l}2.49 \\
3.20\end{array}$ \\
\hline 5,0 & 0,0013 & 2,0 & 38,2 & 37,0 & $23,8-24,0$ & $\begin{array}{l}1.55 \\
1.47\end{array}$ & $\begin{array}{l}3.11 \\
2.52\end{array}$ \\
\hline 7,0 & 0,0179 & 7,0 & 36,8 & 35,3 & $19,5-21,5$ & $\begin{array}{l}1.36 \\
1.26\end{array}$ & $\begin{array}{l}2.14 \\
2.30\end{array}$ \\
\hline 7,5 & 0,0058 & 3,25 & 37,7 & 36,1 & $18,0-19,5$ & $\begin{array}{l}1.22 \\
1.32\end{array}$ & $\begin{array}{l}2,32 \\
2.45\end{array}$ \\
\hline 6,0 & 0,1024 & 6,0 & 37,8 & 34,5 & $13,5-22,5$ & $\begin{array}{l}1.18 \\
1.45\end{array}$ & $\begin{array}{l}2.56 \\
4.15\end{array}$ \\
\hline 4,5 & 0,3981 & 4,5 & 38,6 & 36,1 & $16,0-22,5$ & $\begin{array}{l}1.24 \\
1.40\end{array}$ & $\begin{array}{l}2.55 \\
3.03\end{array}$ \\
\hline 3,5 & 0,0479 & 3,5 & 37,8 & 35,6 & $12,0-20,5$ & $\begin{array}{l}1.18 \\
1.11\end{array}$ & $\begin{array}{l}2.10 \\
2.34\end{array}$ \\
\hline 3,0 & 0,1600 & 3,0 & 38,4 & 35,5 & $4,5-16,0$ & $\begin{array}{l}1.37 \\
1.27\end{array}$ & $\begin{array}{l}2.52 \\
2.00\end{array}$ \\
\hline 6,5 & 0,0025 & 6,5 & 38,2 & 35,1 & $15,5-20,0$ & $\begin{array}{l}1.30 \\
1.22\end{array}$ & $\begin{array}{l}2.23 \\
1.57\end{array}$ \\
\hline 3,5 & 0,0816 & 3,5 & 38,1 & 35,2 & $7,0-10,0$ & $\begin{array}{l}1.13 \\
1.16\end{array}$ & $\begin{array}{l}1.43 \\
1.40\end{array}$ \\
\hline 3,0 & 0,0572 & 3,0 & 37,8 & 36,2 & $6,0-13,0$ & $\begin{array}{l}1.24 \\
1.12\end{array}$ & $\begin{array}{l}1.32 \\
1.19\end{array}$ \\
\hline 5,0 & 0,2585 & 5,0 & 38,2 & 35,9 & $13,8-20,0$ & $\begin{array}{l}1.04 \\
1.25\end{array}$ & $\begin{array}{l}2.52 \\
3.47\end{array}$ \\
\hline 4,5 & 0,2960 & 4,5 & 38,7 & 35,6 & $16,5-21,0$ & 1.10 & 3.16 \\
\hline 2,0 & 0,0302 & 2,0 & 38,1 & 36,0 & $16,0-22,0\{$ & $\begin{array}{l}1.07 \\
1.14\end{array}$ & $\begin{array}{l}3.13 \\
4.20\end{array}$ \\
\hline 4,0 & 0,2175 & 4,0 & 38,4 & 35,8 & $17,0-19,0$ & $\begin{array}{l}1.11 \\
1.12\end{array}$ & $\begin{array}{l}3.12 \\
3.50\end{array}$ \\
\hline 4,0 & 0,0019 & 4,0 & 38,4 & 36,7 & $17,0-22,5$ & $\begin{array}{l}1.09 \\
1.19\end{array}$ & $\begin{array}{l}3.22 \\
4.17\end{array}$ \\
\hline 4,5 & 0,1171 & 4,5 & 38,8 & 36,4 & $17,0-22,0\}$ & $\begin{array}{l}1.18 \\
1.24\end{array}$ & $\begin{array}{l}3.13 \\
4.22\end{array}$ \\
\hline \multirow[t]{2}{*}{4,5} & 0,0121 & 7,5 & 38,5 & 37,2 & $19,5-23,0$ & $\begin{array}{l}1.15 \\
1.20\end{array}$ & $\begin{array}{l}3.35 \\
3.31\end{array}$ \\
\hline & 0,0011 & 2,0 & 38,1 & 36,0 & $19,5-22,0\}$ & $\begin{array}{l}1.22 \\
1.24\end{array}$ & $\begin{array}{l}3.46 \\
4.10\end{array}$ \\
\hline 7,0 & 0,0013 & 7,0 & 38,1 & 36,2 & $19,4-22,0$ & $\begin{array}{l}1.25 \\
1.30\end{array}$ & $\begin{array}{l}3.53 \\
4.50\end{array}$ \\
\hline 5,0 & 0,1177 & 5,0 & 38,3 & 36,4 & $19,0-21,0$ & $\begin{array}{l}1.22 \\
1.27\end{array}$ & $\begin{array}{l}3.46 \\
4.14\end{array}$ \\
\hline 4,0 & 0,3484 & 4,0 & 38,3 & 35,2 & $16,6-19,0$ & $\begin{array}{l}1.12 \\
1.27\end{array}$ & $\begin{array}{l}3.12 \\
3.38\end{array}$ \\
\hline 2,0 & 0,0028 & 5,0 & 38,6 & 36,5 & $14,4-21,0$ & $\begin{array}{l}1.10 \\
1.25\end{array}$ & $\begin{array}{l}3.40 \\
4.55\end{array}$ \\
\hline 2,0 & 0,0166 & 2,0 & 38,1 & 36,0 & $12,0-20,0$ & $\begin{array}{l}1.08 \\
1.27\end{array}$ & $\begin{array}{l}2.51 \\
4.46\end{array}$ \\
\hline 5,0 & 0,0055 & 5,0 & 38,4 & 36,6 & $12,5-17,5$ & $\begin{array}{l}1.05 \\
1.16\end{array}$ & $\begin{array}{l}3.09 \\
3.47\end{array}$ \\
\hline
\end{tabular}




\begin{tabular}{|c|c|c|c|c|c|c|c|c|}
\hline \multirow{3}{*}{ Nr. } & \multirow[b]{3}{*}{$\begin{array}{c}\text { Körper- } \\
\text { gewicht } \\
\text { (g) }\end{array}$} & \multirow[b]{3}{*}{ Datum } & \multirow{3}{*}{$\begin{array}{l}\text { Fesse- } \\
\text { lungs- } \\
\text { dauer } \\
\text { (std.) }\end{array}$} & \multicolumn{3}{|c|}{ Blutzucker } & \multirow{2}{*}{\multicolumn{2}{|c|}{$\frac{\text { Harn }}{(\%)}$}} \\
\hline & & & & Vor der & Maximum & & & \\
\hline & & & & $\begin{array}{c}\text { Fesse- } \\
\text { lung } \\
(\%)\end{array}$ & $\begin{array}{c}\text { während } \\
\text { der } \\
\text { Fesselung } \\
(\%)\end{array}$ & $\begin{array}{c}\text { bis zum } \\
\text { Maximum } \\
\text { (Std.) }\end{array}$ & $\begin{array}{l}\text { Kurz nach } \\
\text { der } \\
\text { Fesselung }\end{array}$ & $\begin{array}{c}\text { Maximum } \\
\text { wäbrend } \\
\text { der } \\
\text { Fesselung } \\
\end{array}$ \\
\hline 28 & 1700 & 9. XII. & 7,0 & 0,11 & 0,21 & 1,0 & 0,026 & 0,258 \\
\hline 29 & 1850 & 11. XII. & 8,0 & 0,14 & 0,21 & 1,0 & 0,026 & 0,026 \\
\hline 30 & 1580 & 13. XII. & 6,0 & 0,10 & 0,30 & 3,0 & 0,026 & 5,100 \\
\hline 31 & 1580 & 16. XII. & 8,0 & 0,10 & 0,18 & 4,0 & 0,032 & 2,570 \\
\hline 32 & 1510 & 18. XII. & 7,0 & 0,09 & 0,27 & 3,0 & 0,026 & 8,944 \\
\hline 33 & 1600 & 7. I. & 7,0 & 0,10 & 0,22 & 3,0 & 0,013 & 0,156 \\
\hline 34 & 1900 & $9 . \mathrm{I}$ & 8,0 & 0,10 & 0,23 & 3,0 & 0,013 & 0,258 \\
\hline 35 & 2010 & 14. I. & 8,0 & 0,10 & 0,29 & 3,0 & 0,013 & 0,156 \\
\hline 36 & 2200 & 15. I & 7,0 & 0,10 & 0,29 & 4,0 & 0,013 & 2,980 \\
\hline 37 & 1820 & 16. I. & 7,0 & 0,10 & 0,34 & 5,5 & 0,013 & 4,860 \\
\hline 38 & 1980 & 17. I. & 8,0 & 0,12 & 0,27 & 3,0 & 0,013 & 0,156 \\
\hline 39 & +1620 & 22. I. & 8,0 & 0,10 & 0,44 & 3,0 & 0,013 & 3,374 \\
\hline 40 & 1960 & 24. I. & 7,0 & 0,11 & 0,37 & 2,0 & 0,039 & 0,414 \\
\hline 41 & 1825 & $27 . \mathrm{I}$. & 7,0 & 0,09 & 0,19 & 1,0 & 0,026 & 0,026 \\
\hline 42 & 1910 & 15. II. & 6,0 & 0,09 & 0,29 & 2,0 & 0,026 & 10,240 \\
\hline 43 & 1745 & $26 . \mathrm{III}$ & 7,0 & 0,10 & 0,32 & 5,0 & 0,013 & 6,702 \\
\hline 44 & 1495 & 29. III. & 6,0 & 0,11 & 0,27 & 4,0 & 0,037 & 1,174 \\
\hline 45 & 1945 & 31. III. & 7,0 & 0,10 & 0,28 & 3,0 & 0,013 & 0,491 \\
\hline 46 & 2170 & 4. IV. & 7,0 & 0,09 & 0,32 & 3,0 & 0,013 & 9,263 \\
\hline 47 & 1600 & 7. IV. & 7,0 & 0,12 & 0,23 & 3,0 & 0,026 & 0,039 \\
\hline 48 & 1450 & 9. IV. & 7,0 & 0,09 & 0,34 & 3,0 & 0,043 & 0,929 \\
\hline 49 & 2120 & 12. IV. & 7,0 & 0,10 & 0,26 & 3,0 & 0,026 & 0,167 \\
\hline 50 & 170.5 & 14. IV. & 7,0 & 0,09 & 0,22 & 4,0 & 0,013 & 0,258 \\
\hline 51 & 1475 & 16. IV. & 7,0 & 0,13 & 0,23 & 2,0 & 0,026 & 0,052 \\
\hline 52 & 1405 & 19. IV. & 6,0 & 0,10 & 0,28 & 6,0 & 0,013 & 0,926 \\
\hline 53 & 1595 & 21. IV. & 7,0 & 0,13 & 0,18 & 5,0 & 0,013 & 0,026 \\
\hline 54 & 1460 & 24. IV. & 7,0 & 0,12 & 0,18 & 3,0 & 0,026 & 0,170 \\
\hline 55 & 1620 & $26 . \mathrm{IV}$ & 7,0 & 0,11 & 0,20 & 5,0 & 0,026 & 6,820 \\
\hline
\end{tabular}

(Fort- 


\begin{tabular}{|c|c|c|c|c|c|c|c|}
\hline \multicolumn{3}{|l|}{ zucker } & \multicolumn{2}{|c|}{ Körpertemperatur } & \multirow[b]{3}{*}{$\begin{array}{c}\text { Zimmer- } \\
\text { temperatur } \\
\left.{ }^{\circ} \mathrm{C}\right) \\
\end{array}$} & \multicolumn{2}{|c|}{ Katathermometer } \\
\hline \multirow[b]{2}{*}{$\begin{array}{c}\text { Zeit bis } \\
\text { zum } \\
\text { Maximum } \\
\text { (Std.) } \\
\end{array}$} & \multicolumn{2}{|c|}{ g pro Stunde } & \multirow{2}{*}{$\begin{array}{c}\text { Kurz } \\
\text { nach } \\
\text { der } \\
\text { Fesselung } \\
\left({ }^{\circ} \mathrm{C}\right) \\
\end{array}$} & \multirow{2}{*}{$\begin{array}{c}\text { Minimum } \\
\text { während } \\
\text { der } \\
\text { Fesselung } \\
(\circ \mathrm{C}) \\
\end{array}$} & & \multirow[b]{2}{*}{$\begin{array}{l}\text { Nass- } \\
\text { kolben }\end{array}$} & \multirow[b]{2}{*}{$\begin{array}{c}\text { Trocken- } \\
\text { kolben }\end{array}$} \\
\hline & $\begin{array}{c}\text { Maximum } \\
\text { während } \\
\text { der } \\
\text { Fesselung }\end{array}$ & $\begin{array}{c}\text { Zeit bis } \\
\text { zum } \\
\text { Maximum } \\
\text { (Std.) }\end{array}$ & & & & & \\
\hline \multirow[t]{2}{*}{2,0} & 0,0062 & 4,0 & 38,8 & 36,8 & $12,2-19,5\{$ & $\begin{array}{l}1.03 \\
1.20\end{array}$ & $\begin{array}{l}3.00 \\
4.44\end{array}$ \\
\hline & 0,0034 & 2,0 & 39,0 & 36,8 & $10,0-16,3\}$ & $\begin{array}{l}1.08 \\
1.09\end{array}$ & $\begin{array}{l}2.48 \\
3.26\end{array}$ \\
\hline 2,0 & 0,1161 & 4,0 & 38,2 & 36,4 & $10,5-19,0\{$ & 1.05 & $\begin{array}{l}2.45 \\
4.10\end{array}$ \\
\hline 2,0 & 0,0450 & 2,0 & 38,3 & 36,3 & $10,0-18,0\{$ & $\begin{array}{l}1.03 \\
1.15\end{array}$ & $\begin{array}{l}3.57 \\
3.55\end{array}$ \\
\hline 4,0 & 0,4248 & 4,0 & 38,8 & 36,5 & $10,0-19,0\}$ & $\begin{array}{l}1.00 \\
1.15\end{array}$ & $\begin{array}{l}2.55 \\
4.37\end{array}$ \\
\hline 4,0 & 0,0468 & 4,0 & 38,2 & 36,1 & $8,5-19,0\{$ & $\begin{array}{l}1.00 \\
1.19\end{array}$ & $\begin{array}{l}2.21 \\
4.30\end{array}$ \\
\hline 2,0 & 0,0029 & 5,0 & 37,1 & 34,8 & $8,0-17,5\{$ & $\begin{array}{r}.55 \\
1.10\end{array}$ & $\begin{array}{l}2.17 \\
3.52\end{array}$ \\
\hline 8,0 & 0,0033 & 8,0 & 39,2 & 37,1 & $11,7-17,2\{$ & $\begin{array}{l}1.07 \\
1.12\end{array}$ & $\begin{array}{l}2.42 \\
3.39\end{array}$ \\
\hline 4,0 & 0,3502 & 4,0 & 37,8 & 35,5 & $7,4-16,0\}$ & $\begin{array}{l}1.06 \\
1.13\end{array}$ & $\begin{array}{l}2.06 \\
3.49\end{array}$ \\
\hline 2,0 & 0,3786 & 5,0 & 38,4 & 36,3 & $8,0-16,7\}$ & $\begin{array}{l}1.11 \\
1.10\end{array}$ & $\begin{array}{l}2.30 \\
3.57\end{array}$ \\
\hline 5,0 & 0,0025 & 5,0 & 38,1 & 36,6 & $8,0-18,0$ & $\begin{array}{l}1.13 \\
1.15\end{array}$ & $\begin{array}{l}2.31 \\
4.05\end{array}$ \\
\hline 5,0 & 0,0135 & 5,0 & 37,7 & 34,4 & $10,5-15,8\{$ & $\begin{array}{l}1.08 \\
1.03\end{array}$ & $\begin{array}{l}2.32 \\
3.24\end{array}$ \\
\hline \multirow[t]{2}{*}{5,0} & 0,0135 & 5,0 & 38,0 & 35,9 & $8,5-19,5\}$ & $\begin{array}{l}1.08 \\
1.13\end{array}$ & $\begin{array}{l}2.33 \\
4.15\end{array}$ \\
\hline & 0,0011 & 4,0 & 38,6 & 38,0 & $8,0-17,5\{$ & $\begin{array}{r}.59 \\
1.12\end{array}$ & $\begin{array}{l}2.21 \\
3.48\end{array}$ \\
\hline 4,0 & 0,3226 & 4,0 & 37,4 & 35,3 & $5,0-9,3\{$ & $\begin{array}{r}.56 \\
1.01\end{array}$ & $\begin{array}{l}1.47 \\
2.07\end{array}$ \\
\hline 4,0 & 0,2781 & 4,0 & 37,6 & 35,8 & $11,0-17,6$ & 1.06 & 2.59 \\
\hline 4,0 & 0,0320 & 4,0 & 38,0 & 36,3 & $12,0-17,3$ & 1.03 & 3.07 \\
\hline 2,0 & 0,0196 & 2,0 & 38,0 & 36,3 & $14,5-22,5\{$ & $\begin{array}{l}1.11 \\
1.23\end{array}$ & $\begin{array}{l}3.25 \\
5.03\end{array}$ \\
\hline 4,0 & 0,5419 & 4,0 & 38,6 & 36,3 & $13,0-21,0\}$ & $\begin{array}{r}.59 \\
1.15\end{array}$ & $\begin{array}{l}2.41 \\
3.51\end{array}$ \\
\hline 4,0 & 0,0010 & 4,0 & 37,8 & 36,1 & $12,5-17,3\{$ & $\begin{array}{l}1.05 \\
1.08\end{array}$ & $\begin{array}{l}3.12 \\
3.15\end{array}$ \\
\hline 4,0 & 0,0186 & 4,0 & 37,7 & 35,4 & $14,0-18,5\{$ & $\begin{array}{l}1.05 \\
1.11\end{array}$ & 3.30 \\
\hline 4,0 & 0,0040 & 4,0 & 88,6 & 35,9 & $15,0-21,6\{$ & $\begin{array}{l}1.12 \\
1.14\end{array}$ & $\begin{array}{l}3.37 \\
3.54\end{array}$ \\
\hline 4,0 & 0,0258 & 4,0 & 38,5 & 36,3 & $17,5-18,7\{$ & $\begin{array}{l}1.12 \\
1.12\end{array}$ & $\begin{array}{l}3.39 \\
4.18\end{array}$ \\
\hline 4,0 & 0,0017 & 4,0 & 37,4 & 35,1 & $12,5-17,2\{$ & $\begin{array}{l}1.07 \\
1.01\end{array}$ & 3.09 \\
\hline 4,0 & 0,0194 & 4,0 & 37,8 & 36,0 & $14,0-19,7\{$ & $\begin{array}{l}1.05 \\
1.09\end{array}$ & $\begin{array}{l}3.00 \\
3.49\end{array}$ \\
\hline 4,0 & 0,0018 & 2,0 & 38,2 & 36,7 & $17,2-22,3$ & $\begin{array}{l}1.20 \\
1.20\end{array}$ & $\begin{array}{l}4.24 \\
4.08\end{array}$ \\
\hline 4,0 & 0.0044 & 4,0 & 37,1 & 32,0 & $10,0-15,0\{$ & $\begin{array}{r}.56 \\
1.00\end{array}$ & $\begin{array}{l}2.16 \\
2.50\end{array}$ \\
\hline 5,0 & 0,2880 & 4,0 & 37,8 & 35,1 & $12,0-17,4\{$ & $\begin{array}{l}1.02 \\
1.06\end{array}$ & $\begin{array}{l}2.29 \\
3.31\end{array}$ \\
\hline
\end{tabular}




\begin{tabular}{|c|c|c|c|c|c|c|c|c|}
\hline \multirow[b]{3}{*}{ Nr. } & \multirow[b]{3}{*}{$\begin{array}{c}\text { Körper- } \\
\text { gewicht } \\
\text { (g) }\end{array}$} & \multirow[b]{3}{*}{ Datum } & \multirow{3}{*}{$\begin{array}{l}\text { Fesse- } \\
\text { luugs- } \\
\text { dauer } \\
\text { (Std.) }\end{array}$} & \multicolumn{3}{|c|}{ Blutzucker } & \multirow{2}{*}{\multicolumn{2}{|c|}{$\frac{\text { Harn }}{(\%)}$}} \\
\hline & & & & Vor der & Maximum & & & \\
\hline & & & & $\begin{array}{c}\begin{array}{c}\text { Fesse- } \\
\text { lung } \\
(\%)\end{array} \\
\end{array}$ & $\begin{array}{c}\text { während } \\
\text { der } \\
\text { Fesselung } \\
(\%)\end{array}$ & $\begin{array}{c}\text { bis zum } \\
\text { Maximum } \\
\text { (Std.) }\end{array}$ & $\begin{array}{c}\text { Kurz nach } \\
\text { der } \\
\text { Fesselung }\end{array}$ & $\begin{array}{l}\text { Maximum } \\
\text { während } \\
\text { der } \\
\text { Fesselung }\end{array}$ \\
\hline 56 & 1650 & 1. V. & 6,0 & 0,14 & 0,20 & 4,1 & 0,013 & 0,052 \\
\hline 57 & 1550 & 3. V. & 7,0 & 0,13 & 0,31 & 4,0 & 0,013 & 3,000 \\
\hline 58 & $224 \overline{-}$ & 5. V. & 7,0 & 0,12 & 0,27 & 4,0 & 0,013 & 1,750 \\
\hline 59 & 2090 & 13. VII. & 7,0 & 0,15 & 0,23 & 4,0 & 0,026 & 0,039 \\
\hline 60 & 1670 & 15. VII. & 8,0 & 0,11 & 0,31 & 4,0 & 0,013 & 0,039 \\
\hline 61 & 2550 & 16. VII. & 7,0 & 0,10 & 0,30 & 4,0 & 0,013 & 0,026 \\
\hline 62 & 1935 & 17. VII. & 7,0 & 0,09 & 0,29 & 4,0 & 0,026 & 5,674 \\
\hline 63 & 1795 & 20 . VII & 7,0 & 0,10 & 0,16 & 1,0 & 0,026 & 0,013 \\
\hline 64 & 1520 & 21. VII. & 7,0 & 0,11 & 0,23 & 4,0 & 0,026 & 1,030 \\
\hline 65 & 1705 & 22. VII. & 7,0 & 0,12 & 0,19 & 2,0 & 0,026 & 0,052 \\
\hline 66 & 1810 & 23. VII. & 7,0 & 0,11 & 0,25 & 4,0 & 0,026 & 0,180 \\
\hline 67 & 2420 & 24. V II. & 7,0 & 0,10 & 0,20 & 3,0 & 0,026 & 0,079 \\
\hline 68 & 1590 & 28. VII. & 7,0 & 0,10 & 0,16 & 5,0 & 0,026 & 0,052 \\
\hline 69 & 1540 & 29. VII. & 7,0 & 0,09 & 0,13 & 3,0 & 0,013 & 0,013 \\
\hline 70 & 2030 & 30. VII. & 7,0 & 0,09 & 0,12 & 3,0 & 0,013 & 0,013 \\
\hline 71 & 2070 & 31. VII. & 7,0 & 0,10 & 0,22 & 1,0 & 0,018 & 0,430 \\
\hline 72 & 1590 & 2. VIII. & 7,0 & 0,11 & 0,14 & 4,0 & 0,026 & 0,029 \\
\hline 73 & 1815 & 3. VIII. & 7,0 & 0,11 & 0,17 & 1,0 & 0,013 & 0,026 \\
\hline 74 & 1830 & 6. VIII. & 7,0 & 0,09 & 0,27 & 3,0 & & \\
\hline 75 & 1465 & 7. VIII. & 7,0 & 0,12 & 0,20 & 2,0 & 0,026 & 5,790 \\
\hline 76 & 2230 & $6 . \mathrm{IX}$. & 7,0 & 0,11 & 0,29 & 3,0 & 0,026 & 5,668 \\
\hline 77 & 1895 & $15 . \mathrm{IX}$ & 7,0 & 0,12 & 0,15 & 1,0 & 0,026 & 0,026 \\
\hline 78 & 1820 & 16. IX. & 7,0 & 0,12 & 0,20 & 2,0 & 0,052 & 0,052 \\
\hline 79 & 1835 & 17. IX. & 7,0 & 0,11 & 0,21 & 2,0 & 0,026 & 3,930 \\
\hline 80 & 1765 & 18. IX. & 7,0 & 0,12 & 0,19 & 1,0 & 0,026 & 0,065 \\
\hline 81 & 1545 & $20 . \mathrm{IX}$ & 7,0 & 0,13 & $0,\llcorner 0$ & 5,0 & 0,013 & 4,583 \\
\hline 82 & 1560 & 21. IX. & 7,0 & 0,10 & 0,22 & 2,0 & 0,013 & 1,505 \\
\hline 83 & 1560 & 24. IX. & 7,0 & 0,12 & 0,18 & 4,0 & 0,052 & 0,078 \\
\hline
\end{tabular}




\begin{tabular}{|c|c|c|c|c|c|c|c|}
\hline \multicolumn{3}{|l|}{ zucker } & \multicolumn{2}{|c|}{ Körpertemperatur } & \multirow[b]{3}{*}{$\begin{array}{l}\text { Zimmer- } \\
\text { temperatur } \\
\quad\left({ }^{\circ} \mathrm{C}\right)\end{array}$} & \multicolumn{2}{|c|}{ Katathermometer } \\
\hline & \multicolumn{2}{|c|}{$\mathrm{g}$ pro Stunde } & \multirow{2}{*}{$\begin{array}{c}\text { Kurz } \\
\text { nach } \\
\text { der } \\
\text { Fesselung } \\
\left(^{\circ} \mathrm{C}\right) \\
\end{array}$} & \multirow{2}{*}{$\begin{array}{c}\text { Minimum } \\
\text { während } \\
\text { der } \\
\text { Fesselung } \\
\left({ }^{\circ} \mathrm{C}\right) \\
\end{array}$} & & \multirow[b]{2}{*}{$\begin{array}{l}\text { Nass- } \\
\text { kolben }\end{array}$} & \multirow[b]{2}{*}{$\begin{array}{l}\text { Trocken- } \\
\text { kolben }\end{array}$} \\
\hline $\begin{array}{c}\text { Zeit bis } \\
\text { zamm } \\
\text { Maximum } \\
\text { (Std.) } \\
\end{array}$ & $\begin{array}{c}\text { Maximum } \\
\text { während } \\
\text { der } \\
\text { Fesselung }\end{array}$ & $\begin{array}{c}\text { Zeit bis } \\
\text { zum } \\
\text { Maximum } \\
\text { (Std.) } \\
\end{array}$ & & & & & \\
\hline 2,0 & 0,0027 & 4,0 & 38,4 & 36,5 & $16,0-19,6$ & $\begin{array}{l}1.09 \\
1.12\end{array}$ & $\begin{array}{l}3.02 \\
3.30\end{array}$ \\
\hline 4,0 & 0,2100 & 4,0 & 38,0 & 36,1 & $15,3-21,3$ & $\begin{array}{l}1.08 \\
1.22\end{array}$ & $\begin{array}{l}2.58 \\
3.47\end{array}$ \\
\hline 4,0 & 0,0700 & 4,0 & 38,2 & 35,9 & $15,5-19,5$ & $\begin{array}{l}1.11 \\
1.22\end{array}$ & $\begin{array}{l}3.05 \\
3.47\end{array}$ \\
\hline 4,0 & 0,0019 & 4,0 & 39,4 & 37,3 & $24,0-28,0$ & $\begin{array}{l}1.47 \\
2.24\end{array}$ & $\begin{array}{l}5.34 \\
8.54\end{array}$ \\
\hline 5,0 & 0,0014 & 5,0 & 39,0 & 38,5 & $26,8-32,0$ & $\begin{array}{l}2.02 \\
1.57\end{array}$ & $\begin{array}{r}7.58 \\
\text { über } 18 .\end{array}$ \\
\hline 2,0 & 0,0008 & 4,0 & 39,8 & 38,9 & $28,0-30,5$ & $\begin{array}{l}1.50 \\
2.01\end{array}$ & $\begin{array}{r}9.11 \\
10,20\end{array}$ \\
\hline 4,0 & 0,1347 & 2,0 & 39,1 & 36,9 & $27,4-31,5$ & $\begin{array}{l}2.02 \\
2.05\end{array}$ & $\begin{array}{r}8.05 \\
20.45\end{array}$ \\
\hline 2,0 & 0,0013 & 4,0 & 38,7 & 37,0 & $27,3-30,0$ & $\begin{array}{l}2.00 \\
1.56\end{array}$ & $\begin{array}{l}7.25 \\
8.15\end{array}$ \\
\hline 4,0 & 0,0350 & 4,0 & 38,4 & 37,4 & $27,5-29,5$ & $\begin{array}{l}1.56 \\
1.45\end{array}$ & $\begin{array}{l}7.43 \\
8.21\end{array}$ \\
\hline 2,0 & 0,0016 & 2,0 & 38,8 & 37,3 & $25,4-29,6$ & $\begin{array}{l}1.39 \\
2.05\end{array}$ & $\begin{array}{l}5.53 \\
9.22\end{array}$ \\
\hline 4,0 & 0,0594 & 4,0 & 38,7 & 36,5 & $26,7-29,3$ & $\begin{array}{l}1.54 \\
1.44\end{array}$ & $\begin{array}{l}6.47 \\
9.18\end{array}$ \\
\hline 4,0 & 0,0041 & 4,0 & 38,3 & 36,7 & $26,2-29,7$ & $\begin{array}{l}1.58 \\
2.05\end{array}$ & $\begin{array}{l}6.14 \\
7.40\end{array}$ \\
\hline \multirow[t]{3}{*}{4,0} & 0,0021 & 4,0 & 39,4 & 37,5 & $26,3-28,5$ & $\begin{array}{l}1.58 \\
2.06\end{array}$ & $\begin{array}{l}6.24 \\
6.50\end{array}$ \\
\hline & 0,0004 & 2,0 & 38,6 & 36,9 & $26,0-29,0$ & $\begin{array}{l}1.44 \\
2.09\end{array}$ & $\begin{array}{l}5.55 \\
8.39\end{array}$ \\
\hline & 0,0015 & 4,0 & 38,4 & 36,4 & $26,3-29,1\{$ & $\begin{array}{l}1.44 \\
1.57\end{array}$ & $\begin{array}{l}6.35 \\
8.50\end{array}$ \\
\hline 2,0 & 0,0082 & 2,0 & 38,7 & 37,4 & $26,7-29,8$ & $\begin{array}{l}1.29 \\
2.03\end{array}$ & $\begin{array}{l}5.45 \\
8.42\end{array}$ \\
\hline 2,0 & 0,0003 & 2,0 & 38,7 & $3 \pi, 0$ & $26,6-29,7$ & 1.55 & 6.02 \\
\hline 2,0 & 0,0006 & 2,0 & 38,2 & 35,9 & $26,5-30,0\{$ & $\begin{array}{l}1.55 \\
2.12\end{array}$ & $\begin{array}{r}6.57 \\
10.16\end{array}$ \\
\hline & & . & $\Sigma 9,1$ & 35,5 & $24,5-26,2\}$ & $\begin{array}{l}1.35 \\
1.42\end{array}$ & $\begin{array}{l}5.40 \\
6.27\end{array}$ \\
\hline 4,0 & 0,0851 & 4,0 & 39,8 & 37,3 & $25,0-27,6$ & $\begin{array}{l}1.53 \\
2.02\end{array}$ & $\begin{array}{l}5.50 \\
6.13\end{array}$ \\
\hline \multirow[t]{3}{*}{4,0} & 0,3032 & 4,0 & 39,2 & 36,6 & $25,6-27,2$ & $\begin{array}{l}1.42 \\
1.51\end{array}$ & $\begin{array}{l}5.45 \\
6.50\end{array}$ \\
\hline & 0,0006 & 7,0 & 38,5 & 36,9 & $19,5-21,8\{$ & $\begin{array}{l}1.16 \\
1.20\end{array}$ & $\begin{array}{l}3.42 \\
4.02\end{array}$ \\
\hline & 0,0014 & 4,0 & 38,7 & 37,1 & $19,5-23,9\{$ & $\begin{array}{l}1.20 \\
1.28\end{array}$ & $\begin{array}{l}343 \\
5.02\end{array}$ \\
\hline 4,0 & 0,0990 & 4,0 & 38,4 & 36,7 & $20,1-20,8$ & $\begin{array}{l}1.20 \\
1.22\end{array}$ & $\begin{array}{l}3.50 \\
4.09\end{array}$ \\
\hline 4,0 & 0,0041 & 4,0 & 38,6 & 36,1 & $19,8-23,9\{$ & $\begin{array}{l}1.22 \\
1.30\end{array}$ & $\begin{array}{l}3.47 \\
5.07\end{array}$ \\
\hline 4,0 & 0,0871 & 4,0 & 38,1 & 34,8 & $16,8-21,0\}$ & $\begin{array}{l}1.10 \\
1.15\end{array}$ & $\begin{array}{l}3.17 \\
4.02\end{array}$ \\
\hline 2,0 & 0,0828 & 2,0 & 38,4 & 36,3 & $17,2-21,8$ & $\begin{array}{l}1.13 \\
1.19\end{array}$ & $\begin{array}{l}3.18 \\
4.14\end{array}$ \\
\hline 4,0 & 0,0007 & 4,0 & 38,8 & 36,7 & $24,2-27,0\{$ & $\begin{array}{l}1.41 \\
1.54\end{array}$ & $\begin{array}{l}5.23 \\
7.14\end{array}$ \\
\hline
\end{tabular}


Frühling. Die Assimilationskraft der Kaninchenleber verhält sich ebenso.1) Der Grund zu diesen Schwankungen des Jeberglykogengehaltes könnte in den Beziehungen des Fesselungsdiabetes zu den Jahreszeiten liegen.

Auch kommt es nicht selten vor, das leichte Glykosurie bei psychischen oder nervösen Erkrankungen auftritt und durch heftige Gemütshewegungen und psychische Überanstrengungen beim gesunden Menschen Glykosurie auftritt und der Blutzuckergehalt des Diabetikers leichten Grades sich vermehrt. (Viele Versuchsbeispiele und Literatur in W. B. Cannon, A. T. Shohl und W. C. Wright ${ }^{2}$, S. Mita ${ }^{3}$, O. Fol in, W. Denis und W. G.Smillie ${ }^{4}$, W. B. Cannon ${ }^{5 / 6)}$ und K. Sakaguchi 7 ). Da die Jahreszeiten und das Klima auf psychische Erkrankungen irgend einen Eintluss besitzen ${ }^{8 / 9}$ und auch psychische Tätigkeiten in allgemeinen von Klima, Jahreszeiten und Tageszeiten beeinflusst werden ${ }^{0}$, könnten die Jahreszeiten durch ihre Einwirkung auf die höheren Hirntätigkeiten den Fesselungsdiabetes beeinflussen, wenn der Fesselungsdiabetes nichts anıleres als Affekthyperglykümie wäre, wie Cannon gerneint hat.

Die Frage, welche Bedingung oder welche Bedingungen die Schwankungen in der Stärke des Fesselungsdiabetes in den verschiedenen Jahreszeiten herbeiführen, muss ich hier offen lassen; ich habe nur auf die Möglichkeit hinweisen wollen.

Der Gehilt der Nebennieren an chromaffiner Substanz vermindert sich auch beim Fesselungsdiabetes, aber in geringerem Grade als bei der Zuckerstich- und Diuretinglykosurie. ${ }^{11)}$

Die Reaktion des Harnes wird sauer, wenn sie im Beginn des Versuches alkalisch gewesen ist, und die Azidität vermehrt sich mit der Zeit. Ganz Gleiches kommt auch beim nicht gefesselten Kaninchen vor, wie im Kap. II. Es besteht da kein quantitativer Unterschied. Diese Reaktionsveränderung ist also von der Zeit der Nahrungsaufnahme abhängig. Keine besondere Beziehung zum Fesselungsdiabetes.

Albuminurie leichten Grades kommt beim Fesselungsdiabetes sehr selten vor.

1) J. Asakawa (朝川), Nihon-Naikagakkwai-Zasshi, 8 (1920), 193. (jap.)

2) W. B. Cannon, A.'T. Shohl und W. S. Wright, Amer. Journ. Physiol. 29 (1911-12), 280.

3) S. Mita, Monatsschr. f. Psychiat. u. Neurol. 32 (1912), 159.

4) O. Folin, W. Den is und W. G. Smill ie, Journ. biol. Chem. 17 (1913-14), 519.

5) W. B. Cannon, Amer. Journ. Physiol. 33 (1914), 356.

6) W. B. Cannon, Bodily Changes in Pain, Hunger and Rage, New York \& London 1916,70 .

7) K. Sakaguchi, Mitteilungen aus der Medizinischen Fakultät der Kaiserlichen Universität zu Tokyo, 20 (1918), 471.

8) E. Kraepelin, Psychiatrie, VII. Aufl, 1. Bd. Leipzig 1903, 118.

9) S. Kure (㕦), Grundris der Psychiatrie (精神病學集要), II. Aut., 1. Bd. Tokyo 1917,333 . (jap.)

10) W. Wundt, Grundzüge d. physiol. Psychologie, VI. Auf., III. Bd. Leipzig 1911, 596.

11) I. Fuji i, diese Ztschr. 1 (1920), 38. 


\section{Kap. IV. Hyperglykämie und Glykosurie bei kurzdauernder Fesselung.}

Bei den Versuchen über experimentellen Diabetes ist es viel öfter nötig, das Versuchstier kurze Zeit, etwa 15-30-60 Minuten lang, auf dem Operationstische in Rücken- oder in Bauchlage zu fesseln, als langdanernde Fesselung wie im vorigen Kapitel.

\section{Versuch II.}

2. VI. 1919. Kaninchen $\hat{o} 1550 \mathrm{~g}$.

\begin{tabular}{|c|c|c|c|c|c|c|c|c|}
\hline \multirow{3}{*}{ Zeit } & \multirow{3}{*}{$\begin{array}{c}\text { Körper- } \\
\text { tempera- } \\
\text { tur } \\
\left({ }^{\circ} \mathrm{C}\right)\end{array}$} & \multirow{3}{*}{$\begin{array}{c}\text { Blut. } \\
\text { zucker } \\
(\%)\end{array}$} & \multicolumn{4}{|c|}{ Harn } & \multirow{3}{*}{$\begin{array}{c}\text { Zimmer- } \\
\text { tempera } \\
\text { tur } \\
\left({ }^{\circ} \mathrm{C}\right)\end{array}$} & \multirow{3}{*}{$\begin{array}{l}\text { Kata- } \\
\text { thermometer }\end{array}$} \\
\hline & & & \multirow{2}{*}{$\begin{array}{c}M \text { enge } \\
(\mathrm{ccm})\end{array}$} & \multirow{2}{*}{$\begin{array}{l}\text { Reak- } \\
\text { tion }\end{array}$} & \multicolumn{2}{|c|}{ Zucker } & & \\
\hline & & & & & $(\%)$ & $\begin{array}{l}\text { g pro } \\
\text { Std. }\end{array}$ & & \\
\hline $\begin{array}{l}8.45 \text { A.M. } \\
9.12 \\
9.15\end{array}$ & $\begin{array}{c}38,3 \\
\text { gefesselt }\end{array}$ & 0,11 & & neutral & 0,017 & & 18,0 & \\
\hline 9.25 & Rückenlige & & & & & & & $\begin{array}{l}\text { Nasskolben } 1.12 \\
\text { Trockenkolben } 3.35\end{array}$ \\
\hline $\begin{array}{l}9.47 \\
9.55\end{array}$ & $\begin{array}{c}36,3 \\
\text { abgebunden }\end{array}$ & 0,16 & & & & & 18,5 & \\
\hline 10.20 & 37,7 & 0,18 & & & & & 19,0 & \\
\hline 11.20 & 38,8 & 0,14 & 4,5 & sauer & 0,017 & 0,0004 & 19,5 & \\
\hline $\begin{array}{l}12.15 \text { F.AH. } \\
2.15\end{array}$ & $\begin{array}{l}39,2 \\
39,3\end{array}$ & $\begin{array}{l}0,14 \\
0,11\end{array}$ & 5,2 & sauer & 0,017 & 0,0003 & $\begin{array}{l}20,0 \\
21,0\end{array}$ & \\
\hline
\end{tabular}

Versuch IV.

10. VI. 1919. Kaninchen $1640 \mathrm{~g}$.

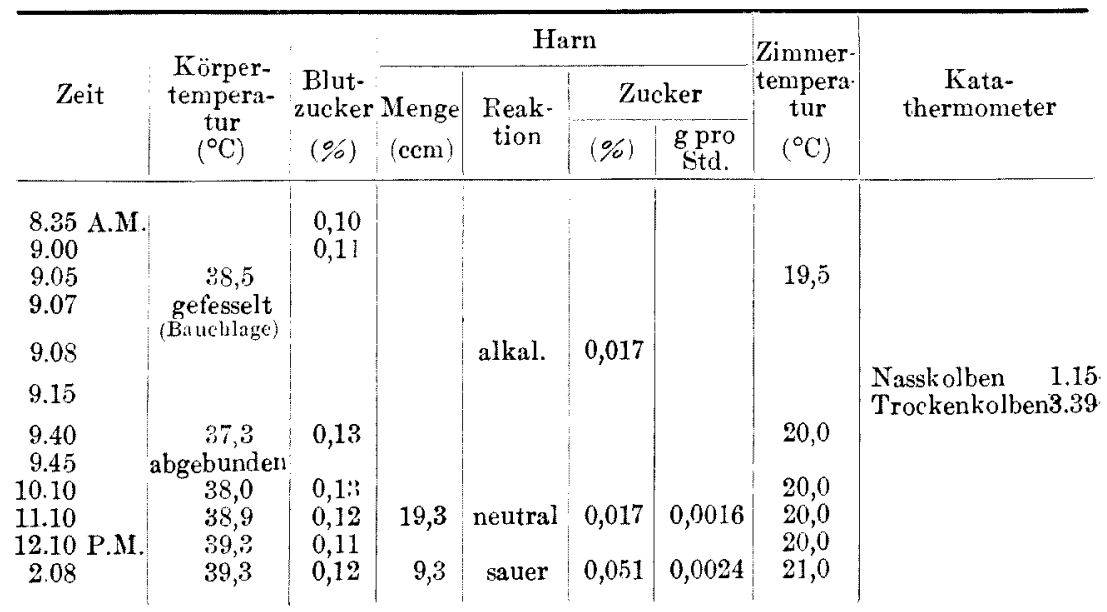


Versuch IX.

20. XII. 1919. Kaninchen of $1940 \mathrm{~g}$.

\begin{tabular}{|c|c|c|c|c|c|c|c|c|}
\hline \multirow{3}{*}{ Zeit } & \multirow{3}{*}{$\begin{array}{c}\text { Körper- } \\
\text { tempera- } \\
\text { tur } \\
\left({ }^{\circ} \mathrm{C}\right)\end{array}$} & \multirow{3}{*}{$\begin{array}{c}\text { Blut- } \\
\text { zucker } \\
(\%)\end{array}$} & \multicolumn{4}{|c|}{ Harn } & \multirow{3}{*}{$\begin{array}{c}\text { Zinmer } \\
\text { tempera } \\
\text { tur } \\
\left({ }^{\circ} \mathrm{C}\right)\end{array}$} & \multirow{3}{*}{$\begin{array}{c}\text { Kata- } \\
\text { thermometer }\end{array}$} \\
\hline & & & \multirow{2}{*}{$\begin{array}{r}\text { Menge } \\
(\mathrm{ccm})\end{array}$} & \multirow{2}{*}{$\begin{array}{c}\text { Reak- } \\
\text { tion }\end{array}$} & \multicolumn{2}{|c|}{ Zucker } & & \\
\hline & & & & & $(0.0)$ & $\begin{array}{l}\text { g pro } \\
\text { Std. }\end{array}$ & & \\
\hline 8.50 A.M. & & 0,10 & & & & & & \\
\hline 8.55 & 88,2 & & & & & & 10,0 & \\
\hline 8.58 & gefesselt & & & & & & & \\
\hline 8.59 & (Rückenlage) & & & alkal. & 0,013 & & & Nogatolhen \\
\hline 9.01 & & & & & & & & Trockenkolben 2.46 \\
\hline 9.12 & 37,1 & 0,16 & & & & & 10,5 & \\
\hline 9.17 & abgebunden & & & & & & & \\
\hline 9.32 & 37,9 & 0,16 & & & & & 11,2 & \\
\hline 9.56 & 38,1 & 0,15 & & & & & 11,6 & \\
\hline 10.55 & 38,5 & 0,13 & 5,0 & schwach & 0,013 & 0,0003 & 13,0 & \\
\hline 11.57 & 38,9 & 0,10 & & & & & 13,8 & \\
\hline 12.55 P.M. & 38,9 & 0,10 & & & & & 14,5 & \\
\hline 2.40 & 39,1 & 0,10 & 15,4 & sauer & 0,026 & 0,0011 & 16,0 & \\
\hline
\end{tabular}

Versuch XII.

3. XII. 1920. Kaninchen $\hat{o} 2235 \mathrm{~g}$.

\begin{tabular}{|c|c|c|c|c|c|c|c|c|}
\hline \multirow{3}{*}{ Zeit } & \multirow{3}{*}{$\begin{array}{c}\text { Körper- } \\
\text { tempera- } \\
\text { tur } \\
\left({ }^{\circ} \mathrm{C}\right)\end{array}$} & \multirow{3}{*}{$\begin{array}{c}\text { Blut- } \\
\text { zucker } \\
(\%)\end{array}$} & \multicolumn{4}{|c|}{ Harn } & \multirow{3}{*}{$\begin{array}{c}\text { Zimmer- } \\
\text { tempera- } \\
\text { tur } \\
\left({ }^{\circ} \mathrm{C}\right)\end{array}$} & \multirow{3}{*}{$\begin{array}{c}\text { Kata- } \\
\text { thermometer }\end{array}$} \\
\hline & & & \multirow{2}{*}{$\begin{array}{c}\text { Menge } \\
(\mathrm{com})\end{array}$} & \multirow{2}{*}{$\begin{array}{c}\text { Reak- } \\
\text { tion }\end{array}$} & \multicolumn{2}{|c|}{ Zucker } & & \\
\hline & & & & & $(0)$ & $\begin{array}{l}\text { g pro } \\
\text { Std. }\end{array}$ & & \\
\hline 8.57 A.M. & & 0,10 & & & & & & \\
\hline 9.03 & 38,0 & & & alkal. & 0,021 & & 14,8 & \\
\hline 9.11 & g fesselt & & & & & & & \\
\hline 9.12 & Lükevlay & & & & & & & $\begin{array}{l}\text { Nasskolben } \quad 1.09 \\
\text { Trockenkolben } 3.21\end{array}$ \\
\hline 9.16 & 37,9 & 0,10 & & & & & 15,0 & \\
\hline 9.18 & abgebunden & & & & & & & \\
\hline 9.28 & 37,9 & 0,11 & & & & & 15,6 & \\
\hline 9.43 & 38,1 & 0,11 & & & & & 16,0 & \\
\hline 10.13 & 38,1 & 0,10 & & & & & 18,0 & \\
\hline 11.12 & 38,3 & 0,10 & 4,2 & $\begin{array}{l}\text { sehwach } \\
\text { alkal. }\end{array}$ & 0,021 & 0,0004 & 20,3 & \\
\hline 12.13 P.M & 38,6 & 0,10 & & & & & 22,2 & \\
\hline 1.15 & 38,7 & 0,10 & 4,0 & $\left|\begin{array}{c}\text { schwach } \\
\text { alkal. }\end{array}\right|$ & 0,021 & 0,0004 & 22,2 & \\
\hline
\end{tabular}

(Die maximale Körpertemperaturangaben nach der Entfesselung mit dem Fragezeichen in der Tabelle II bedeuten, das; die am Ende des Versuches gemessene Körpertemperatur die höchste war.) 


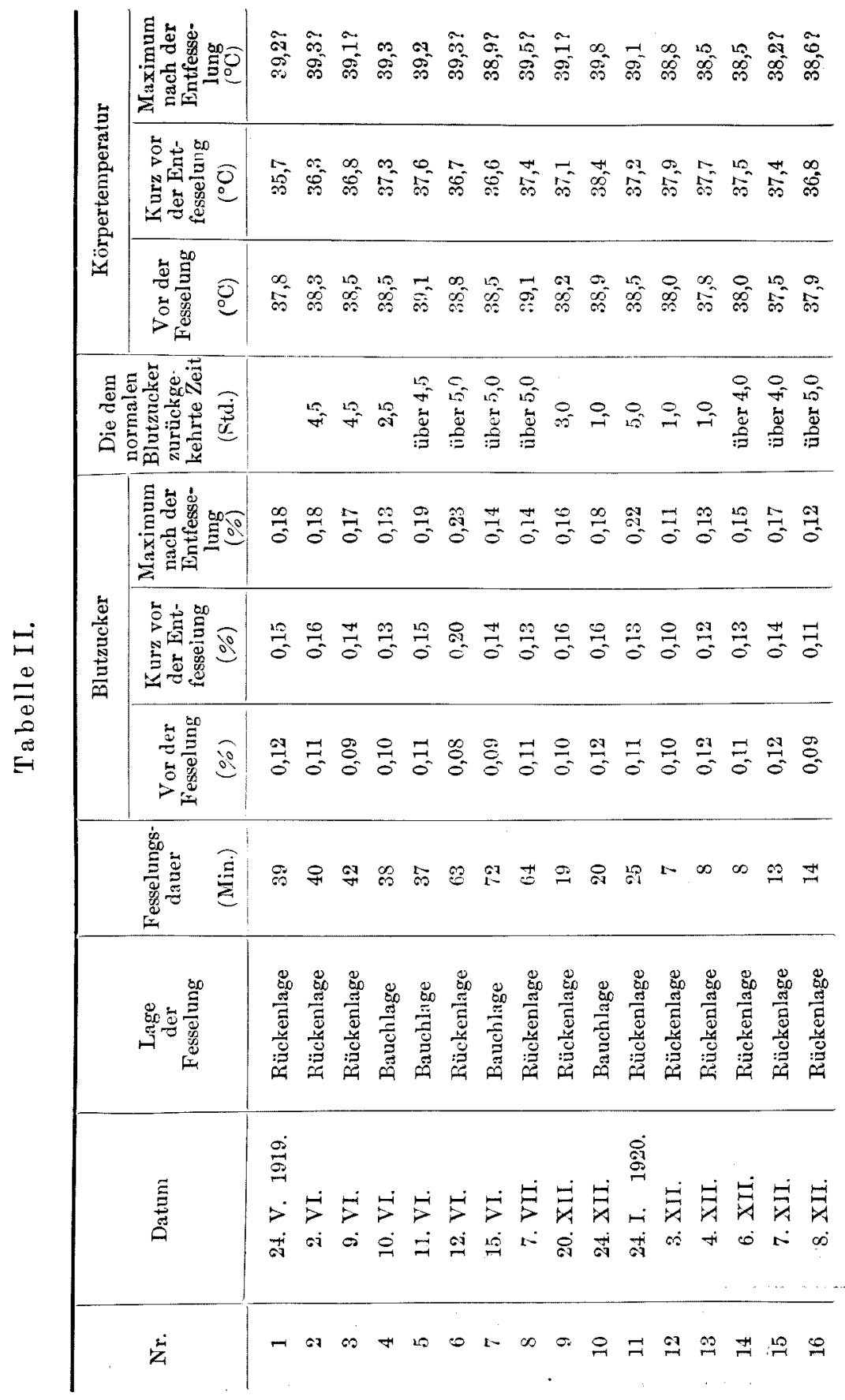


Wenn das Kaninchen kurze Zeit auf den Operationstische gebunden wird, vermehrt sich immer sein Blutzuckergehalt. Wenn die Fesselung nur kurz ist, z.B. sieben oder acht Minuten lang, dann ist der Grad der Vermehrung ganz minimal oder fast null.

Der höchste Blutzuckergehalt kommt meistens nicht während der Fesselung, sondern etwa eine halbe bis eine Stunde nach der Entfesselung vor (d.i. der Blutzuckergehalt war maximal bei der ersten Bestimmung nach dem Losbinden). Nachher vermindert er sich allmählich und sinkt eudlich in etwa vier, fünf oder mehr. Stunden bis auf seinen ursprünglichen Wert herab. Die Stärke der Hyperglykämie ist niedriger als bei langdauernder Fesselung. Das kann man sich schon aus den Versuchen im vorigen Kapitel denken, bei welchen der Blutzuckergehalt meistens in drei bis fünf Stunden sein Maximum erreicht.

Der Harnzuckergehalt vermehrte sich nur bei zwei unter 16 Versuchen, und zwar bei Versuch III $(0,119 \%)$ und VI $(0,356 \%)$. Die Körpertemperatur sinkt schnell nach der Fesselung und erreicht in einer halben oder einer Stunde ihr Minimum. Später sinkt sie meistens nicht weiter, genau wie bei den Versuchen im vorigen Kapitel. Nach dem Losbinden fängt sie bald an zu steigen, erreicht in anderthalb Stunde ihre ursprüngliche Höhe und steigt noch weiter, bis sie endlich nicht selten einen halben bis einen Grad den Anfangswert überschreitet. Weil ich die erste Körpertemperaturmessung nach ein- bis zweimaliger Blutentnahme vorgenommen habe, ist wahrscheinlich der Anfangswert ein wenig nielliger als die normale Körpertemperatur.

Bei den halbstündigen Fesselungsversuchen von Jacobsen ${ }^{1}$ ) ist der Blutzuckergehalt meistens bei der letzten Blutprobe wilhrend der Fesse]ung maximal, dann füngt er schon eine halbe Stunde nach dem Losbinden an, sich zu vermindern, und erreicht in zwei Stunden seinen ursprünglichen Wert. Unter szinen vier Versuchen zeigt nur einer ein ähnliches Bild wie meine Versuche.

Harnreaktion wie im vorigen Kapitel.

Wenn das Kaninchen gefesselt wird, vermehrt sich, mag auch die Zeit sehr kurz sein, der Blutzıckergehalt ohne Ausnahme. Deshalb muss man die Fesselung des Kaninchens bei rerschiedenen Versuchen über experimentellen Diabetes möglichst vermeiden; wenn es aber nicht möglich ist, nuss man einen ganz strengen Kontrollversuch anstellen.

Weil der Fesselungsdiabetes immer von der Körpertımperaturerniedrigung begleitet ist, könnte man schliesen, dass das Kaninchen den normalen Blutzuckergehalt hat, wenn seine Körpertmperatur nicht subnormal ist. (Der Blutzuckergelıalt des Kaninchens ist trotz hoher Körpertemperatur infolge des Wärmestichs doch normal'23)

1) A. Th. B. Jacobsen, Biochem. Zeitschr. 51 (1913), 443.

2) Yoshi, Kuno (久野), Tokyo-Igakkwai-Zasshi, 28 (1914), 1403. (jap.)

3) K o. Nai to (內藤), Tohoku-Jgaku-Zasshi, 4 (1919), 128. (jap.) 


\section{Kap. Y. Kann Fesselungshyperglykämie und -glykosurie durch Wiederholung der Fesselung zum Yerschwinden gebracht werden?}

Cannon, Shohl und Wright $t^{1)}$ haben gesagt, dass bei der Katze die ,emotional glycosuria" nicht mehr auftritt, wenn sie wiederholt auf dem Operationstische gefesselt war. $\mathrm{Bang}^{2)}$ hat auch mitgeteilt, dass das Kaninchen keine psychische Hyperglykämie mehr zeigt, wenn es ans Laboratoriumsleben gewöhnt sei. Das zu experimentellen Unter-

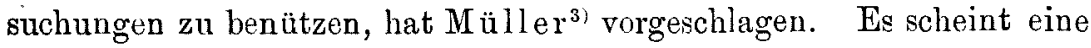
sehr gute Idee zu sein. Aber niemand hat Versuchsbeispiele gezeigt. Wie Müller als Erwiderung auf die Angriffe Rolly und Oppermann's die Wichtigkeit der experimentellen Untersuchungen seiner Mitarbeiter Hirsch und Reinbach betont hat, so muss diese gute Idee einmal durch Experimente als begründet bewiesen werden. Freilich führt von der Wahrscheinlichkeit zur Gewissheit immer ein weiter Weg, wie Müller damals schrieb.

Also müssen vor allem systematische und exakte Untersuchungen darüber angestellt werden.

Fünf Kaninchen wurden jeden Tag (beim Kaninchen der IV. Versuchsreihe wurde die Fesselung aus äusseren Gründen drei Tage lang unterbrochen) zwei und eine halbe Stunde bis sechs, ja sieben Stunden lang (meistens drei Stunden lang) gefesselt. Jedes Kaninchen wurde so acht- bis zwölfmal wiederholt in Pückenlage gefesselt und auf Blutzuckergehalt untersucht. Obwohl es nicht an Fällen fehlt, wo der Fesselungsdiabetes dazu ueigt, durch Wiederholung der Fesselung geringer zu werden, so sind doch die Versuchsresultate zu schwankend, um Bang's Beschreibung als richtig anerkennen und Müller's Hoffnung als erfüllt betrachten zu können.

In der Versuchsreihe I und V vermindert sich die Fesselungshyperglykämie allmählich bis zum dritten resp. fünften Tage, nachher bleibt die Hyperglykämie nicht nur fast konstant, wenn sie auch niedrigen Grades ist, sondern bisweilen verstärkt sie sich noch ein wenig.

Nach den Versuchsreihen II, III und IV vermindert sich die $\mathrm{Hy}$ -

1) W. B. Cannon, A. T. Shohl und W. S. Wright, Amer. Journ. Physiol. 29 (1911-12), 280.

2) I. Bang, H oppe-Seyler's Zeitschr. 88 (1913), 44.

3) J. Müller, Hoppe-Seyler's Zeitschr. 91 (1914), 287. 


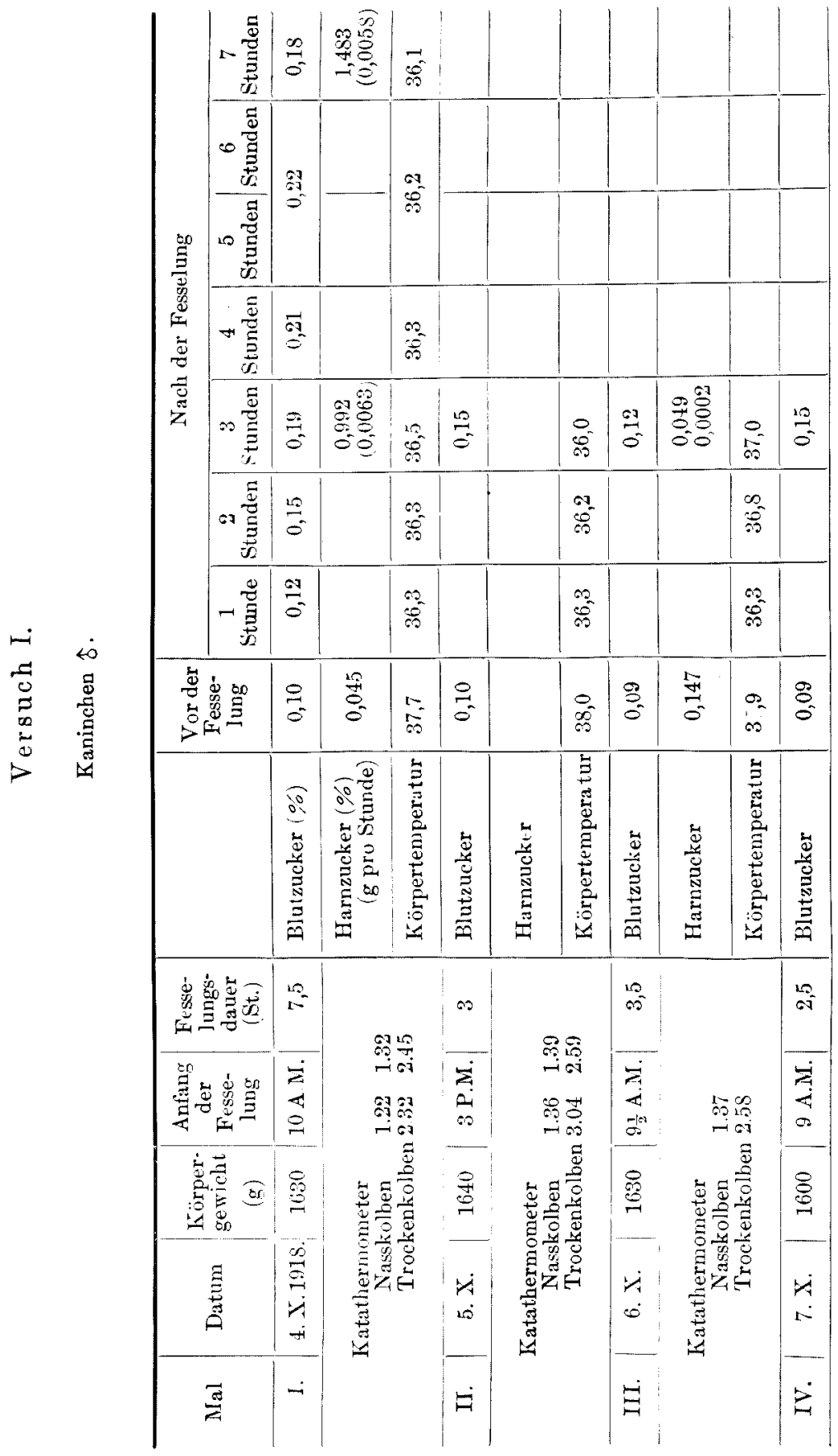




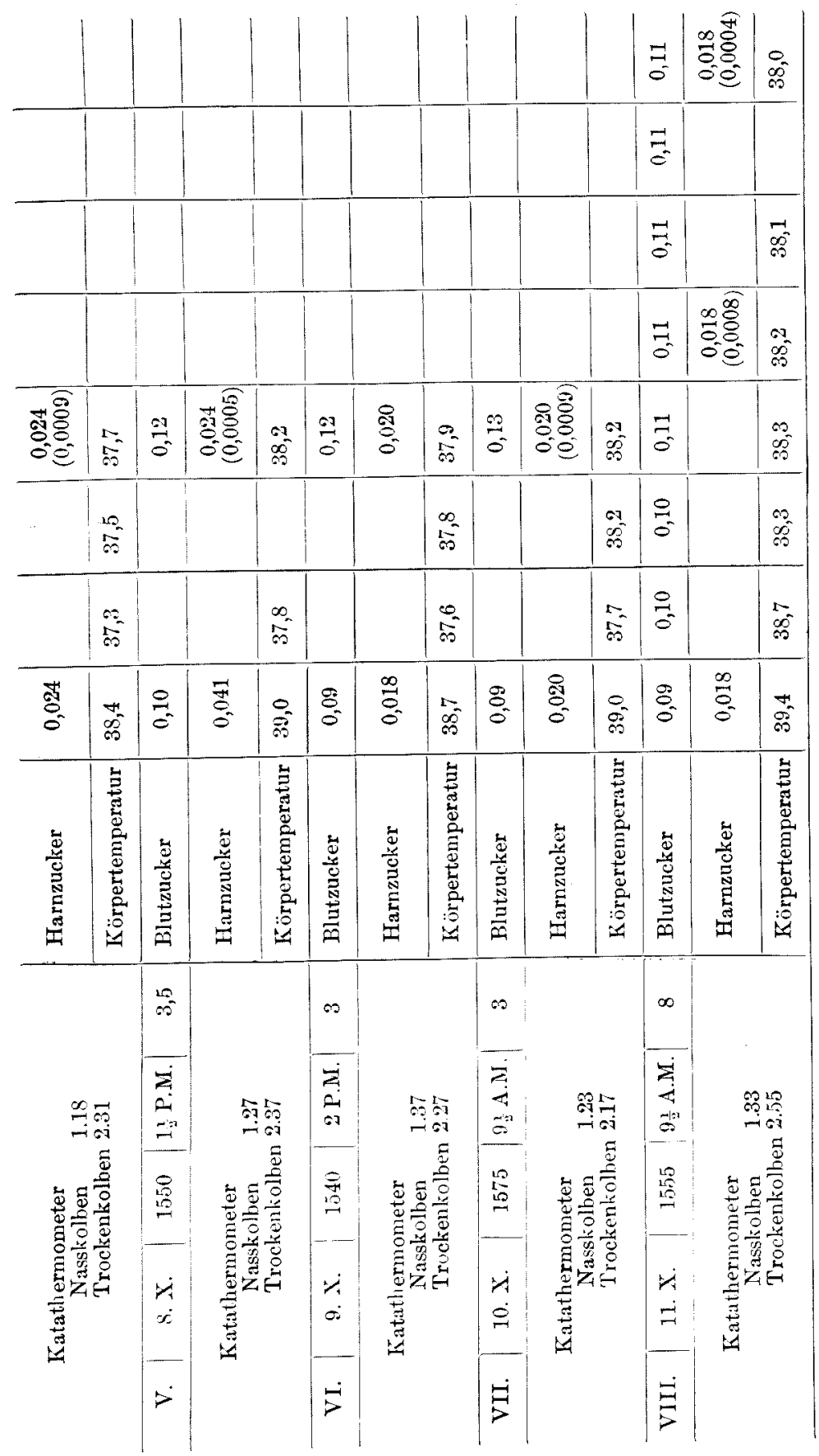




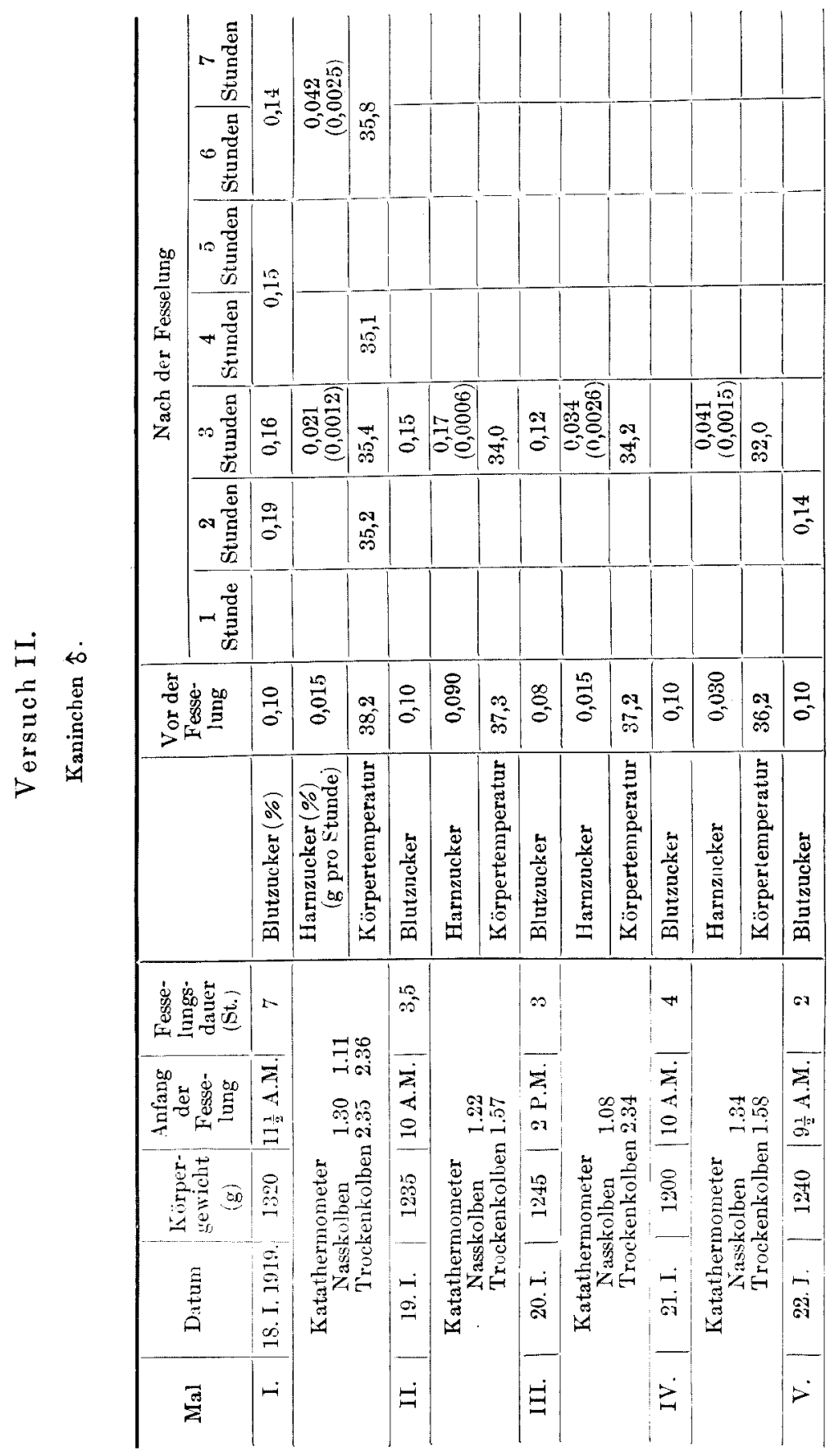




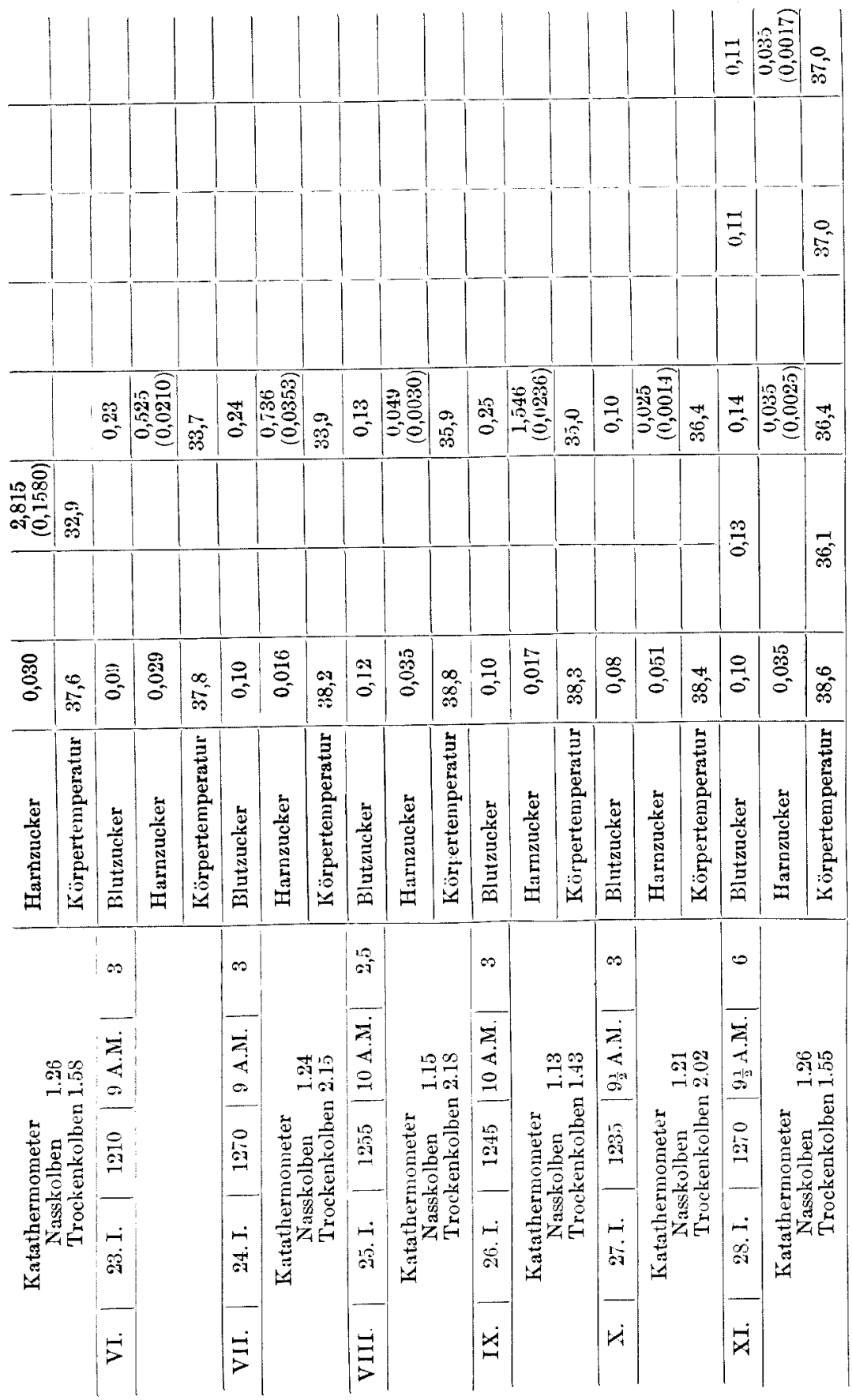




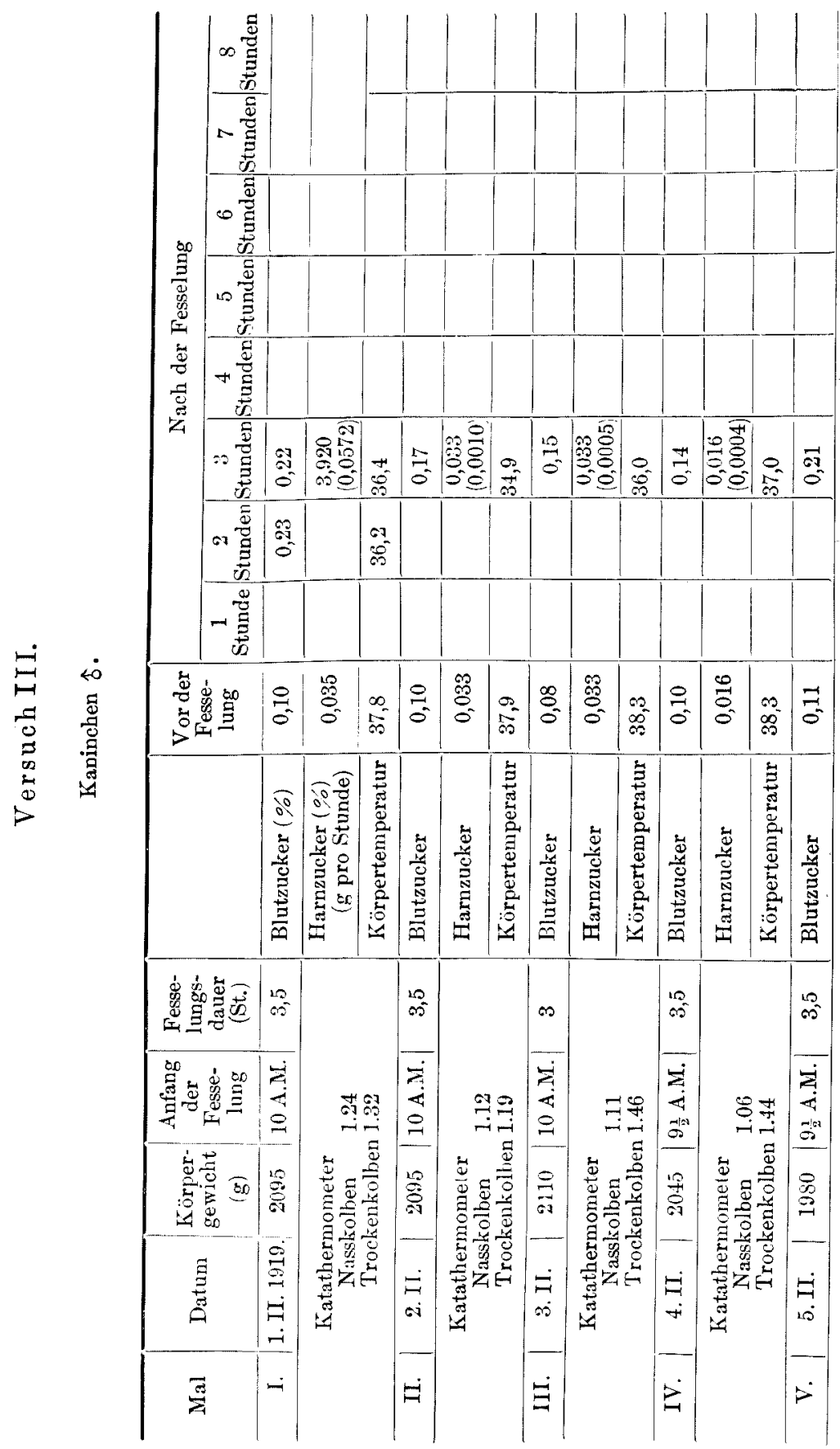




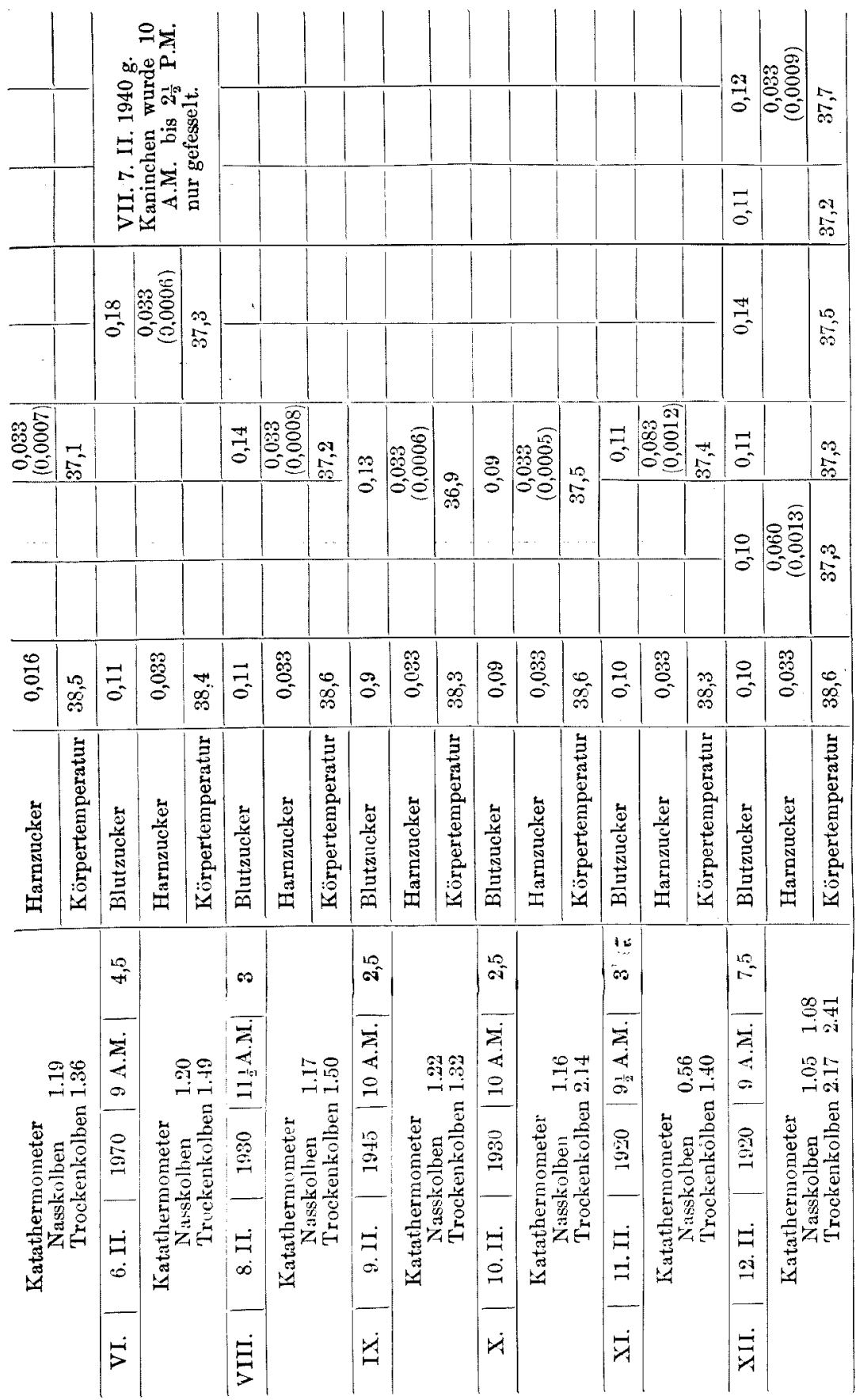




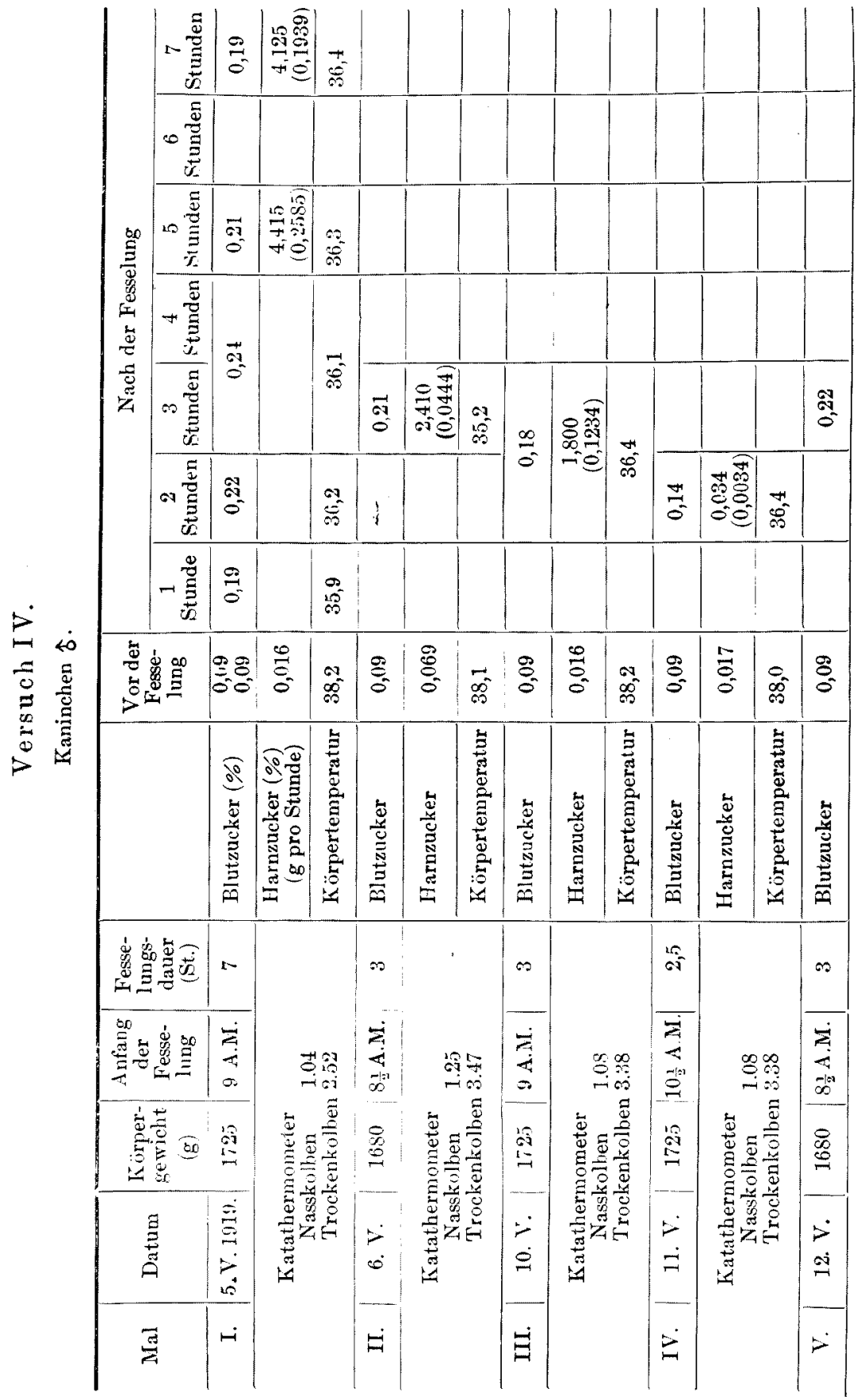




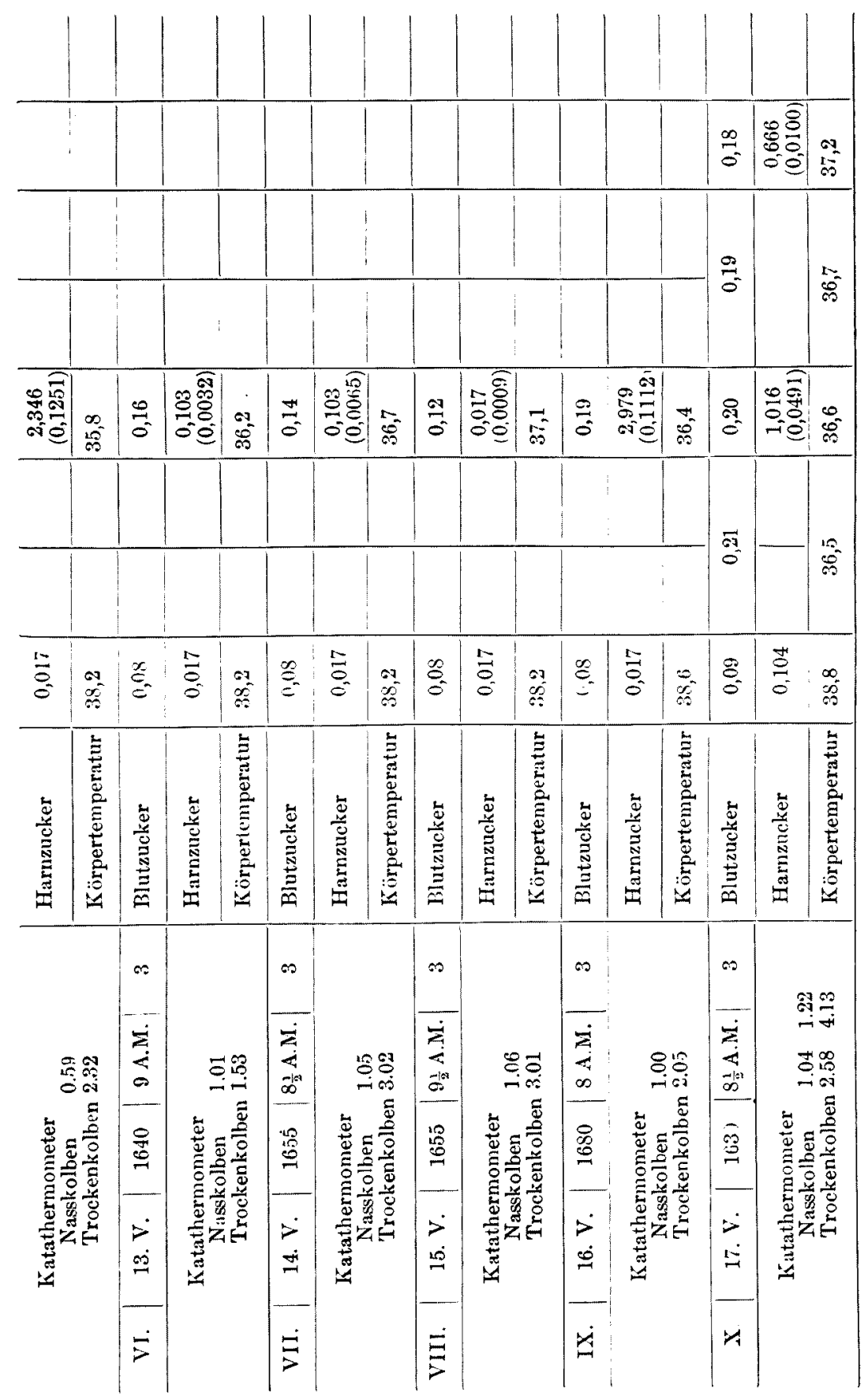




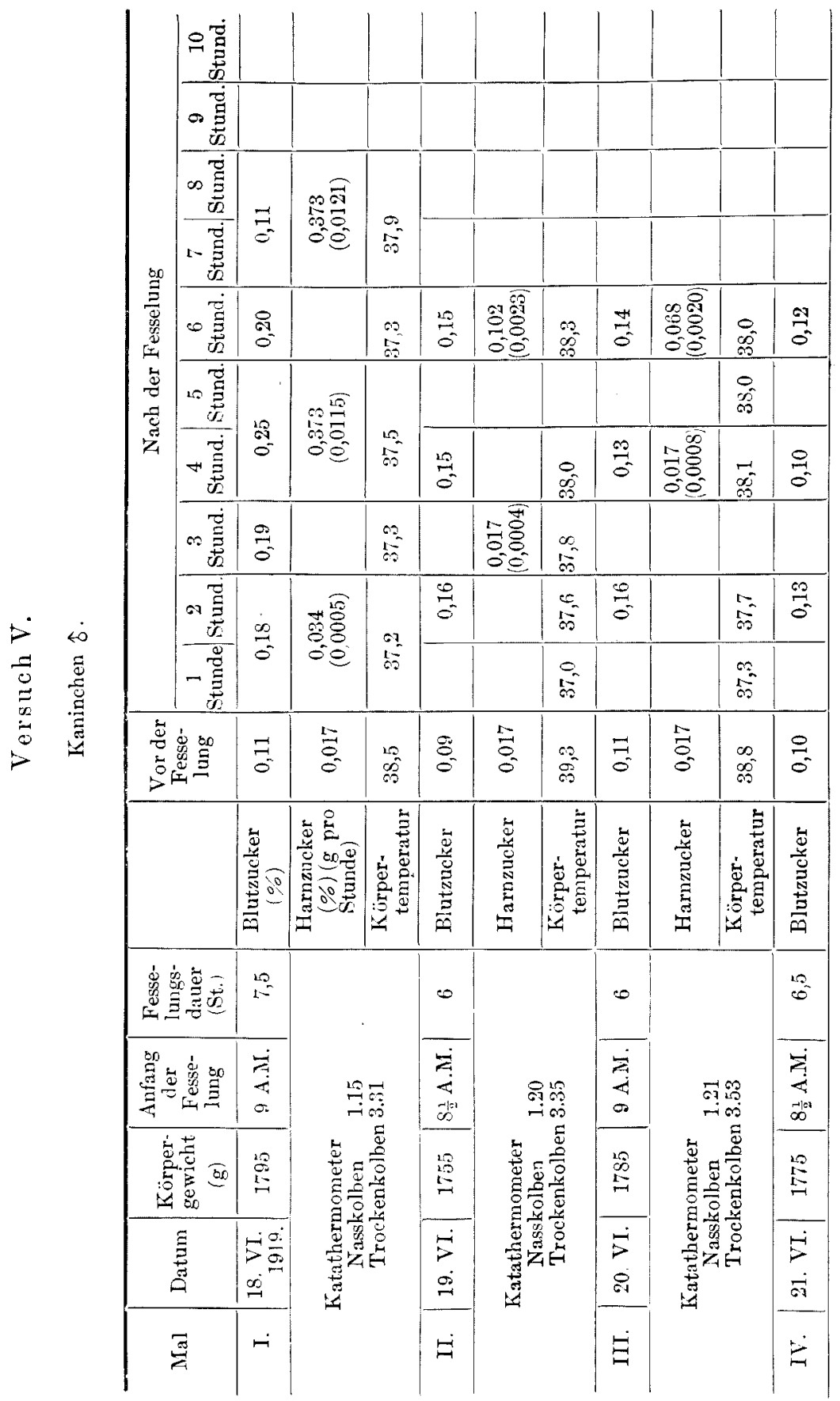




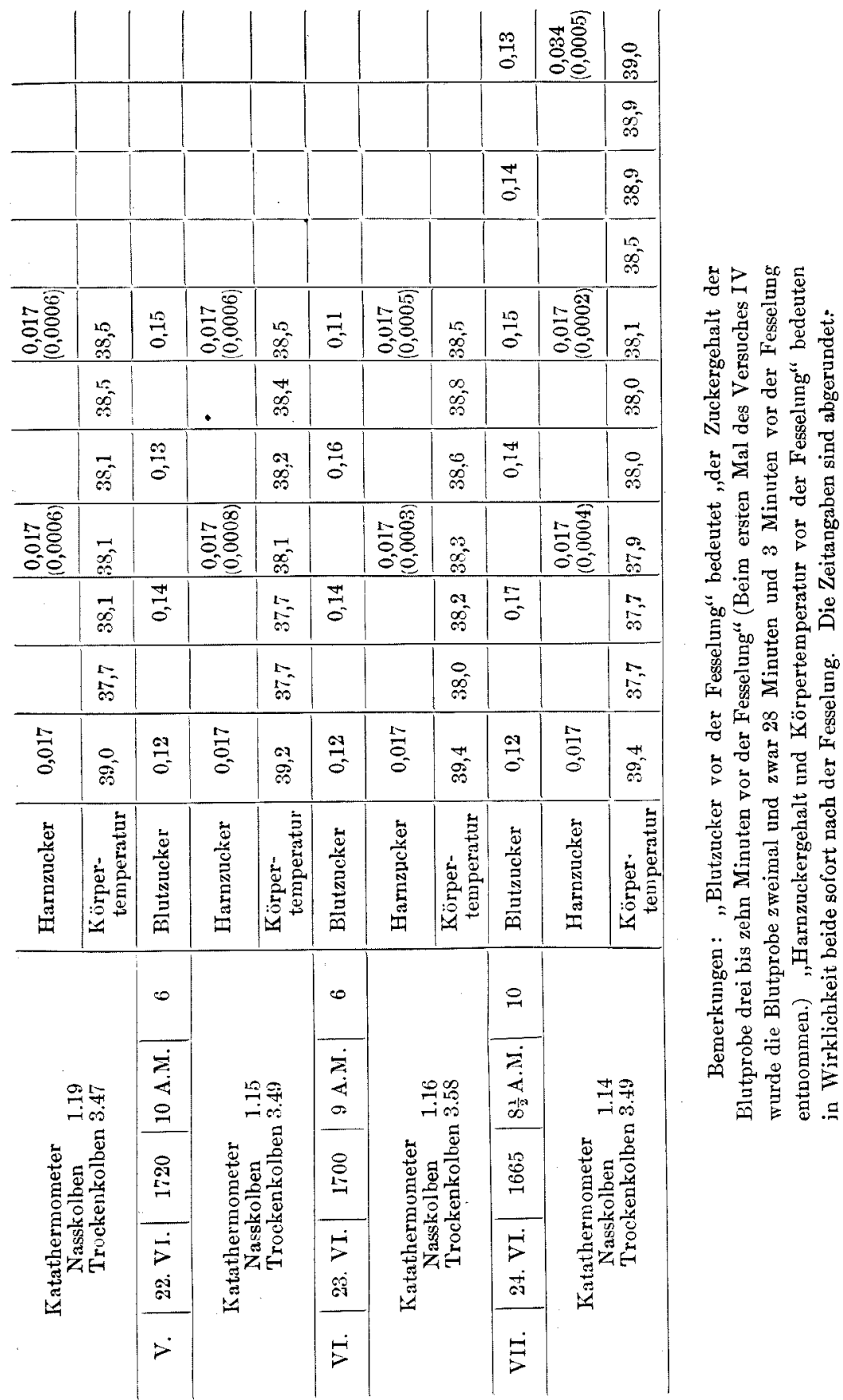


perglykämie erst mit der Zeit, aber bald tritt plötzlich hohe Hyperglykämie auf, und dann wieder neigt sie zur Verminderung, welche dann bald wieder von plötzlicher Erhöhung unterbrochen wird. Danach scheint es, dass die Hyperglyliämie rhythmischen Schwankungen unterworfen ist. In der Versuchsreihe I kann man auch darauf hinweisende Andeutungen finden. Wenn der Blutzuckergehalt durch Wiederholung der Fesselung in regelmässigem Rhythmus schwankt, so könnte man das ja im Sinne von Bang und Müller benutzen. In Wirklichkeit ist es aber leider nicht so regelnässig. Die Versuchsreihe II zeigt fast gar keine Regelmässigkeit.

In der Mehrzahl schwankt der Harnzuckergehalt in derselben Weise wie der Blutzuckergehalt.

Der Harnzuckergehalt des gefesselten Kaninchens bleibt nicht selten konstant, wenngleich sich der Blutzuckergehalt durch die Fesselung ohne Ausnahme vermehrt. Nach mehrtägigen Fesselungsversuchen ein und desselben Kaninchens ist dies für das einzelne Tier nicht mehr eigentümlich. Gewöhnlich ist die Glykosurie desto grösser, je grösser die Hyperglykämie ist. Nicht selten aber tritt bald gar keine Glykosurie, bald bedeutende Glyliosurie auf, trotz der gleichen Stärke der Hyperglykämie bei ein und demselben Kaninchen.

Falls Hyperglykämie und Körpertemperaturerniedrigung bedeutend sind, ist auch die Glykosurie gross. Die Körpertemperaturerniedrigung vermindert sich, wenn die Hyperglykämie durch Wiederholung der Fesselung geringer wird.

Die Schwankungen der Hyperglylaâmie und Körpertemperaturerniedrigung durch Wiederholung der Fesselung haken mit denen des Abkühlungsgrades des Versuchszimmers nichts zu tun, denn der Abküblungsgrad, welcher mittelst L. Hill's Katathermometer gemessen wurde, und die Zimmertemperatur, welche ich mir gespart habe, in dic Protokollen einzutragen, zeigen mit jenen gar keinen Parallelismus.

\section{Kap. VI. Kann Fesselungshy perglykämie und -glykosurie durch Schutz gegen Erniedrigung der Körpertem- peratur verhütet werden?}

Durch Fesselung des Kaninchens sinkt die Körpertemperatur und bietet etwa ein Spiegelbild zur Erhöhung des Blut- und Harnzuckergehalter. 
Die Veränderuugen in der äusseren Temperatur und Körpertemperatur haben grosse Bedeutung für den Stoffiwechsel des Tieres. Durch Abkühlung des Tieres zeigten sich Verschwinden des Leberglykogens, Auftreten der Glykosurie, der Hyperglykämie, des Eiweisses und der Milchsäure im Harne. ${ }^{12,3) 4) 5}$ )

Die Hypothese ${ }^{6}$, dass bei Hyperglykämie und -glykosurie durch Abkühlung des Tieres die abnorm niedrige Temperatur direkt auf die Leber glykogenolytisch wirkt, ist nicht haltbar. Das Leberglykogen war nicht vermindert bei der des Wärmeregulationsmechanismus' beraubten und durch Abkühlung getöteten Katze.2) Beim beiderseitig splanchnikotomierten Kaninchen tritt weder Hyperglykämie noch Glykosurie auf, durch die Injektion von Diuretin, Chlorammonium- uni konzentrierter Kochsalzlösung oder durch den Zuckerstich, trotz starker Körpertemperaturerniedrigung wie sonst. Nach Sachikado Morita ${ }^{7}$ tritt weder Hyperglykämie noch Glykosurie auf durch die Erniedrigung der Körpertemperatur des Kaninchens durch den Zwischenhirnstich nach Leschke bis auf ungefähr $30^{\circ} \mathrm{C}$. Wenn die Körpertemperatur unter etwa $30^{\circ} \mathrm{C}$ sinkt, treten sie auf. Doch sind sie auch von zentralem Mechanismus. Sie bleiben aus, wenn die beiderseitigen Eplanchnici vorher durchschnitten worden sind.

G. E $m b$ den, H. Lüthje und E. Liefmann ${ }^{8}$, sahen die Verminderung des Blutzuckergehaltes des normalen Hundes kei hoher Ungebungstemperatur und die Vermehrung desselben bei niedriger Temperatur. Die Versuchsresultate von H. Freund und F. Marchand ${ }^{6}$, die bei niedriger Umgebungstemperatur Vermehrung des Blutzuckergebalts trotz des Konstantbleibens der Körpertemperatur fanden, sind schwerlich als sichere Beweise zu betrachten. Dagegen haben B. Kramer und H. W. Coffin ${ }^{9}$ beim sich ruhig haltenden Hunde Vermehrung des Blutzuckers erst nach über 24 stündigem Aufenthalt des Tieres im sehr kalten Zimmer beobachtet. Die Versuchsergebnisse von S. L. Frederic und E. L. Scott ${ }^{10}$ ), dass bei niedriger Umgehungstemperatur und niedriger Feuchtigkeit der Blutzucker des Tieres sich vermehrt, ind zu schwankend, um daraus eine solche Schlussfolgerung zu ziehen. Nach J. Asakawa ${ }^{11)}$, verursacht eine plötzliche Änderung der Umgebungstemperatur die Schwankung des Blutzuckergehaltes des normalen Kaninchens. Langdauernder Aufenthalt in einem kalten oder warmen Raum hat darauf gar keinen Ejnfluss.

Über den Einfluss der Erhöhung der Umgebungs- oder Körpertemperatur auf den Blutzuckergehalt gehen Versuchsresultate verschiedener Forscher noch etwas weit auseinander.

1) Cl. Bernard. Léçons sur les liquides de l'organisme, T. II, Paris 1859, 455.

2) R. Boehm und F. A. Hof fmann, Schmiedeberg's Arch. 8 (1878), 375.

3) T. Araki, Hoppe-Seyler's Zeitschr. 16 (1892), 553.

4) H. Freund und F. Marchand, Schmiedeberg's Arch. 72 (1912), 56.

5) Glässner, Wien. klin. Wochenschr. 1906, 920.

6) H. Freund und F. Marchand, Schmiedeberg's Arch. 73 (1913), 276.

7) S. Morita (森田幸門), Kongress f. inn. Med. in Tokyo, April 1920.

8) G. Emden, H. Lüthje und E. Liefmann, Hofmeister's Beitr. 10 (1907) 275 .

9) B. Kramer und H. W. Coff in, Journ. biol. Chem. 25 (1916), 423.

10) S. L. Frederic und E. L. Scott, Amer. Journ. Physiol. 40 (1918), 486.

11) J. Asakawa(朝川), Nihon-Naikwagakkwai-Zasshi, 8 (1920), 193. (jap.) 
Die Vérmehrung des Blutzuckérs nach dem Wärmestich ${ }^{1)}$ wird nicht als durch die Körpertemperaturerhöhung verursacht angesehen, und sogar von anderer Seite verneint.2)3) Obgleich Blutzuckervermehrung bei verschiedenen Infektionskrankheiten beobachte wurde, ist sie wahrscheinlich nicht durch die Körpertemperaturerhöhung, sondern durch die fieborerzeugenden Gifte verursicht.4)

Über den Einfluss der Erhöhung der Umgebungstemperatur auf den experimentellen Diabetes ist nicht viel bekannt. Die Beobachtung von $H . L u ̈ t h j e^{5)}$, dass der Blutzuckergehalt des total pankreaslosen Hundes unter dem Einfluss der Umgebungstemperatur steht, wurde von Ed. Allard ${ }^{6)}$ nur bein Hunde mit partieller Pankreasexstirpation bestätigt. Lüthje und seine Mitarbeiter ${ }^{7 / 8}$ haben dann wieder ihre frühere Angabe bestätigt mit der Einschränkung, dass sie nur unter gewissen Bedingungen der Nahrungsbeschaffepheit deutlich hervortreten

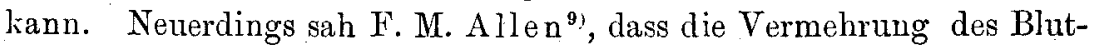
zucker- und Harnzuckergehaltes des Hundes mit partieller Pankreasexstirpation bei niedriger Umgebungstemperatur keine konstante Erscheinung ist. Beim diabetischen Hunde mit der Exstirpation des grösseren Teils des Pankreas ist dieser Einfluss der Umgebungstemperatur bemerkbar und zwar ist er desto grösser, je weniger dessen Toleranz für Zucker ist. Im Gegensatz zu Kohl er ${ }^{10)}$ hat W. Weiland ${ }^{11)}$ beobachtet, dass die Phloridzinglykosurie bei niedriger Temperatur sich vermehrt, infolge der Vermehrung des Blutzuckergehalts.

Fr. Rolly and Fr. Oppermann ${ }^{12}$ ) haben die Vermehrung des Blutzuckergehaltes bei der Erhöhung der Körpertemperatur eines mittelschweren and schweren Diabetikers durch Erwärmung mittels Glühlampen beobachtet. Nur zum Schlusse haben sie hinzugefürgt, dass beim leichten Diabetiker, der wohlgenährt. war und an keiner Krankheit des Zirkulationssystems litt, durch nicht zu intensive Schwitzkur die Glykosurie vermindert wird.

1) H. Sen ator, Zeitschr. klin. Med. 67 (1909), 253.

2) Yoshi. Kuno (久野), Tokyo-Igakkwai-Zasshi 28 (1914), 1403. (jap.)

3) K. Na i o (內藤), Tohoku-Igaku-Zasshi 4 (1919), 128. (jap.)

4) R. Watanabe und K. Sakaguchi, Mitteilungen aus d. Med. Fakultät d. Kaiserlichen Universität zu 'Tokyo 13 (1915), 99.

5) H. Lüth.j e, Verhandl. Kongr. inn. Med. 22 (1905), 268.

6) Ed. Allard, Schmiedeberg's Arch. 59 (1908), 111.

7) H. Lüth.je, Verhandl. Kongr. inn. Med. 24 (1907), 264.

8) M. A l maga und G. Embden, Hof meister's Beitr. 17 (1906), 298.

9) F. M. Allen, Amer. Journ. Physiol. 54 (1921), 425.

10) Kohler, zitiert nach H. Senator.

11). Aus Physiol. Abstract 3 (1918-19), 182.

12) Fr. Rolly und Fr. Oppermann, Biochem. Zeitschr. 48 (1913), 200. 
Bei verschiedenen experimentellen Diabetesformen ist die Körpertemperaturerniedrigung nichts seltenes: wie bei Zuckerstich-, Diuretinglykosurie des Kaninchens, Salzglykosurie und Atherglykosurie. Wie wir oben auseinandergesetzt haben, tritt einerseits durch Ablühlung des Tieres Hyperglykämie und Glykosurie auf; und anderseitş ișt es, wenn auch nicht ganz sicher, festgestellt, dass die Vermehrung des Blut- und Harnzuckergehaltes sowohl bei einigen experimentellen als auch bei menschlichem Diabetes infolge Erhöhung der Umgebungstemperatur abnimmt. Daher ist es nicht ohne Interesse zu versuchen, die Hyperglykämie und Glykosurie zentralen Mechanismus' durch Schutz gegen die Körpertemperaturerniedrigung zu verhüten, obgleich die Körpertemperaturerniedrigung eines gewissen Grades selbst sie nicht hervorrufen kann.

Bei der Ätherglykosurie konnte K. Grube ${ }^{1)}$ durch Schutz gegen die Körpertemperaturerniedrigung die Glykosmrie gut verhüten. Er hat die Blutzuckerbestimmung nicht ausgeführt. Neuerdings konnte Koichi Naito' ${ }^{2}$ durch dieselbe Manipulation die Glykosurie durch subkutane Injektion von Chlorammonium und Magnesiumsulfat fast hemmen, obgleich die Hyperglykämie dabei konstant blieb. Auch wenn man bei intravenöser Injektion von $20 \%$ iger Kochsalzlösung die Körpertemperaturerniedrigung verhütet, so hat das für die Hyperglykämie und Glylkosurie doch keinen Erfolg.

Das Vorkommen der Körpertemperaturerniedrigung beim Fesselungsdiabetes von Katze und Kaninchen wurde von Boehm und $\mathrm{Hoff}$ mann, von Hirsch und Reinbach und von mir immer konstatiert. Die ersteren hatten sie für die Ursache des Fesselungsdiabetes gehalten und versuchten vergebens ihn durch Schutz gegen die Körpertemperaturerniedrigung zu verhüten. Hirsch und Reinbach haben es auch beim Kaninchen versucht, aber gleichfalls ohne Erfolg.

$\mathrm{Zu}$ etwas anderen Resultaten als Hirsch und Reinbach bin ich bei der Nachprüfung ihrer Versuche gekommen.

Zur Erwärmung des in Rückenlage gefesselten 'Tieres habe ich die obere Kupferplatte des Kaninchenbrettes (eines Kastens) durch eine oder zwei elektrische Lampen im Kasten geheizt, der ein kleines Fenster mit Deckel zur Regulierung hat. Um rasche Abkühlung oder Erwärmung zu rermeiden, wurde ein 'Tuch aus Wolle zwischen die Kupferplatte und das Kaninchen gelegt, und wurde die Bauchwand des gefesselten Kaninchens mit einem Handtuch bedeckt.

1) K. Grube, Pflüger's Arch. 138 (1911), 601.

2) K. Naito, Tohoku Journ. Exper. Med. 1 (1920), 131. 
Versuch $\mathrm{I}$.

4. XII. 1918. Kaninuhen 1800 g. (20. XI. 1918. Fesselungsversuch [Versuch VIII in Kapital III]).

\begin{tabular}{|c|c|c|c|c|c|c|c|c|}
\hline \multirow{3}{*}{ Zeit } & \multirow{3}{*}{$\begin{array}{c}\text { Körper- } \\
\text { tempera } \\
\text { tur } \\
\left({ }^{\circ} \mathrm{C}\right)\end{array}$} & \multirow{3}{*}{$\begin{array}{c}\text { Blut- } \\
\text { zucker } \\
(\%)\end{array}$} & \multicolumn{4}{|c|}{ Harn } & \multirow{3}{*}{$\begin{array}{c}\text { Zimmer- } \\
\text { tempera- } \\
\text { tur } \\
\left({ }^{\circ} \mathrm{C}\right)\end{array}$} & \multirow{3}{*}{$\begin{array}{c}\text { Kata- } \\
\text { thermometer }\end{array}$} \\
\hline & & & \multirow{2}{*}{$\left|\begin{array}{c}\text { Menge } \\
(\mathrm{ccm})\end{array}\right|$} & \multirow{2}{*}{$\begin{array}{l}\text { Reak- } \\
\text { tion }\end{array}$} & \multicolumn{2}{|c|}{ Zucker } & & \\
\hline & & & & & $(\%)$ & $\begin{array}{l}\text { g pro } \\
\text { Std. }\end{array}$ & & \\
\hline $\begin{array}{l}\text { 9.55 A.M. } \\
10.05\end{array}$ & gefesselt & 0,09 & & & & & & \\
\hline 10.06 & 38,9 & 0,09 & & $\begin{array}{l}\text { alkal. } \\
(3,0)\end{array}$ & 0,018 & & $i 2,5$ & Nasskolben $\quad 1.21$ \\
\hline 10.25 & & & & & & & & Trockenkolben 1.51 \\
\hline 11.06 & 38,4 & 0,14 & & & & & 14,5 & \\
\hline 12.25 P.M. & 38,4 & 0,14 & 4,0 & $\begin{array}{l}\text { sauer } \\
(18,2)\end{array}$ & 0,025 & 0,0004 & 17,0 & \\
\hline $\begin{array}{l}1.29 \\
2.29\end{array}$ & $\begin{array}{l}38,6 \\
38,6\end{array}$ & $\begin{array}{l}0,14 \\
0,14\end{array}$ & & & & & $\begin{array}{l}18,5 \\
19,5\end{array}$ & \\
\hline 3.29 & 38,5 & 0,16 & 3,6 & $\begin{array}{l}\text { sauer } \\
(61,0)\end{array}$ & 0,075 & 0,0009 & 20,0 & \\
\hline $\begin{array}{l}4.30 \\
5.30\end{array}$ & $\begin{array}{l}38,7 \\
38,7\end{array}$ & $\begin{array}{l}0,15 \\
0,13\end{array}$ & & & & & $\begin{array}{l}21,0 \\
19,5\end{array}$ & \\
\hline 6.00 & & & & & & & & $\begin{array}{l}\text { Nasskolben } 1.13 \\
\text { Trockenkolben } 2.19\end{array}$ \\
\hline 6.30 & 38,7 & 0,13 & 2,8 & $\begin{array}{r}\text { sauer } \\
(76,0)\end{array}$ & 0,491 & 0,0046 & 19,0 & \\
\hline 6.45 & Tod di & urch $\mathbf{N}$ & ackensc & hlag & & & & \\
\hline
\end{tabular}

Marksubstanz der Nebennieren stark gefärbt, kein Unterschied zwischen beiden Nebennieren.

Versuch III.

26. II. 1919. Kaninchen of $1400 \mathrm{~g}$.

\begin{tabular}{|c|c|c|c|c|c|c|c|c|}
\hline \multirow{3}{*}{ Zeit } & \multirow{3}{*}{$\begin{array}{c}\text { Körper- } \\
\text { tempera- } \\
\text { tur } \\
\left({ }^{\circ} \mathrm{C}\right)\end{array}$} & \multirow{3}{*}{$\begin{array}{l}\text { Blut- } \\
\text { zucker } \\
(\%)\end{array}$} & \multicolumn{4}{|c|}{ Harn } & \multirow{3}{*}{$\begin{array}{c}\text { Zinamer- } \\
\text { tempera- } \\
\text { tur } \\
\left({ }^{\circ} \mathrm{C}\right)\end{array}$} & \multirow{3}{*}{$\begin{array}{c}\text { Kata- } \\
\text { thermometer }\end{array}$} \\
\hline & & & \multirow{2}{*}{$\begin{array}{l}\text { Menge } \\
(\mathrm{ccm})\end{array}$} & \multirow{2}{*}{$\begin{array}{l}\text { Reak- } \\
\text { tion }\end{array}$} & \multicolumn{2}{|c|}{ Zucker } & & \\
\hline & & & & & $(\%)$ & $\begin{array}{l}\text { g pro } \\
\text { Stti. }\end{array}$ & & \\
\hline $\begin{array}{l}11.10 \text { A.M. } \\
1123\end{array}$ & gefesselt & 0,09 & & & & & & \\
\hline 11.24 & 38,7 & 0,11 & & sauer & 0,032 & & 14,0 & \\
\hline 11.50 & & & & & & & & $\begin{array}{lr}\text { Nasskolben } & 1.07 \\
\text { Trockenkolben } 3.15\end{array}$ \\
\hline 12.40 P.M & 38,2 & 0,10 & & & & & 16,0 & \\
\hline 1.35 & 38,4 & 0,11 & 2,6 & $\begin{array}{l}\text { sauer } \\
\quad(10,0)\end{array}$ & 0,051 & 0,0006 & 17,0 & \\
\hline $\begin{array}{l}2.35 \\
3.40 \\
5.05\end{array}$ & $\begin{array}{l}38,4 \\
38,3 \\
38,3\end{array}$ & $\begin{array}{l}0,11 \\
0,11 \\
0,11\end{array}$ & 1,4 & sauer & 0,051 & 0,0004 & $\begin{array}{l}18,5 \\
19,0 \\
19,0\end{array}$ & \\
\hline 6.10 & & & & & & & & $\begin{array}{l}\text { Nasskolben } 1.12 \\
\text { Trockenkolben3.23 }\end{array}$ \\
\hline 6.30 & 38,4 & 0,10 & 3,4 & $\begin{array}{l}\text { sauer } \\
\qquad(50,0)\end{array}$ & 0,051 & 0,0006 & 18,0 & \\
\hline 6.43 & $\operatorname{Tod} d u$ & $\operatorname{irch} \mathrm{N}$ & ckensch & lag & & & & \\
\hline
\end{tabular}

Marksubstanz der Nebennieren stark gefärbt, kein Unterschied zwischen beiden Nebennieren. 
Versuch VI.

25. XII. 1919, Kaninchen of $2250 \mathrm{~g}$.

\begin{tabular}{|c|c|c|c|c|c|c|c|c|}
\hline \multirow{3}{*}{ Zeit } & \multirow{3}{*}{$\begin{array}{c}\text { Körper- } \\
\text { tempera- } \\
\text { tur } \\
\left({ }^{\circ} \mathrm{C}\right)\end{array}$} & \multirow{3}{*}{$\begin{array}{c}\text { Blut- } \\
\text { zucker } \\
(\%)\end{array}$} & \multicolumn{4}{|c|}{ Harn } & \multirow{3}{*}{$\begin{array}{c}\text { Zimmer- } \\
\text { tempera- } \\
\text { tur } \\
\left({ }^{\circ} \mathrm{C}\right)\end{array}$} & \multirow{3}{*}{$\begin{array}{l}\text { Kata- } \\
\text { thermometer }\end{array}$} \\
\hline & & & \multirow{2}{*}{$\begin{array}{r}\text { Menge } \\
(\mathrm{ccm})\end{array}$} & \multirow{2}{*}{$\begin{array}{c}\text { Reak- } \\
\text { tion }\end{array}$} & \multicolumn{2}{|c|}{ Zucker } & & \\
\hline & & & & & $(\%)$ & $\begin{array}{l}\text { g pro } \\
\text { Std. }\end{array}$ & & \\
\hline 10.00 A.M & & 0,12 & & & & & & \\
\hline 10.06 & gefesselt & & & & & & & \\
\hline 10.07 & 38,5 & & & sauer & 0,026 & & 11,0 & \\
\hline 10.15 & & & & & & & & $\begin{array}{l}\text { Nasskolben } 1.08 \\
\text { Trockenkolben } 2.39\end{array}$ \\
\hline 11.07 & 37,7 & 0,14 & & & & & 12,8 & \\
\hline 12.08 P.M & 37,8 & 0,15 & 4,0 & sauer & 0,026 & 0,0005 & 14,0 & \\
\hline 1.08 & 37,9 & 0,14 & & & & & 15,0 & \\
\hline 2.05 & 37,9 & 0,13 & 3,8 & sauer & 0,026 & 0,0005 & 16,0 & \\
\hline 3.05 & 38,0 & 0,13 & & & & & 16,8 & \\
\hline 4.05 & 38,0 & 0,13 & & & & & 17,7 & \\
\hline 4.12 & & & & & & & & $\begin{array}{l}\text { Nasskolben } 1.10 \\
\text { Trockenkolben } 3.42\end{array}$ \\
\hline 5.06 & 38,1 & 0,13 & 9,0 & sauer & 0,026 & 0,0008 & 18,0 & \\
\hline
\end{tabular}

\section{Versuch VII.}

12. I. 1920 . Kaninchen $\hat{o} 1950$.

\begin{tabular}{|c|c|c|c|c|c|c|c|c|}
\hline \multirow{3}{*}{ Zeit } & \multirow{3}{*}{$\begin{array}{c}\text { Körper- } \\
\text { tempera- } \\
\text { tur } \\
\left({ }^{\circ} \mathrm{C}\right)\end{array}$} & \multirow{3}{*}{$\begin{array}{c}\text { Blut- } \\
\text { zucker } \\
(\%)\end{array}$} & \multicolumn{4}{|c|}{ Harn } & \multirow{3}{*}{$\begin{array}{c}\text { Zimmer- } \\
\text { tempera- } \\
\text { tur } \\
\left({ }^{\circ} \mathrm{C}\right)\end{array}$} & \multirow{3}{*}{$\underset{\text { thermometer }}{\text { Kata- }}$} \\
\hline & & & \multirow{2}{*}{$\begin{array}{l}\text { Menge } \\
(\mathrm{ccm})\end{array}$} & \multirow{2}{*}{$\begin{array}{l}\text { Reak- } \\
\text { tion }\end{array}$} & \multicolumn{2}{|c|}{ Zucker } & & \\
\hline & & & & & $(\%)$ & $\begin{array}{l}\text { g pro } \\
\text { Std. }\end{array}$ & & \\
\hline 10.58 A.M & & $0,1.2$ & & & & & & \\
\hline 11.04 & gefesselt & & & & & & & \\
\hline 11.05 & 38,5 & & & alkal. & 0,013 & & 14,0 & \\
\hline 11.10 & & & & & & & & $\begin{array}{l}\text { Nasskolben } 1.06 \\
\text { Trockenkolben } 3.19\end{array}$ \\
\hline 12.05 P.M & 38,0 & 0,17 & & & & & 15,0 & \\
\hline 1.05 & 37,9 & 0,17 & 7,8 & saner & 0,052 & 0,0020 & 16,3 & \\
\hline 2.05 & 38,0 & 0,16 & & & & & 17,8 & \\
\hline 3.05 & 38,5 & 0,16 & 6,0 & sauer & 0,026 & 0,0008 & 18,5 & \\
\hline 4.05 & 38,1 & 0,15 & & & & & 19,5 & \\
\hline 5.06 & 37,9 & 0,15 & & & & & 19,5 & \\
\hline 5.15 & & & & & & & & $\begin{array}{l}\text { Nasskoben } 1.10 \\
\text { Trockenkolben } 3.51\end{array}$ \\
\hline 6.05 & 37,8 & 0,14 & 8,0 & sauer & 0,039 & 0,0016 & 19,0 & \\
\hline 6.10 & Tod du & $\operatorname{rrch~} \mathrm{Na}$ & ickensch & & & & & \\
\hline
\end{tabular}

Marksubstanz der Nebennieren ziemlich stark gefärbt, kein Unterschied zwischen beiden Nebennieren. 
Tabelle

\begin{tabular}{|c|c|c|c|c|c|c|c|c|}
\hline \multirow{3}{*}{$\mathrm{Nr}$} & \multirow{3}{*}{$\begin{array}{l}\text { Körper- } \\
\text { gewicht }\end{array}$} & \multirow[b]{3}{*}{ Datum } & \multirow[b]{3}{*}{$\begin{array}{l}\text { Fesse- } \\
\text { lungs- } \\
\text { dauer } \\
\text { (Std.) }\end{array}$} & \multicolumn{3}{|c|}{ Blutzucker } & \multirow{2}{*}{\multicolumn{2}{|c|}{$(\%)$}} \\
\hline & & & & & & & & \\
\hline & & & & $\begin{array}{l}\text { Vor der } \\
\text { Fesse- } \\
\text { lung } \\
(0,0)\end{array}$ & $\begin{array}{c}\text { während } \\
\text { der } \\
\text { Fesselung } \\
(\%)\end{array}$ & $\begin{array}{c}\text { Zeit } \\
\text { bis zum } \\
\text { Maximum } \\
\text { (Std.) }\end{array}$ & $\begin{array}{c}\text { Kurz } \\
\text { nach der } \\
\text { Fesselung }\end{array}$ & $\begin{array}{c}\text { Maximum } \\
\text { während } \\
\text { der } \\
\text { Fesselung } \\
\end{array}$ \\
\hline 1. & 1800 & 4. XII. & 8,5 & 0,09 & 0,16 & 5,5 & 0,018 & 0,491 \\
\hline 2. & 2175 & 21. I. 1919 & 8,0 & 0,09 & 0,16 & 2,0 & 0,035 & 0,035 \\
\hline 3. & 1400 & $26 . \mathrm{II}$. & 7,5 & 0,09 & 0,11 & 5,5 & 0,032 & $0,0.51$ \\
\hline 4. & 1300 & 1. III. & 8,0 & 0,13 & 0,18 & 2,0 & 0,024 & 0,043 \\
\hline 5. & 1885 & 23. XII. & 7,0 & 0,10 & 0,16 & 3,0 & 0,013 & 0,156 \\
\hline 6. & 2250 & 25. XII. & 7,0 & 0,12 & 0,15 & 2,0 & 0,026 & 0,026 \\
\hline 7. & 1950 & 12: I. 1920 & 7,0 & 0,12 & 0,17 & 2,0 & 0,013 & 0,052 \\
\hline 8. & 1860 & $22 . \mathrm{I}$ & 8,0 & 0,11 & 0,16 & 3,0 & 0,013 & 0,065 \\
\hline 8.) & 1900 & $\begin{array}{c}29 . \mathrm{XI} \\
1918 .\end{array}$ & 8,0 & 0,09 & 0,29 & 5,0 & 0,015 & 12,440 \\
\hline 10. & 2025 & 6. I. 1919 & 7,5 & 0,07 & 0,21 & 3,5 & 0,016 & 2,344 \\
\hline 42. $)^{21}$ & 1910 & $\begin{array}{l}\text { 15. II. } \\
1920 .\end{array}$ & 6,0 & 0,09 & 0,29 & 2,0 & 0,026 & 10,240 \\
\hline
\end{tabular}

Bei diesen Fällen tritt auch Hyperglykämie anf, die ihr Maximum in zwei bis fünf Stunden erreicht wie beim gewöhnlichen Fesselungsversuche. Der Grad der Hyporglykämie ist aber mit dem gewöhnlichen nicht vergleichbar, und zwar ist er etwa nur ein Viertel des letzteren. Die Glykosurie tritt nur bei einigen Fällen auf, und ihr Grad ist auch klein. Das Kaninchen vom Versuche 1, 2 resp. 8 ist das vom Versuch 8, 10 resp. $42 \mathrm{im}$ Kapitel III. Der Unterschied des Grades der Hyperglykämie und Glykosurie in beiden Versuchsreihen ist bedeutend. Man könnte den Grund des grossen Unterschiedes der Wiederholung der Fesselung zuschreiben; dazu sind aber die Unterschiede zu gross, und zu lange Zeit ist $z$ wischen beiclen Versuchen verflossen.

Der Gehalt der Nebennieren an chromaffiner Substanz wurde bei vier Fällen untersucht, darunter latte er sich bei drei Fällen fast gar nicht vermindert, während er sich bei dem einen übrigbleibenden Falle mittelmässig vermindert hatte.

Die Harnreaktion verhält sich wie beim gewöhulichen Fesselungsversuche. 
III.

\begin{tabular}{|c|c|c|c|c|c|c|c|}
\hline \multicolumn{3}{|c|}{ Harnzucker } & \multicolumn{2}{|c|}{ Köpertemperatur } & \multirow{3}{*}{$\underset{\text { temperatur }}{\text { Zimmer- }}$} & \multirow{2}{*}{\multicolumn{2}{|c|}{ Katathermometer }} \\
\hline \multirow[b]{2}{*}{$\begin{array}{l}\text { Zeit } \\
\text { bis zum } \\
\text { Maxinuum } \\
\text { (Std.) }\end{array}$} & \multicolumn{2}{|c|}{ g pro Stunde } & \multirow[b]{2}{*}{$\begin{array}{c}\text { Kurz } \\
\text { nach der } \\
\text { Fesselung } \\
\left({ }^{\circ} \mathrm{C}\right)\end{array}$} & \multirow[b]{2}{*}{$\begin{array}{l}\text { Während } \\
\text { der } \\
\text { Fesselung } \\
\left({ }^{\circ} \mathrm{C}\right)\end{array}$} & & & \\
\hline & $\begin{array}{c}\text { Maximum } \\
\text { während } \\
\text { der } \\
\text { Fesselung }\end{array}$ & $\mid \begin{array}{c}\text { Zeit } \\
\text { bis zum } \\
\text { Maximum } \\
\text { (Std.) }\end{array}$ & & & & $\begin{array}{l}\text { Nass- } \\
\text { kolben }\end{array}$ & $\begin{array}{l}\text { Trocken } \\
\text { kolben }\end{array}$ \\
\hline 8,5 & 0,0046 & 8,5 & 38,9 & $38,4-38,7$ & $13,0-19,0$ & 1.21 & 1.51 \\
\hline & 0,0019 & 2,0 & 39,3 & $37,8-38,1$ & $9,0-11,0$ & 1.18 & 2.01 \\
\hline 1,0 & 0,0006 & 7,5 & 38,7 & $38,2-38,4$ & $14,0-19,0$ & 1.07 & 3.15 \\
\hline 2,0 & $0,001 \tilde{5}$ & 2,0 & 39,5 & $39,1-3 !, 3$ & $14,0-21,0$ & 1.09 & 2.58 \\
\hline \multirow[t]{2}{*}{7,0} & 0,0019 & 7,0 & 38,8 & $38,0-39,2$ & $8,8-15,5$ & 1.01 & 2.28 \\
\hline & 0,0008 & 7,0 & 38,5 & $37,7-38,0$ & $11,0-18,0$ & 1.08 & 2.39 \\
\hline 2,0 & 0,0020 & 2,0 & 38,5 & $38,5-37,8$ & $14,0-19,5$ & 1.06 & 3.19 \\
\hline 8,0 & 0,0012 & 8,0 & 38,0 & $37,8-37,9$ & $11,8-15,8$ & 1.00 & $3: 05$ \\
\hline 4,5 & 0,3981 & 4,5 & 38,6 & (Minimum) & $16,0-22,5$ & 1.24 & 2.55 \\
\hline 3,0 & 0,1600 & 3,0 & 38,4 & 35,5 & $4,5-16,0$ & 1.37 & 2.32 \\
\hline 4,0 & 0,3226 & 4,0 & 37,4 & $3 \overline{0}, 3$ & $5,0-9,3$ & .56 & 1.47 \\
\hline
\end{tabular}

Unter den Versucbsprotokollen von Hirsch und Reinbach 1) habe ich nur fünf Versuche gefunden, welche mit meinen diesen Versuchen direkt vergleichbar sind und unten tabellarisch zusammengestellt wurden.

\begin{tabular}{|c|c|c|c|c|c|c|}
\hline \multirow[b]{2}{*}{ Nr. } & \multirow{2}{*}{$\begin{array}{c}\text { Fesselongs- } \\
\text { dauer } \\
\text { (Std.) }\end{array}$} & \multirow{2}{*}{$\begin{array}{c}\text { Schütz } \\
\text { ror } \\
\text { Arkühlung }\end{array}$} & \multicolumn{2}{|c|}{ Blutzucker $(\%)$} & \multicolumn{2}{|c|}{ Körpertemperatur $\left({ }^{\circ} \mathrm{C}\right)$} \\
\hline & & & $\begin{array}{l}\text { Vor der } \\
\text { Fesselung }\end{array}$ & $\begin{array}{c}\text { Maximum } \\
\text { wiihrend der } \\
\text { Feselung }\end{array}$ & $\begin{array}{l}\text { Vor der } \\
\text { Fesselung }\end{array}$ & $\begin{array}{l}\text { Minimum } \\
\text { wïhrend der } \\
\text { Fesselung }\end{array}$ \\
\hline VI. & 4 & - & 0,12 & 0,22 & & 36,4 \\
\hline VIII. & 3 & - & 0,12 & 0,21 & 37,4 & 86,8 \\
\hline VII. & 3 & + & 0,15 & 0,21 & 38,0 & 37,8 \\
\hline IX. & 2 & + & 0,13 & 0,27 & & 3,7 \\
\hline$x$ & 6 & + & 0,17 & 0,33 & 87,9 & $\therefore 8$ \\
\hline
\end{tabular}

Wie Tabelle III zeigt, wirl die Fesselungshyperglykämie und -glykosurie durch den Schutz gegen die Körpertenperaturemiedrigung stark vermindert, aler nicht gänzlich gehemmt. Für solche eine quantitative Frage sind ihre Veruchsbeispiele zu zu wenig. Unter ihren Versuchen spricht nur Versuch IX gegen meinen Versuchs. ergebnissen.

1) E. Hirsch und II. Reinbach, Hoppe-Seyler's Zeitschr. 87 (1913), 122. 


\section{Kap. YII. Fesselungsversuche am doppelseitig splanchniko. tomierten Kaninchen.}

Der Fesselungsdiabetes erscheint als ein Diabetes zentralen Mechanismus' wie Piqûre-, Diuretin- oder Salzglykosurie. Er ist immer von Körpertemperaturerniedrigung und Verminderung des Gehaltes der Nebennieren an chromaffiner Substanz begleitet.

Bis jetzt ist er aber noch keinen experimentellen Untersuchungen unterzogen worden, wahrscheinlich weil er schon von vornherein in sich klar zu sein scheint.

Cannon, Shohl und Wright ${ }^{1)}$, die bii der aufgeregten Katze die Glykosurie auftreten sahen, haben weiter die Katze ihrer beiden Nebennieren beraubt und sie sich aufregen lassen; diesmal aber trat keine Glykosurie auf. Daraufhin haben sie die ,emotional glycosuria“" für nichts anderes als eine Adrenalinglykosurie halten zu können geglaubt.

Die Ansicht, dass die Ursache des Fesselungsdiabetes Affelkte oder psychische Aufregungen sind, ist von anderen Seiten nicht als berechtigt anerkannt..23) Gegen die weit verbreitete Hypothese, dass die Hypersekretion von Adrenalin aus den Nebennieren die Hyperglykämie zentralen Mechanismus' hervorrufe, wurden verschiedene Experim $\_n$ taldata von verschiedenen Seiten vorgebracht, dit jener Ansicht geradezu direkt widersprechen oder nicht mit ihr vertinbar erscheinen. ${ }^{456677) 8895}$

Hier beschäftige ich mich mit der Frage, ob der Fesselungsdiabetes wirklich vom zentralen Mechanismus ist. (Tab. IV. S. 61-62.)

Da der Tonus des Splanchnicusgebietes in etwa acht Tagen nach der Splanchnikotomie wiedergestellt wird ${ }^{10)}$, wurden die Versuche immer erst frühestens acht Tage nach der Splanchnikotomie ausgeführt.

1) W. B. Cannon, A. T. Shohl und W.S. Wright, Amer. Journ. Physiol. 29 $(1911-12), 280$.

2) G. N. Stewart und J. M. Rogoff, Amer. Joura. Physiol. 44 (1917), 543.

3) Suke. Morita, Schmiedeberg's Arch. 78 (1915), 188.

4) E. Wertheimer and G. Battez, Arch. internat. physiol. 9(1910), 363.

5) H. Freund und F. Marchand, Sch miedeberg's Arch. 76 (1914), 324.

6) J. Negrin und E. Th. Brïcke, Zeitschr. biol. Techn, u. Meth. 3 (1914), 311.

7) I. Fujii, Tohoku Journ. Exper. Med. 1 (1920), 38.

8) G. N. Stewart und J. M. Rogoff, Amer. Journ. Physiol. 46 (1918), 90.

9) S. Kuriy am a, Journ. biol. Chem. 34 (19:8), 299

10) L. Hill, Schäfer's Text-Book of Physiol. Edinburgh 1900, II. 138. 
Versuch II.

7. I. 1919. Kaninchen $\delta$. Beiderseitige Splanchnikotomie.

16. I. 1919. $1620 \mathrm{~g}$.

\begin{tabular}{|c|c|c|c|c|c|c|c|c|}
\hline \multirow{3}{*}{ Zeit } & \multirow{3}{*}{$\begin{array}{c}\text { Körper- } \\
\text { tempera- } \\
\text { tur } \\
\left({ }^{\circ} \mathrm{C}\right)\end{array}$} & \multirow{3}{*}{$\begin{array}{c}\text { Blut- } \\
\text { zucker } \\
(\%)\end{array}$} & \multicolumn{4}{|c|}{ Harn } & \multirow{3}{*}{$\begin{array}{c}\text { Zimmer- } \\
\text { tempera- } \\
\text { tur } \\
\left({ }^{\circ} \mathrm{C}\right)\end{array}$} & \multirow{3}{*}{$\begin{array}{c}\text { Kata- } \\
\text { thermoneter }\end{array}$} \\
\hline & & & \multirow{2}{*}{$\begin{array}{r}\text { Menge } \\
(\mathrm{cem})\end{array}$} & \multirow{2}{*}{$\begin{array}{c}\text { Reak- } \\
\text { tion }\end{array}$} & \multicolumn{2}{|c|}{ Zucker } & & \\
\hline & & & & & $(\%)$ & $\begin{array}{l}\text { g pro } \\
\text { Std. }\end{array}$ & & \\
\hline $\begin{array}{l}9.10 \text { A.M. } \\
9.25\end{array}$ & gefesselt & 0,10 & & & & & & \\
\hline 9.26 & $\left(\begin{array}{c}\text { (Rückenlage) } \\
38,2\end{array}\right.$ & & & $\begin{array}{r}\text { alkal. } \\
(1,5)\end{array}$ & 0,014 & & 9,5 & \\
\hline 9.30 & & 0,10 & & & & & & \\
\hline 9.50 & & & & & & & & $\begin{array}{l}\text { Nasskolben } 1.16 \\
\text { Trockenkolben } 1.50\end{array}$ \\
\hline $\begin{array}{l}10.30 \\
11.32 \\
12.45 \text { P.M. }\end{array}$ & $\begin{array}{l}35,5 \\
35,9 \\
35,8\end{array}$ & $\begin{array}{l}0,11 \\
0,11 \\
0,11\end{array}$ & 2,3 & sauer & 0,021 & 0,0003 & $\begin{array}{l}12,0 \\
14,0 \\
15,5\end{array}$ & \\
\hline 2.05 & 36,3 & 0,13 & 3,1 & $\left(\begin{array}{c}\text { sauer } \\
(10,0)\end{array} \mid\right.$ & 0,081 & 0,0003 & 36,5 & \\
\hline 3.30 & 36,8 & 0,12 & & & & & 18,0 & \\
\hline 4.45 & & & & & & & & $\begin{array}{l}\text { Nasskolben } 1.15 \\
\text { Trockenkolben } 2.25\end{array}$ \\
\hline 5.00 & $3 \pi, 1$ & 0,12 & 10,4 & $\left|\begin{array}{c}\text { sauer } \\
(11,0)\end{array}\right|$ & 0,017 & 0,0006 & 18,5 & \\
\hline 5.12 & Tod dure & ch Nack & renschla & & & & & \\
\hline
\end{tabular}

Marksubstanz der Nebennieren stark gefärbt, kein Unterschied zwischen beiden Nebennieren.

Versuch IV.

16. X. 1919. Kaninchen $\hat{\delta}$. Beiderseitige Splanchnikotomie.

12. XI. 1919. $1825 \mathrm{~g}$.

\begin{tabular}{|c|c|c|c|c|c|c|c|c|}
\hline \multirow{3}{*}{ Zeit } & \multirow{3}{*}{$\begin{array}{c}\text { Körper- } \\
\text { temipera- } \\
\text { tur } \\
\left({ }^{\circ} \mathrm{C}\right)\end{array}$} & \multirow{3}{*}{$\begin{array}{c}\text { Blut- } \\
\text { zucker } \\
(\%)\end{array}$} & \multicolumn{4}{|c|}{ Harn } & \multirow{3}{*}{$\begin{array}{c}\text { Zimmer- } \\
\text { tempera- } \\
\text { tur } \\
\left({ }^{\circ} \mathrm{C}\right)\end{array}$} & \multirow{3}{*}{$\begin{array}{l}\text { Kata- } \\
\text { thermometer }\end{array}$} \\
\hline & & & \multirow{2}{*}{$\begin{array}{l}\text { Menge } \\
\text { (ccm) }\end{array}$} & \multirow{2}{*}{$\begin{array}{l}\text { Reak- } \\
\text { tion }\end{array}$} & \multicolumn{2}{|c|}{ Zucker } & & \\
\hline & & & & & $(\%)$ & $\begin{array}{l}\text { g pro } \\
\text { Std. }\end{array}$ & & \\
\hline $\begin{array}{l}8.52 \text { A.M. } \\
8.58\end{array}$ & gefesselt & 0,10 & & & & & & \\
\hline 8.59 & 38,0 & & & alkal. & 0,013 & & 13,0 & \\
\hline 9.07 & & & & & & & & $\begin{array}{l}\text { Nasskolben } 1.08 \\
\text { Trockenkolben } 3.10\end{array}$ \\
\hline $\begin{array}{l}10.00 \\
11.00\end{array}$ & 35,0 & 0,12 & & lolkgl. & 0013 & & $\begin{array}{l}14,5 \\
160\end{array}$ & \\
\hline 12.20 P.M. & 35,5 & 0,11 & & & & & 17,0 & \\
\hline 1.00 & 35,6 & 0,12 & & & & & 18,0 & \\
\hline 2.02 & 35,9 & 0,11 & 9,0 & sauer & 0,013 & 0,0004 & 19,0 & \\
\hline 3.00 & 36,1 & 0,11 & & & & & 192 & \\
\hline 4.0 & 36,3 & 11 & & & & & 20,9 & Nasskolben $\quad 1.26$ \\
\hline 4.10 & & & & & & & & Trockenkolben 4.59 \\
\hline $\begin{array}{l}5.00 \\
5.11\end{array}$ & $\begin{array}{c}36,6 \\
\text { Tod durc }\end{array}$ & $\begin{array}{c}0,11 \\
\mathrm{Nacl}\end{array}$ & $\begin{array}{c}12,2 \\
\text { kenschl }\end{array}$ & sauer & 0,013 & $0,(1005$ & 20,0 & \\
\hline
\end{tabular}

Marksubstanz der Nebennieren stark gefärbt, kein Unterschied $\mathrm{zwischen}$ beiden Nebennieren. 
Durch die Fesselung des beiderseitig splanchnikotomierten Kaninchens tritt Hyperglykämie leichten Grades, etwa in einem Fünftel der Stärke von der des normalen Kaninchens auf. Glykosurie fehlt meistens, oder sie ist von ganz geringem Grade, wenn sie auftritt. Die Körpertemperaturerniedrigung tritt ein wie beim normalen Tiere; das spricht also auch gegen die Hypothese, dass die Kälte direkt auf die Leber glykogenolytisch einwirke.

Der Gehalt der Nebennieren an chromaffiner Substanz vermindert sich garnicht.

Die Harnreaktion verhält sich wie in den anderen Versuchsreihen.

Da die Hyperglykämie anch so noch bei dem beiderseitig'splanchnikotomierten Kaninchen auftritt, wenn auch in geringerem Grade, habe ich weiter denselben Versuch unter Verhütung der Körpertemperaturerniedrigung wiederholt. (Tab. V. S. 61-62.)

\section{Versuch II.}

19. II. 1919. Kaninchen $\delta 1590$ g. Beiderseitige Splanchnikotomie.

9. III. $1919.1550 \mathrm{~g}$.

\begin{tabular}{|c|c|c|c|c|c|c|c|c|}
\hline \multirow{3}{*}{ Zeit } & \multirow{3}{*}{$\begin{array}{c}\text { Körper- } \\
\text { tempera- } \\
\text { tur } \\
\left({ }^{\circ} \mathrm{C}\right)\end{array}$} & \multirow{3}{*}{$\begin{array}{c}\text { Blut- } \\
\text { zucker } \\
(\%)\end{array}$} & \multicolumn{4}{|c|}{ Harn } & \multirow{3}{*}{$\begin{array}{c}\text { Zimmer } \\
\text { tempera- } \\
\text { tur } \\
\left({ }^{\circ} \mathrm{C}\right)\end{array}$} & \multirow{3}{*}{$\begin{array}{c}\text { Kata- } \\
\text { thermometer }\end{array}$} \\
\hline & & & \multirow{2}{*}{$\begin{array}{r}\text { Menge } \\
(\mathrm{cm})\end{array} \mid$} & \multirow{2}{*}{$\begin{array}{c}\text { Reak- } \\
\text { tion }\end{array}$} & \multicolumn{2}{|c|}{ Zucker } & & \\
\hline & & & & & $(\%)$ & $\begin{array}{l}\text { gepro } \\
\text { Std. }\end{array}$ & & \\
\hline 9.55 A.M & & 0,11 & & & & & & \\
\hline 10.05 & gefesselt & & & & & & & \\
\hline 10.06 & $\mid \begin{array}{c}\text { (Rückenla } \\
38,7\end{array}$ & & & $\begin{array}{l}\text { schwach } \\
\text { a]kal. }\end{array}$ & 0,017 & & 14,5 & \\
\hline 10.10 & & 0,10 & & & & & & \\
\hline 10.25 & & & & & & & & $\begin{array}{l}\text { Nasskolben } 1.02 \\
\text { Trockenkolben } 2.35\end{array}$ \\
\hline 11.15 & 37,9 & 0,10 & & & & & 15,5 & \\
\hline 12.10 P.M. & 38,2 & 0,10 & 3,2 & neutral & 0,017 & 0,0003 & 16,0 & \\
\hline 1.10 & 38,3 & 0,10 & & & & & 17,0 & \\
\hline 2.40 & 38,4 & 0,11 & 3,3 & sauer & 0,017 & 0,0003 & 17,5 & \\
\hline 4.10 & 38,0 & 0,11 & & & & & 17,0 & \\
\hline 5.10 & 38,2 & 0,11 & 2,6 & sauer & 0,017 & 0,0002 & 18,0 & \\
\hline 5.2 .5 & Tod du & Irch Na & kensch & 1)ag & & & & \\
\hline
\end{tabular}

Marksubstanz der Nebennieren stark gefärbt, kein Unterschied zwischen beiden Nebennieren. 


\section{Versuch IV.}

17. X. 1919. Kaninchen $\hat{\delta}$. Beiderseitige Splanchnikotomie.

13. XI. 1919. $1920 \mathrm{~g}$.

\begin{tabular}{|c|c|c|c|c|c|c|c|c|}
\hline \multirow{3}{*}{ Zeit } & \multirow{3}{*}{$\begin{array}{c}\text { Körper- } \\
\text { tempera- } \\
\text { tur } \\
\left({ }^{\circ} \mathrm{C}\right)\end{array}$} & \multirow{3}{*}{$\begin{array}{c}\text { Blut- } \\
\text { zucker } \\
(\%)\end{array}$} & \multicolumn{4}{|c|}{ Harn } & \multirow{3}{*}{$\begin{array}{c}\text { Zimmer- } \\
\text { tempera- } \\
\text { tur } \\
\left({ }^{\circ} \mathrm{C}\right)\end{array}$} & \multirow{3}{*}{$\begin{array}{l}\text { Kata- } \\
\text { thermometer }\end{array}$} \\
\hline & & & \multirow{2}{*}{$\begin{array}{l}\text { Menge } \\
(\mathrm{ccm})\end{array} \mid$} & \multirow{2}{*}{$\mid \begin{array}{c}\text { Reak- } \\
\text { tion }\end{array}$} & \multicolumn{2}{|c|}{ Zucker } & & \\
\hline & & & & & $(\%)$ & $\begin{array}{l}\text { g pro } \\
\text { Std. }\end{array}$ & & \\
\hline 8.45 A.M. & & 0,12 & & & & & & \\
\hline 8.53 & gefesselt & & & & & & & \\
\hline 8.54 & $\begin{array}{c}(\text { Rucken 1age } \\
39,1\end{array}$ & & & alkal. & 0,013 & & 15,5 & \\
\hline 9.00 & & & & & & & & $\begin{array}{l}\text { Nasskolben } 1.14 \\
\text { Trockenkolben } 3.41\end{array}$ \\
\hline 9.55 & 38,5 & 0,14 & & & & & 17,0 & \\
\hline 10.55 & 38,3 & 0,14 & 2,5 & alkal. & 0,013 & 0,0002 & 18,0 & \\
\hline 11.55 & 38,6 & 0,14 & & & & & 19,5 & \\
\hline 12.56 P.M. & 38,7 & 0,15 & & & & & 20,3 & \\
\hline 1.57 & 38,9 & 0,15 & 11,5 & sauer & 0,013 & 0,0005 & 21,0 & \\
\hline 2.55 & 38,8 & 0,14 & & & & & 21,5 & \\
\hline 3.55 & 38,7 & 0,14 & & & & & 22,3 & \\
\hline 4.03 & & & & & & & & $\begin{array}{l}\text { Nasskolben } 1.30 \\
\text { Trockenkolben5.27 }\end{array}$ \\
\hline 4.55 & 38,6 & 0,13 & 4,8 & sauer & 0,013 & 0,0002 & 22,0 & \\
\hline 5.09 & Tod dure & ch Nack & kenschl & & & & & \\
\hline
\end{tabular}

Marksubstanz der Nebennieren stark gefärbt, kein Unterschied zwischen beiden Nebennieren.

Die Resultate sind ganz dieselben wie beim analogen Versuche ohne Verhütung der Körpertemperaturerniedrigung.

T. R. Elliott ${ }^{1)}$ konnte bei der Katze die Adrenalinsekretion aus der Nebenniere durch die Durchschneidung von N. Splanchnicus major nicht zu völligem Stillstand bringen. Nach Stewart und Rogoff ${ }^{2}$ ) sistiert die Adrenalinsekretion aus den Nebennieren, wenn $\mathrm{Nn}$. Splanchnici majores mit den sympathischen Sträugen in der Brusthöhle durchschnitten sind, während die Durchschneidung der Nn. Splanchnici majores in der Bauchhöhle dazu nicht genügt. Sie haben weiter bei einer Katze durch die Durchschneidung der Splanchnici und Nervenfassern, welche zum Semilunarganglion verlaufen, die Adrenalinsekretion aus den Nebennieren vollkommen zum Verschwinden gebracht.

In der Absicht, den Ursprung dieser doch noch auftretenden $\mathrm{Hy}$ perglylämie aufzusuchen, habe ich beim Kaninchen die drei oberen

1) T. R. Elli ott, Journ. I'hysiol. 44 (1912), 374.

2) G. N. Stewart und J. M. Rog off, Journ. Pharmacol. 8 (1916), 479. 
Tabelle

\begin{tabular}{|c|c|c|c|c|c|c|c|c|}
\hline \multirow[b]{2}{*}{ Nr. } & \multirow[b]{2}{*}{$\begin{array}{l}\text { Körper- } \\
\text { gewicht }\end{array}$} & \multirow[b]{2}{*}{$\begin{array}{c}\text { Tage } \\
\text { nach der } \\
\text { Opera- } \\
\text { tion }\end{array}$} & \multirow[b]{2}{*}{ Datum } & \multirow[b]{2}{*}{$\begin{array}{l}\text { Fesse- } \\
\text { lungs- } \\
\text { dauer } \\
\text { (Std.) }\end{array}$} & \multicolumn{3}{|c|}{ Blutzucker } & \multirow[b]{2}{*}{$\begin{array}{c}\text { Kurz } \\
\text { nach der } \\
\text { Fesselung }\end{array}$} \\
\hline & & & & & $\begin{array}{c}\text { Vor } \\
\text { der } \\
\text { Fesselung } \\
(\%)\end{array}$ & $\begin{array}{l}\text { Maximum } \\
\text { während } \\
\text { der } \\
\text { Fesselung } \\
(\%)\end{array}$ & $\begin{array}{c}\text { Zeit } \\
\text { bis zum } \\
\text { Maximum } \\
\text { (Std.) }\end{array}$ & \\
\hline 1. & 1780 & 13 & 6. XII. & 8,5 & 0,11 & 0,14 & 7,0 & 0,035 \\
\hline 2. & 1620 & 9 & 16. I. 1919 & 7,5 & 0,10 & 0,13 & 4,5 & 0,041 \\
\hline 3. & 1220 & 16 & 5. III. & 7,5 & 0,08 & 0,10 & 3,0 & 0,051 \\
\hline 4. & 1825 & 20 & 12. XI. & 8,0 & 0,10 & 0,12 & 1,0 & 0,013 \\
\hline 5. & 1880 & 30 & 14. XI. & 7,0 & 0,12 & 0,15 & 4,0 & 0,013 \\
\hline
\end{tabular}

Tabelle

\begin{tabular}{|c|c|c|c|c|c|c|c|c|}
\hline \multirow[b]{2}{*}{ Nr. } & \multirow[b]{2}{*}{$\begin{array}{l}\text { Körper- } \\
\text { gewicht }\end{array}$} & \multirow[b]{2}{*}{$\begin{array}{c}\text { Tage } \\
\text { nach der } \\
\text { Opera- } \\
\text { tion }\end{array}$} & \multirow[b]{2}{*}{ Datum } & \multirow[b]{2}{*}{$\begin{array}{l}\text { Fesse- } \\
\text { lungs- } \\
\text { dauer }\end{array}$} & \multicolumn{3}{|c|}{ Blutzucker } & \multirow[b]{2}{*}{$\begin{array}{c}\text { Kurz } \\
\text { nach der } \\
\text { Fesselung }\end{array}$} \\
\hline & & & & & $\begin{array}{c}\text { Vor der } \\
\text { Fesselung } \\
(\%)\end{array}$ & $\begin{array}{c}\text { Maximum } \\
\text { währeud } \\
\text { der } \\
\text { Fesselung } \\
(\%)\end{array}$ & $\begin{array}{c}\text { Zeit } \\
\text { bis zum } \\
\text { Maximum } \\
\text { (Std.) }\end{array}$ & \\
\hline 1. & 1610 & 10 & 17. L. 1919 & 8 & 0,11 & 0,12 & 1,0 & 0,033 \\
\hline 2. & 1555 & 18 & 9. III. & 7 & 0,11 & 0,11 & & 0,017 \\
\hline 3. & 1825 & 23 & 9. XI. & 8 & 0,10 & 0,12 & 3,0 & 0,013 \\
\hline 4. & 1920 & 29 & 13. XI. & 8 & 0,12 & 0,15 & 5,0 & 0,013 \\
\hline$\tilde{5}$. & 1600 & 31 & 15. XI. & 7 & 0,12 & 0,15 & 2,0 & 0,013 \\
\hline
\end{tabular}

Tabelle

\begin{tabular}{|c|c|c|c|c|c|c|c|c|}
\hline \multirow[b]{2}{*}{$\mathrm{Nr}$. } & \multirow[b]{2}{*}{$\begin{array}{l}\text { Körper- } \\
\text { gewicht }\end{array}$} & \multirow{2}{*}{$\begin{array}{l}\text { Tage } \\
\text { nach der } \\
\text { Opera- } \\
\text { tion }\end{array}$} & \multirow[b]{2}{*}{ Datum } & \multirow[b]{2}{*}{$\begin{array}{l}\text { Fesse- } \\
\text { lungs- } \\
\text { dauer } \\
\text { (Std.) }\end{array}$} & \multicolumn{3}{|c|}{ Blutzucker } & \multirow[b]{2}{*}{$\begin{array}{c}\text { Kurz } \\
\text { nach der } \\
\text { Fesselung }\end{array}$} \\
\hline & & & & & $\begin{array}{l}\text { Vor der } \\
\text { Fesselung } \\
(06)\end{array}$ & $\begin{array}{c}\text { Maximum } \\
\text { während } \\
\text { der } \\
\text { Fesselung } \\
(\%)\end{array}$ & $\begin{array}{c}\text { Zeit } \\
\text { bis zum } \\
\text { Maximum } \\
\text { (Std.) }\end{array}$ & \\
\hline 1. & $18 \cup 0$ & 14 & $\begin{array}{c}25 . X_{1919} \\
.\end{array}$ & 8 & 0,11 & 0,14 & 2,0 & 0,013 \\
\hline 2. & 1610 & 15 & 26. XI. & 6 & 0,12 & 0,12 & & 0,013 \\
\hline 3 & 1790 & 11 & 29. XI. & 7 & 0,13 & 0,16 & 1,0 & 0,026 \\
\hline 4. & 1640 & 13 & 2. XII. & 8 & 0,12 & 0,14 & $\cdot 4,0$ & 0,013 \\
\hline 5. & 1410 & 17 & 6. XII, & 8 & 0,13 & 0,16 & 3,0 & 0,013 \\
\hline 6. & 1935 & 13 & 8. I. 1920 . & 7 & 0,11 & 0,14 & 4,0 & 0,013 \\
\hline 7. & 1980 & 15 & $10 . \mathrm{I}$ & 8 & 0,12 & 0,14 & 2,0 & 0,026 \\
\hline
\end{tabular}


IV.

\begin{tabular}{|c|c|c|c|c|c|c|c|c|}
\hline \multicolumn{4}{|c|}{ Harnzucker } & \multicolumn{2}{|c|}{ Körpertemperatur } & \multirow[b]{3}{*}{$\begin{array}{c}\text { Zimmer- } \\
\text { tempera- } \\
\text { tur } \\
\left({ }^{\circ} \mathrm{C}\right)\end{array}$} & \multirow{2}{*}{\multicolumn{2}{|c|}{$\begin{array}{c}\text { Kata- } \\
\text { thermometer }\end{array}$}} \\
\hline \multicolumn{2}{|l|}{$(\%)$} & \multicolumn{2}{|c|}{ g pro Stunde } & \multirow[b]{2}{*}{$\begin{array}{c}\text { Kurz } \\
\text { nach der } \\
\text { Fesse- } \\
\text { lung } \\
\left({ }^{\circ} \mathrm{C}\right)\end{array}$} & \multirow[b]{2}{*}{$\begin{array}{c}\text { Mininuum } \\
\text { während } \\
\text { der } \\
\text { Fesselung } \\
\left({ }^{\circ} \mathrm{C}\right)\end{array}$} & & & \multirow[b]{2}{*}{$\begin{array}{c}\text { Trocken- } \\
\text { kolben }\end{array}$} \\
\hline $\begin{array}{c}\text { Maximum } \\
\text { während } \\
\text { der } \\
\text { Fesselnng }\end{array}$ & $\begin{array}{c}\text { Zeit } \\
\text { bis zum } \\
\text { Maximum } \\
\text { (Std.) }\end{array}$ & $\begin{array}{c}\text { Maximum } \\
\text { während } \\
\text { der } \\
\text { Fesselung }\end{array}$ & $\begin{array}{c}\text { Zeit } \\
\text { bis zum } \\
\text { Maximum } \\
\text { (Std.) }\end{array}$ & & & & $\begin{array}{l}\text { Nass- } \\
\text { kolben }\end{array}$ & \\
\hline 0,049 & 2,0 & 0,0003 & 2,0 & 38,4 & 35,4 & $13,0-22,5$ & 1.22 & 2.56 \\
\hline 0,021 & 2,0 & 0,0009 & 7,5 & 38,2 & 35,5 & $9,5-18,5$ & 1.15 & 2.25 \\
\hline 0,051 & & 0,0017 & 7,5 & 37,4 & 33,9 & $10,5-18,5$ & 2.15 & 3.05 \\
\hline 0,012 & & 0,0006 & 8,0 & 38,0 & 35,0 & $13,0-20,5$ & 1.08 & 3.10 \\
\hline 0,013 & & 0,0003 & 5,0 & 38,0 & 35,0 & $16,0-21,5$ & 1.15 & 3.17 \\
\hline
\end{tabular}

V.

\begin{tabular}{|c|c|c|c|c|c|c|c|c|}
\hline \multicolumn{4}{|c|}{ Harnzucker } & \multicolumn{2}{|c|}{ Körpertemperatur } & \multirow{3}{*}{$\begin{array}{c}\text { Zimmer- } \\
\text { tempera- } \\
\text { tur }\end{array}$} & \multicolumn{2}{|c|}{$\begin{array}{c}\text { Kata- } \\
\text { thermometer }\end{array}$} \\
\hline \multicolumn{2}{|l|}{$(\%)$} & \multicolumn{2}{|c|}{ g pro Stunde } & \multirow[b]{2}{*}{$\begin{array}{c}\text { Kurz } \\
\text { nach der } \\
\text { Fesse- } \\
\text { lung } \\
\left({ }^{\circ} \mathrm{C}\right)\end{array}$} & \multirow[b]{2}{*}{$\begin{array}{l}\text { Während } \\
\text { der } \\
\text { Fesselung } \\
\left({ }^{\circ} \mathrm{C}\right)\end{array}$} & & \multirow[b]{2}{*}{$\begin{array}{l}\text { Nass- } \\
\text { kolben }\end{array}$} & \multirow[b]{2}{*}{$\begin{array}{c}\text { Trocken- } \\
\text { kolben }\end{array}$} \\
\hline $\begin{array}{c}\text { Maximun } \\
\text { während } \\
\text { der } \\
\text { Fesselung }\end{array}$ & $\begin{array}{c}\text { Zeit } \\
\text { bis zum } \\
\text { Maximnm } \\
\text { (Std.) }\end{array}$ & $\begin{array}{c}\text { Maximum } \\
\text { während } \\
\text { der } \\
\text { Fesselung }\end{array}$ & $\begin{array}{c}\text { Zeit } \\
\text { bis zum } \\
\text { Maximum } \\
\text { (Std.) }\end{array}$ & & & & & \\
\hline 0,041 & 2,0 & & 5,0 & 38,8 & $38,4-38,7$ & $15,5-18,0$ & 1.13 & 1.59 \\
\hline 0,017 & & 0,0003 & 2,0 & 38,7 & $37,9-38,4$ & $14,5-18,0$ & 1.02 & 2.35 \\
\hline 0,039 & 2,0 & 0,0012 & 2,0 & 37,7 & $37,5-37,8$ & $12,5-18,0$ & 1.05 & 2.35 \\
\hline 0,013 & & 0,0006 & 8,0 & 39,1 & $38,3-38,9$ & $15,5-22,0$ & 1.14 & 3.41 \\
\hline 0,026 & 2,0 & 0,0008 & 2,0 & 39,0 & $38,3-39,0$ & $17,5-22,5$ & 1.17 & 4.19 \\
\hline
\end{tabular}

VI.

\begin{tabular}{|c|c|c|c|c|c|c|c|c|}
\hline \multicolumn{4}{|c|}{ Harnzucker } & \multicolumn{2}{|c|}{ Körpertemperatur } & \multirow{3}{*}{$\begin{array}{c}\text { Zimmer- } \\
\text { tempera- } \\
\text { tur }\end{array}$} & \multicolumn{2}{|c|}{$\begin{array}{c}\text { Kata- } \\
\text { thermometer }\end{array}$} \\
\hline \multicolumn{2}{|l|}{$(\%)$} & \multicolumn{2}{|c|}{ g pro Stunde } & \multirow[b]{2}{*}{$\begin{array}{c}\text { Kurz } \\
\text { nach der } \\
\text { Fesse- } \\
\text { lung } \\
\left({ }^{\circ} \mathrm{C}\right)\end{array}$} & \multirow[b]{2}{*}{$\left|\begin{array}{c}\text { Minimum } \\
\text { während } \\
\text { der } \\
\text { Fesselung } \\
\left({ }^{\circ} \mathrm{C}\right)\end{array}\right|$} & & \multirow[b]{2}{*}{$\begin{array}{l}\text { Nass. } \\
\text { kolben }\end{array}$} & \multirow[b]{2}{*}{$\begin{array}{l}\text { Trocken- } \\
\text { kolben }\end{array}$} \\
\hline $\begin{array}{c}\text { Maximum } \\
\text { während } \\
\text { der } \\
\text { Fesselur:g }\end{array}$ & $\begin{array}{c}\text { Zeit } \\
\text { bis zum } \\
\text { Maximum } \\
\text { (Std.) }\end{array}$ & $\begin{array}{c}\text { Maximum } \\
\text { während } \\
\text { der } \\
\text { Fesselung }\end{array}$ & $\begin{array}{c}\text { Zeit } \\
\text { bis zum } \\
\begin{array}{c}\text { Maximum } \\
\text { (Std.) }\end{array}\end{array}$ & & & & & \\
\hline 0,054 & 5,0 & 0,0021 & 8,0 & 38,0 & 33,3 & $13,2-19,0$ & 1.05 & 3.04 \\
\hline 0.013 & & 0,0005 & 2,0 & 38,3 & 36,0 & $12,0-18,0$ & 1.07 & 2.46 \\
\hline 0,221 & 2,0 & 0,0025 & 2, & 38,8 & 36,0 & $10,0-20,5$ & 1.13 & 2.38 \\
\hline 0,039 & 2,0 & 0,0008 & 2,0 & 38,6 & 35 & $13,0-19,0$ & 1.09 & 3.05 \\
\hline 0,104 & 5,0 & 0,0023 & 2,0 & 38,1 & 34 & $10,5-20,5$ & 1.06 & 2.40 \\
\hline 0,052 & 5,0 & 0,0043 & 5,0 & 37,8 & 35,4 & $11,0-18,8$ & 1.04 & 2.42 \\
\hline 0,091 & 2,0 & 0,0037 & 8,0 & 38,1 & 36,4 & $10,3-20,0$ & 104 & 2.44 \\
\hline
\end{tabular}


sympathischen Ganglien auf beiden Seiten exstirpiert und dazu die beiderseitigen Splanchnici durchschnitten und dann nach einigen Tagen (frühestens nach über acht Tagen) Fesselungsversuche angestellt. Dabei tritt noch Hyperglykämie geringeren Grades anf, wie beim nur heiderseitig splanchnikotomierten Kaninchen. Kein Unterschied des Grades der Hyperglykämie unter den beiden Versuchsreihen. (Tab. VI. S. 61-62.)

\section{Versuch I.}

11. XI. 1919. Kaninchen of $1950 \mathrm{~g}$. Beiderseitige Splanchnikotomie, Extirpation der beiderseitigen drei oberen sympathischen Ganglien unterhalb des Zwercbfells und Durclischneidung ibrer Äste.

25. XI. 1919. $1890 \mathrm{~g}$.

\begin{tabular}{|c|c|c|c|c|c|c|c|c|}
\hline \multirow{3}{*}{ Zeit } & \multirow{3}{*}{$\begin{array}{c}\text { Körper- } \\
\text { tempera- } \\
\text { tur } \\
\left({ }^{\circ} \mathrm{C}\right)\end{array}$} & \multirow{3}{*}{$\begin{array}{c}\text { Blut- } \\
\text { zucker } \\
(\%)\end{array}$} & \multicolumn{4}{|c|}{ Harn } & \multirow{3}{*}{$\begin{array}{c}\text { Zimmer } \\
\text { tempera- } \\
\text { tur } \\
\left({ }^{\circ} \mathrm{C}\right)\end{array}$} & \multirow{3}{*}{$\begin{array}{l}\text { Kata- } \\
\text { thermometer }\end{array}$} \\
\hline & & & \multirow{2}{*}{$\begin{array}{l}\text { Menge } \\
(\mathrm{ccm})\end{array}$} & \multirow{2}{*}{$\begin{array}{c}\text { Reak- } \\
\text { tion }\end{array}$} & \multicolumn{2}{|c|}{ Zucker } & & \\
\hline & & & & & $(\%)$ & $\begin{array}{l}\text { g pro } \\
\text { Std. }\end{array}$ & & \\
\hline 8.45 A.M & & 0,11 & & . & & & & \\
\hline 8.48 & $\begin{array}{c}\text { gefesselt. } \\
\text { (Rückenlage) }\end{array}$ & & & & & & & \\
\hline 8.50 & 38,0 & & & alkal. & 0,013 & & 13,2 & \\
\hline 9.00 & & & & & & & & $\begin{array}{lr}\text { Nasskolben } & 1.05 \\
\text { Trockenkolben } 3.04\end{array}$ \\
\hline 9.50 & 34,5 & 0,14 & & & & & 13,2 & \\
\hline 10.52 & 84,0 & 0,15 & 6,6 & alkal. & 0,013 & 0,0004 & 14,5 & \\
\hline 11.51 & 33,9 & 0,13 & & & & & 15,5 & \\
\hline 12.50 P.M & 33,8 & 0,14 & & & & & 16,0 & \\
\hline 1.50 & 33,4 & 0,14 & 7,5 & sauer & 0,054 & 0,0014 & 16,0 & \\
\hline 2.53 & 33,3 & 0,13 & & & & & 17,3 & \\
\hline 3.50 & 33,3 & 0,18 & & & & & 19,0 & \\
\hline 4.00 & & & & & & & & $\begin{array}{l}\text { Nasskolben } 1.21 \\
\text { Trockenkolben } 4.39\end{array}$ \\
\hline 5.05 & 33,5 & 0,12 & 12,0 & sauer & 0,052 & 0,0021 & 19,0 & \\
\hline 5.12 & Tod duro & Nack & enschl: & & & & & \\
\hline
\end{tabular}

Marksubstanz der Nebennieren stark gefürbt, kein. Unterschied zwischen beiden Nebennieren.

\section{Versuch V.}

19. XI. 1919. Kaninchen 令 1460 g. Beiderseitige Splanchnikotomie, Extirpation der beiderseitigen drei oberen sympathischen Ganglien unterhalb d*s Zwerchfells und Durchschneidung ihrer Äste.

6. XII. $1919.1410 \mathrm{~g}$. 


\begin{tabular}{|c|c|c|c|c|c|c|c|c|}
\hline \multirow{3}{*}{ Zeit } & \multirow{3}{*}{$\begin{array}{c}\text { Körper- } \\
\text { tempera- } \\
\text { tur } \\
\left({ }^{\circ} \mathrm{C}\right)\end{array}$} & \multirow{3}{*}{$\mid \begin{array}{c}\text { Blut- } \\
\text { zucker } \\
(\%)\end{array}$} & \multicolumn{4}{|c|}{ Harn } & \multirow{3}{*}{$\begin{array}{c}\text { Zimmer- } \\
\text { tempera- } \\
\text { tur } \\
\left({ }^{\circ} \mathrm{C}\right)\end{array}$} & \multirow{3}{*}{$\begin{array}{c}\text { Kata- } \\
\text { thermometer }\end{array}$} \\
\hline & & & \multirow{2}{*}{$\begin{array}{l}\text { Menge } \\
(\mathrm{cm})\end{array}$} & \multirow{2}{*}{$\begin{array}{l}\text { Reak- } \\
\text { tion }\end{array}$} & \multicolumn{2}{|c|}{ Zucker } & & \\
\hline & & & & & $(\%)$ & $\begin{array}{l}\text { g pro } \\
\text { Std. }\end{array}$ & & \\
\hline 8.38 A.M & & 0,13 & & & & & & \\
\hline 8.45 & & 0,13 & & & & & & \\
\hline 8.49 & $\begin{array}{c}\text { gefesselt } \\
\text { (Rückenlage) }\end{array}$ & & & & & & & \\
\hline 8.50 & 38,1 & & & alkal. & 0,013 & & 10,5 & \\
\hline 9.10 & & & & & & & & Nasskolken $\quad 1.06$ \\
\hline 9.55 & 35,2 & 0,15 & & & & & 13,0 & \\
\hline 10.52 & 94,4 & 0,15 & 6,0 & saver & 0,078 & 0,0023 & 15,0 & \\
\hline 11.54 & 34,3 & 0,16 & & & & & 16,7 & \\
\hline 12.51 P.M. & 34,3 & 0,14 & & & & & $17, \overline{5}$ & \\
\hline 1.52 & 34,5 & 0,14 & 4,0 & saluer & 0,104 & 0,0014 & 19,0 & \\
\hline 2.53 & 84,5 & 0,12 & & & & & 19,5 & \\
\hline 3.50 & 34.7 & 0,12 & & & & & 20,0 & \\
\hline 4.05 & & & & & & & & $\begin{array}{l}\text { Nasskolben } 1.23 \\
\text { Trockenkolben } 5.10\end{array}$ \\
\hline 4.50 & 34,6 & 0,12 & 9,8 & saner & 0,026 & 0,0009 & 20,5 & \\
\hline 4.58 & Tod durc & ch Nack & renschla & & & & & \\
\hline
\end{tabular}

Marksubstanz der Nebennieren stark gefürbt, kein Unterschied zwischen beiden Nebennieren.

\section{Kap. VIII. Zusammenfassung.}

1. Beim normalen Kaninchen vermehrt sich der Blutzuckergehalt ohne Ausnahme, wienn es auf den Operationstisch gefesselt wird. Bei langdauernder Fesselung steigt er allmählich, erreicht in drei bis sechs Stunden sein Maximum $(0,12-0,44 \%)$. und sinkt dann allmählich wieder. (Doch in einem Zeitraum [etwa achstündige Fesselung] wie bei meinen Versuchen erreicht er seinen ursprünglichen Wert nicht.)

Der Grad der Hyperglykänie ist einerseits wahrscheinlich individuellen Verschiedenheiten unterworfen und hängt anderseits bis zum gewissen Grade von den Jahreszeiten ab. Der Fesselungsdiabetes ist im Winter und Frühling stärker als in den anderen Jahreszeiten. Glykosurie tritt beim gefesselten Kaninchen nicht immer auf; im Winter ist sie häufiger und intensiver. Die Körpertemperatur sinkt nach der Fesselung in einer Stunde steil und dann langsam, um darauf wieder allmählich zu steigen. In einem Zeitraum wie bei meinen Versuchen erreicht sie aber ihren ursprünglichen Wert kaum.

Der Gehalt der Nebennieren an chromaffiner Substanz vermin- 
dert sich; in geringerem Masse als bei der Piquare- und Diuretinglykosurie.

2. Bei kurzdauernder Fesselung des Kaninchens (etwa von einigen Minuten bis zu einer Stunde) tritt auch Hyperglykämie auf, nur in etwas geringerem Masse. Der höchste Punkt (0,11-0,23\%) liegt meistens in einer Zeit, etwa eine halbe bis eine Stunde, ziemlich kurz nach dem Losbinden. Sie vermindert sich dann allmählich und erreicht ihren Anfangswert in etwa drei bis sechs Stunden oder noch später. Sofort nach dem Losbinden steigt die tief gesunkene Körpertemperatur steil empor, und kehrt in zwei bis vier Stunden anf ihren Anfangswert zurück.

3. Wenn das Kaninchen täglich gefesselt und dessen Blut- und Harnzuckergehalt und Körpertemperatur wiederholt untersucht wird, vermindert sich erst die Hyperglykämie von Tag zu Tag allmählich, steigt aber plötzlich, sinkt dann wieder allmählich und so weiter. Diese Schwankungen machen einen etwas rhythmischen Eindruck, sind aber nicht so regelmässig, ja waren sogar einmal unter fünf Versuchsbeispielen ganz regellos, so dass es unmöglich ist, durch diese Manipulation den Einfluss der Fesselung bei irgend welchen anderen experimentellen Diabetesforschung zu eliminieren.

4. Wenn das gefesselte Kaninchen gut gegen Körpertemperaturerniedrigung geschützt wird, dann ist der Grad der Hyperglylämie und Glykosurie viel geringer und die Verminderung des Gehaltes der Nebennieren an chromaffiner Substanz auch sehr gering.

5. Beim doppelseitig splanchnikotomierten Kaninchen tritt die Hyperglykämie geringeren Grades durch Fesselung auf, sowohl ohne, als auch mit Schutz gegen Körpertemperaturerniedrigung.

Der Fesselungsdiabetes beim Kaninchen, mit der Exstirpation der drei oberen sympathischen Ganglien auf beiden Seiten ausser der beiderseitigen Splanchnilsotomie ist von demselben Grade wie beim Kaninchen mit beiderseitiger Splanchnikotomie allein.

Der Gehalt der Nebennieren an chromaffiner Substanz vermindert sich bei beiderseitig splanchnikotomierten Kaninchen nie infolge der Fesselung des Tieres. 